\title{
Factors Significant to Precracking of Fracture Specimens
}

Charles G. Interrante James J. Filliben

U.S. DEPARTMENT OF COMMERCE Technology Administration National Institute of Standards and Technology

Gaithersburg, MD 20899

QC

100 



\title{
Factors Significant to Precracking of Fracture Specimens
}

\section{Charles G. Interrante James J. Filliben}

\author{
U.S. DEPARTMENT OF COMMERCE \\ Technology Administration \\ National Institute of Standards \\ and Technology \\ Gaithersburg, MD 20899
}

November 1989

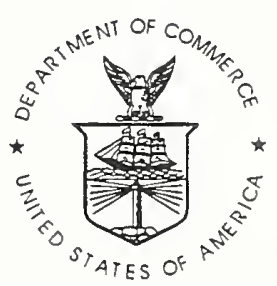

U.S. DEPARTMENT OF COMMERCE Robert A. Mosbacher, Secretary

NATIONAL INSTITUTE OF STANDARDS

AND TECHNOLOGY

Raymond D. Kammer, Acting Director 
ABSTRACT

The significance of four controlied variabies in the technique used to precrack Charpy specimens is determined by analyses of seven response variables computed from results of slow-bend tests of metallic materials. The variables include crack size, stress-intensity factor at the start of precracking, notch preparation prior to precracking, and material. All four variables are shown here to be significant for more than one of the computed responses. All seven responses, each representing alternative methods for evaluations of fracture toughness, were evaluated for each test. These responses are based either on a single value of load or on energy absorbed in the test. The results can be summarized in three major conclusions:

All seven computed responses are linearly related to crack size and the sensitivity to crack size depnds on the choice of response parameter and on the material. (2) Precracking at either very high or very low levels of stressintensity factor, $K_{f}$, are to be avoided. (3) For the three methods of notch preparation, the effects of notch preparation were largely not significant. This work is the result of a study conducted by ASTM Task Group E24.03.03 and members of eight participating laboratories. 
Abstract

Table of Contents

List of Symbols

List of Illustrations

Tables

viii

Figures

1. Background

2. Test Matrix

2.1 Materials

2.2 Laboratory Variabilities

2.3 Notch Preparation Factor

2.4 Stress-Intensity Factor

2.5 Crack Size Factor

2.6 Actual Number of Tests Conducted

3. Test Procedures

4. Calculation of Response from Charpy Test Results

5. Statistical Tests

5.1 Kruskal-Wall is Test

5.1.1 Significance

5.1.2 Reproducibility

5.1.3 Accuracy

5.2 Multiple Linear Regression

5.3 Graphical Analysis Methods

6. Results

6.1 Anomalies in the Data 
6.2 Results of KW Test of Significance for $R_{s b}$ Responses 31

6.3 Results of $\mathrm{KW}$ Test of Significance for All Responses 33

6.4 Effect of Crack Size and Material 34

6.5 Effect of $K_{f}$ maximum $\quad 35$

$\begin{array}{lll}6.5 .1 & \text { Aluminum } & 37\end{array}$

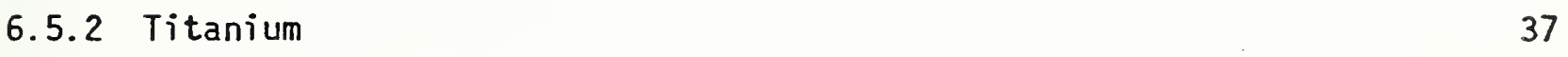

$\begin{array}{llr}6.5 .3 & \text { Steel } & 39\end{array}$

6.6 Effect of Notch Preparation 41

6.7 Sensitivity of the Responses to Crack Size 43

7. Conclusions 45.

8. Acknowledgements 47

$\begin{array}{ll}\text { 9. References } & 48\end{array}$

$\begin{array}{lrl}\text { Tables } & 50-61\end{array}$

$\begin{array}{lr}\text { Figures } & 62-78\end{array}$

$\begin{array}{ll}\text { Appendices } & 79\end{array}$

I. Raw Data Used to Compute Responses of Precracked Charpy Tests 79

IA. ATuminum 79

IB. Titanium $\quad 80$

$\begin{array}{ll}\text { IC. Steel } & 81\end{array}$

II. Reference Toughness and Computed Precracked Charpy Responses 82

IIA. ATuminum $\quad 82$

IIB. Titanium 83

$\begin{array}{ll}\text { IIC. Steel } & 84\end{array}$

III. Results of Kruskal-Wallis Test of Significance, Cumulative Probability Values, for the Crack-Size Factor, a. $\quad 85$

IV. Results of Kruskal-Wallis Test of Significance, Cumulative Probability Values, for the Factor $K_{f}$ maximum. 
V. Results of Kruskal-Wallis Test of Significance, Cumulative Probability Values, for the Factor Notch Preparation, NP.

VI. Residual Standard Deviation from Multiple Linear Regression Analyses for Seven Responses and Three Materials. 


\section{List of Symbols}

A

A, Aluminum -

$a_{25}$

$a_{50}$

$a_{75}$

a

$\bar{a} / w$

B

$\beta$

CVN

CPS

CTS

C

$-$ specimen $(=D 1 / P 1)$

$c_{m}$

$c_{s}$

D1

$\delta$

E

$E_{c}$

EDM

$E_{M}$

$E_{T}$

$E_{T / A}$

$E_{M}^{\prime}$

$\mathrm{K}$

- Normalized crack size

- Machine compliance

- Displacement

- Young's modutus

- Area of uncracked ligament at start of test: $A=B(W-a)$

Aluminum alloy 2419-T851 in the aged condition.

- Crack length at one quarter-thickness location

- Crack length measured at mid-thickness location

- Crack length measured at the other quarter-thickness location

- $\left(a_{25}+a_{50}+a_{75}\right) / 3=$ crack size

- Specimen thickness $=10 \mathrm{~mm}(0.394 \mathrm{in})$

- A coefficient that is a result of a regression analysis

- Charpy $V$ notch (test specimen)

- Cumulative probability statistic

- Compact tension specimen (currently designated $C(T)$

- Experimental determination of total elastic compliance of

- Theoretical elastic specimen compliance

- Displacement to an arbitrary point "1" in the elastic region.

- Energy correction based on specimen compliance and crack length

- Electric discharge machining

- Energy to maximum load, under the load-displacement trace

- Total energy under the load-displacement trace

- Total energy divided by area of uncracked ligament.

- Corrected energy to maximum load $E_{M}^{\prime}=E_{M}-E_{c}$.

- Stress-intensity factor 
- A response, computed from $P^{\star}$ and $Y^{\star}$, termed Tower-bound or equivalent energy

$k_{f}$

- Stress-intensity factor in fatigue precracking

$k_{f}$ maximum $K_{f}$ at the start of precracking in a constant-deflection apparat

$K_{f}$ ratio - $K_{f}$ maximum/K smallest

$K$ smallest - The smallest value of $K$ computed from equations 1,2 , and 3 of this report

$K_{\text {IC }}$

- Reference values of fracture toughness obtained from CTS tests, whether valid (E 399) $K_{I c}$ or invalid $K_{Q}$

$K_{J}$

- A response computed from energy to maximum load

$K_{j}^{\prime}$

- Response $K_{J}$ corrected for machine compliance of specimen

$\mathrm{K}_{\mathrm{Q}}$

- A response computed using $P_{Q}$, as in ASTM Method E 399

$K_{Q-P M}$

- A response computed as for $K_{Q}$, except $P_{M}$ is used in place of $P_{Q}$

$\mathrm{K}_{\mathrm{Q}}^{\prime}$

- A response computed from total energy absorbed in fracture

$\mu$

- Poisson's ratio

$\mathrm{N}$

- The number of observations

v

- Residual degrees of freedom

MLR

- Multiple linear regression

NP

- Notch preparation

N/A - Not applicable

$\%$ RD of $K$ - Percent relative deviation $=\left(K-K_{I C}\right) \times 100 / K_{I C}$

$\% \mathrm{RD}$ of $\mathrm{R}_{\mathrm{sb}}$

PI

- Load to an arbitrary point " 1 " in the elastic region

$P_{M}$

- Maximum load

$P_{Q}$

- Load at the 5 percent secant intercept

$p \star$

- A value of load used to compute equivalent energy 
$R_{S b} \quad-\quad$ Specimen strength ratio in slow-bend testing

$\bar{R}_{s b}$

- Mean $R_{s b}$ for each material

S, Steel - Steel alloy AL MAR (200) in the maraged condition

$S_{y} \quad-\quad$ Significant differences based on magnitude of test responses

$S_{s} \quad-\quad$ Significant differences based on reproducibility of test responses.

s - Standard deviation for replicate responses

$\mathrm{s}_{\mathrm{p}} \quad$ - Standard deviation pooled for all responses of a material

$\sigma_{U} \quad$ - Ultimate tensile strength

$\sigma_{Y} \quad$ - Yield strength

$\sigma_{Y I} \quad-\sigma_{Y}$ at the precracking temperature

$\sigma_{Y 2}-\sigma_{Y}$ at the Charpy test temperature

T, Titanium - Titanium alloy Ti-6Al-4V in the annealed condition

$\mathrm{W}$ - Specimen width $=10.0 \mathrm{~mm}(0.394 \mathrm{in})$

$\bar{Y} \quad-$ Mean response

$Y * \quad-A$ function of $\bar{a} / W$ used to compute $K_{d}^{\star}$

$y_{i} \quad$ - An individual test response 
Table 1. Proposed Test Matrix.

Table 2. Actual Numbers of Tests Conducted for Each Level of the Factors and for each Material.

Table 3. Chemical Composition.

Table 4. Hechanical Properties and Results of Tests of Compact Tension Specimens (CTS) Tested by ASTM Hethod E 399.

Table 5. Determination of $\mathrm{K}$ smallest.

Table 6. Preparation and Testing of Specimens and Preparation of Raw Data.

Table 7. Fatigue Precracking Levels, and Their Codes for Purposes of Data Analysis.

Table 8. Kruskal-Wallis Test of Significance and Cumulative Probability Values for Response $R_{s b}$.

Table 9. Results of Regression Analyses Conducted for Each of Three Materials and for All Computed Responses.

Table 10. Summary of Results for the Factor $K_{f}$ maximum.

Table 11. Effects of Notch Preparation on Results for Steel Specimens. Table 12. Sensitivity of Responses to Crack Size. 


\section{List of Figures}

Figure la. Charpy $V$-notch specimen with a fatigue precrack, and the measures of crack length (S1, S2, $\mathrm{a}_{25}, \mathrm{a}_{50}, \mathrm{a}_{75}$ ) that are taken after testing. Crack-size factor, $\bar{a}=\left(a_{25}+a_{50}+a_{75}\right) / 3$.

$B=W=10 \mathrm{~mm}(.394 \mathrm{in}) . \quad L=55 \mathrm{~mm}(2.165 \mathrm{in})$.

Figure 1b. Three notch preparations used before precracking.

Figure 2. Slow-bend test fixture showing the fixed span of two anvi] blocks, a center loading "striker", the placement of a displacement transducer (LVDT), and a Charpy specimen in position for testing.

Figure 3a. Response $K_{Q}^{\prime}$ based on total energy, $E_{T}$.

Figure 3b. Responses $K_{J}, K_{j}^{\prime}$ and $K_{d}^{\star}$ based on energy to maximum loäd, $E_{M}$ or $E_{M}^{\prime}$.

Figure 3c. Responses $K_{Q-P M}$ and $K_{Q}$ based on a single value of load, $P_{M}$ or $P_{Q}$.

Figure 3. Fracture toughness responses and the principal measurements used to compute them.

Figure 4. Bimodal load-displacement plot common among test results for steel specimens with crack size $\bar{a}<4.6 \mathrm{~mm}(0.120 \mathrm{in})$. 
Figure 5. Plot of response $R_{s b}$ versus $K_{f}$ maximum, showing that all Titanium specimens tested at the highest $K_{f}$ maximum level have small $R_{s b}$ responses and are taken from a single CTS designated $W$.

Figure 6. Plot of response $K_{J}^{\prime}$ for three materials tested, showing the broad range of $K_{F}$ ratios, $K_{f}$ maximum/K smallest, used to precrack Charpy specimens.

Figure 7. Plot of data for Aluminum showing, for each of three levels of $K_{f}$ maximum, that \%RD of $K_{j}^{\prime}$ increases with increases in normalized crack size, $\bar{a} / w$.

Figure 8. Plot of data and a regression line for Aluminum, showing the relationship between response $R_{s b}$ and normalized crack size, $\bar{a} / W$.

Figure 9. Results of seven regression analyses for Aluminum data showing the relationship between \%RD and normalized crack size, $\bar{a} / \mathrm{W}$.

Figure 10. Plot of data and regression results for the response \%RD of $\mathrm{K}_{\mathrm{J}}$ as a function of normalized crack size, $\bar{a} / \mathrm{W}$, for three materials.

Figure 11. Plot of data and regression results for response \%RD of $K_{Q}^{\prime}$ as a function of normalized crack size, à W, for three materials. This plot shows the necessity for omission of $K_{Q}^{\prime}$ data for Steel specimens of crack size code $1(\bar{a} / W<0.356)$. 
Figure 12. Plot of data and regression results for response $R_{s b}$ as $a$ function of normalized crack size for each of three materials.

Figure 13. Plot of \%RD of $K_{j}^{\prime}$ versus the $K_{f}$ ratio, $K_{f}$ maximum/K smallest, for Aluminum specimens, showing the tendency for an increase in the response for specimens precracked at ratios less than 0.4 . This plot typifies and represents similar relationships observed for responses $K_{j}, K_{j}^{i}$, and $K_{d}^{*}$ (which are based on energy to maximum load) and for response $R_{s b}$ (which is based on maximum load).

Figure 14. Plot of \%RD of $K_{j}^{\prime}$ versus the $K_{f}$ ratio, $K_{f}$ maximum/K smallest, for Titanium specimens, showing the tendency for increased variance in responses at very low levels of the $k_{f}$ ratio for specimens with $\bar{a}$ codes of 1 and 2. Similar relationships were observed for responses $K_{Q-P M}, K_{J}, K_{J}$, $K_{d}^{\star}$ and $R_{s b}$

Figure 15. Plot of data and a regression line for response $R_{S b}$ versus the $K_{f}$ ratio, $K_{f}$ maximum/K smallest, for Steel specimens, showing the general tendency for an increase in $R_{s b}$ responses with increases in the $k_{f}$ ratio.

Figure 16. Plot of responses of \%RD of $K_{Q-P M}$ versus the $K_{f}$ ratio, $K_{f}$ maximum/K smallest, for Steel specimens, showing the general tendency for an increase in $K$ responses for each of three coded crack sizes.

Figure 17. Plot of \%RD of $K_{Q-P M}$ versus normalized crack size for Steel specimens, showing that the behavior of some specimens of NP code 1 differs from the normal trend. 



\section{Background}

A proposal for standardization of a precracked Charpy impact test was made by the Executive Committee of ASTM Committee E24, in January of 1971, and Task Group E24.03.03 was formed to deal with this problem. The task group drafted a preliminary document titled, "Proposed Method for Precrack Charpy Impact and Slow-Bend Testing of Metallic Materials," which required experimental work to determine the significance of variables in the fatigue precracking procedures prescribed in the proposed method. The "best procedures" for fatigue precracking had to be established. Further, the expected variability of test results had to be determined for a multiplicity of laboratories using a prescribed test method.

At the request of the Chairman of Task Group E24.03.03, the authors, from the National Institute of Standards and Technology (NIST), fomerly the National Bureau of Standards (NBS), furnished a proposed statistically designed experiment for determining the significance of four precracking variables on results of tests conducted with fatigue precracked Charpy specimens. This proposal included three levels for each of the four variables (here called factors). The factors and their levels were later modeified at meetings of the Task Group before test specimens were prepared. In addition, the proposal specified two methods of testing, slow-bend and impact; together, these proposed tests comprised what the Task Group called Phase I of their testing program.

This is an analysis of the results of the slow-bend tests conducted for Phase I. At the time that this work was being planned, a report published by the National Materials Advisory Board [3] recommended... "that the fatigue-precracked Charpy-size specimen, tested in slow bending to measure the ratio of specimen strength to either the yield strength or 
the ultimate tensile strength of the material (ASTM E 399) be utilized, when applicable, for establishing correlation with plane-strain fracture roughness and minimum acceptance standards in quality-control programs. To foster implementation of this recommendation, the Committee urges that the test method be standardized as soon as practicable..." The Phase I test program was distinguished from other extensive research programs $[1,2]^{7}$ that have used precracked Charpy specimens, as the objective of this program is to establish the effects of precracking variables. The proposed Phase II effort was to be conducted by many laboratories to establish a lab-to-lab variability for precracked Charpy test results.

Charpy test specimens used in this program (shown in Fig. 1) differ from the standard ASTM E 23-66 type A, V-notch Charpy specimen: (1) Charpy specimens for this program (Fig. IA) contain a fatigue precrack; in this respect they are similar to valid plane-strain facture thoughness specimens (ASTM E 399), while the standard Charpy specimen is not precracked; and (2) the standard $V$-notch root-radius of $.25 \mathrm{~mm}(0.010 \mathrm{in})$ is here modified in various ways (Fig. 1B) to facilitate crack initiation under fatigue loading.

This analysis was completed in 1981. While the results of this study and analysis have been made available to various ASTM workers for committee activities, some of this and related information will be pub7 ished in ASTM STP 1072, Charpy Impact Test - Factors and Variables, where it will be available for use in the development of test methods and in future studies. This internal report contains data and other information not available in the ASTM article.

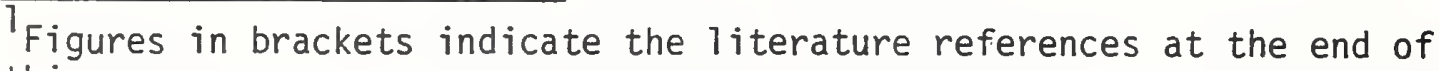
this paper. 


\section{Test Matrix}

In the proposed Phase I program, each of three materials are designated to be tested after being precracked in the various ways specified in the proposed test matrix, table 1 . These specified precracking variables are notch preparation (NP), stress-intensity factor at the start of precracking ( $K_{f}$ maximum), and crack size $(\bar{a})$. Each precracking variable is controlled at three levels, which are coded $\mathbf{1}, 2$, and 3 in the proposed matrix. Thus, there are a total of four factors and three levels per factor in the experimental design. In addition, replicate specimens are specified for each test condition. The actual numbers of specimens tested at each condition, given in table 2 to be discussed later, differ slightly from the proposed 2 replicate tests per condition indicated in table 1 .

Historically, the proposed test matrix was developed from a matrix suggested by the NIST authors working in cooperation with members of ASTH TG E24.03.03. From that NIST test matrix, proposed matrix of table 1 was developed by the Task Group, which finalized the levels of the factors in the matrix. While the number of test conditions had to be limited for economy, this matrix contains all factors and levels deemed by the task group to be necessary to determine the effects of the variables commonly encountered in fatigue precracking of Charpy specimens.

\subsection{Materials}

Three materials included in the Phase I program are an aluminum alloy (2419-T851) in the aged condition, a titanium alloy (Ti-6AT-4V) in the annealed condition, and an 18 NiCoMo steel [AL MAR 18 (200)] in the maraged condition. These materials are referred to here as Aluminum, Titanium, and Steel, and they are coded 4, 5, and 6, respectively, for 
purposes of computer sorting and analysis and for presentations made in the Appendices. They are also coded A, T, and $S$ in some data plots. Their chemical compositions are given in table 3.

The following heat treatments were given prior to precracking: "Aluminum" is the aluminum alloy, as mill treated to the 851 condition. Typical treatment [4] for the 851 condition, in a similar (2219) alloy is: solution treat $535 \mathrm{C}(995 \mathrm{~F})$, stretch, and age at 177 C ( $350 \mathrm{~F}), 18 \mathrm{~h}$ at temperature. "Titanium" is the titanium alloy as solution treated, at $927 \mathrm{C}(1700 \mathrm{~F}), 4 \mathrm{~h}$, furnace cooled $38 \mathrm{C} / \mathrm{h}(100 \mathrm{~F} / \mathrm{h})$ to $315 \mathrm{C}(600 \mathrm{~F})$, and air cooled to room temperature. "Steel" is the maraged steel, as solution annealed and then aged at $488 \mathrm{C}(910 \mathrm{~F}), 4 \mathrm{~h}$.

Mechanical properties of the materials are given in tables 4 and 5 . Properties listed in table 4 are those used for calculations made in the preparation of this report, after the completion of all slow-bend tests. Table 5 gives nominal properties used for preliminary calculations of allowable stress-intensity factors for fatigue precracking, $K_{f}$ maximum.

Reference values of fracture toughness for these materials were furnished from tests conducted with the Compact Tension Specimen (CTS). The results of these tests, given in table 4 , indicate that not all test results meet the validity requirements of $E$ 399. The tests were conducted in accordance with ASTM Method E 399 [5]; and according to the Method, the results are either valid and are referred to as $K_{I c}$, planestrain fracture toughness, or they are not valid and are referred to as $\mathrm{K}_{\mathrm{Q}}$. Table 4 gives the particular requirement that was not met for each test that failed the E 399 validity requirements. Fur simplicity in this writing, these reference values of $K$ will be referred to as $K_{I c}$ values, even though some of the results are actually termed $K_{Q}$ test 
results by fiethod $E$ 399. In this report, these reference values are used to assess the accuracy of the various responses ( $K$ values) computed from resuits of Charpy tests.

For Aluminum, the two reference $K_{I c}$ values given in table 4 for the CTS tests are averaged to obtain a single reference for all Aluminum Charpy specimens. These two results are 39.3 and $38.4 \mathrm{ksi}$ (in) ${ }^{1 / 2}$, obtained from specimens of dimensions $1.5 \times 3 \times 3.6$ in, which were taken from a plate sample (designated 411081 ) that was rolled to 1.5 -in thickness. These resuits are about the same magnitude as results of 38.9 and 38.5 ksi (in) $)^{1 / 2}$ obtained from specimens of dimensions $0.5 \times 3 \times 6$ in, which were taken from the plate sample (designated 411060 ) that was rolled to 0.5-in thickness and from the same cast as that of prate 411081. Although the Charpy specimens were actually taken from the 0.5-in-thick plate, the reference values obtained from specimens taken from the 1.5-in-thick plate were used as the reference values in this report. This was done because the values of $P_{M} / P_{Q}$ for the tests of the 0.5 in-thick plate were relatively high, about 1.7 , whereas those from the 1.5-in-thick plate nearly met the $E 399$ requirement of $P_{M} / P_{Q} \leq 1.1$.

For Titanium, the CTS test results represent two specimen orientations, longitudinal (LT) with values of 77.9 and $80.2 \mathrm{ksi}(i n)^{1 / 2}$, which are designated $R$ and $L$ respectively (see table 4 ), and transverse (TL) with values of 77.4 and 85.5 , which are designated $W$ and $T$ respectively. Charpy specimens of Titanium were taken from the broken halves of the 1-3/8-in-thick CTS specimens used to obtain the reference $K_{I c}$ values. It was noted that these $K_{I c}$ values vary over a broad range from 77.4 to 85.5, and the difference between these two values is large, being about 14 percent of the smaller one. Further, the smallest value represent a 
CTS test result with $P_{M} / P_{Q}$ equal to 1.54 , and this is a wide departure from the $E 399$ requirement of $P_{M} / P_{Q} \leq 1.1$, and in this regard this CTS is unique among all the specimens tested in this Phase I program. In addition, initial correlations made with the data of CTS and Charpy tests indicated that improved correlations would result from the use of four individual $K_{I C}$ reference values for Titanium with each CTS resuit being used as a reference only for the data obtained from Charpy specimens taken from that CTS. Hence, in the analyses presented here, the reference for each Charpy specimen of Titanium is the $K_{I c}$ result of its parent CTS.

For Steel, three CTS test results are averaged to obtain a single reference value of $120.5 \mathrm{ksi}$ (in) ${ }^{1 / 2}$ for Steel Charpy specimens. The Charpy specimens were taken from the same plate, at adjacent locations, and in the transverse (TL) orientations. Results of the CTS tests indicate that the $E 399$ requirement, $B \geq 2.5\left(K_{I C} / \sigma_{Y}\right)^{2}$, was not met for this material, and this is the oniy material, among the three tested, that failed the ASTM thickness requirement.

\subsection{Laboratory Variabilities}

The tasks undertaken by each of eight laboratories that participated in the Phase I program are outlined in table 6. One objective of this program was to conduct the Charpy tests as though oniy a single laboratory had done the work. In keeping with this objective, only one laboratory can be involved for each step of the procedures of preparation and testing of specimens, and analysis of the data, except for those steps for which ASTM prescribed methods are applicable. In practice, this objective was largely met even though five of the laboratories participated in Charpy related tasks (see table 6). However, 
some discrepancies did arise. Precracking of Charpy specimens was done at two laboratories due to an unforseen problem. After the specimens of Titanium and Aluminum had been precracked, it was found that although the rough machining of the specimens of the maraging steel had been done in accordance with the applicable ASTM specification, the lengths of these specimens were on the short side of the specification tolerances. These shorter specimens could not be properly precracked in the machine that had been used for specimens of the other two materials. Therefore, a second laboratory precracked the Steel specimens. As a result, not only were different equipment and personnel involved, but slightly different criteria were used for the stress-intensity factor in fatigue precracking. These differences are described Tater, in Section 2.4.

Other procedures with potential for giving rise to undesirable 1ab-to-1ab procedural effects were generally controlled closely enough so that they are considered to have no significant effects on the test results. Mechanical machining and notching was done at two laboratories, but under the close tolerances of the ASTM specifications for root radius, notch angle, and notch depth. Data reduction from records of the load vs. displacement was done by similar methods at two laboratories, but only after the principals involved had agreed upon a single method for the reduction process.

\subsection{Notch-Preparation Factor}

The notch-preparation (NP) factor in the experimental design has three levels, as shown in figure 1, which are coded 1, 2, and 3 for purposes of computer sorting and analysis of the data. Each of these levels is a method by which a Charpy $V$-notch is prepared prior to precracking of the test specimen. Level 1 is a standard $0.25 \mathrm{~mm}(0.010 \mathrm{in})$ 
root-radius $V$-notch modified by sharpening the root of the notch with a razor blade. Level 2 is a nonstandard $V$-notch of $.125 \mathrm{~mm}$ (0.005 in) root-radius. Level 3 is a standard $0.25 \mathrm{~mm}(0.010 \mathrm{in})$ root-radius $V$-notch modified by sharpening the notch root to about $0.05 \mathrm{~mm}(.002 \mathrm{in})$ root-radius by electric discharge machining (EDM), using a razor blade as an electrode placed just above the notch in the EDM process.

\subsection{Stress-Intensity Factor at Start of Precracking}

The stress-intensity factor at the start of precracking $\left(K_{f}\right.$ maximum) was controlled at three levels for each material in the proposed test matrix. The three levels are dependent upon properties of the materials, as described below. To compute the proposed levels, first a stress-intensity-factor parameter here called "K smallest" is computed by using three formulae:

$$
\begin{aligned}
& K_{(1)}=\left(\sigma_{Y 1} / \sigma_{Y 2}\right) \times K_{I C}\left(k s i(i n)^{I / 2}\right) \\
& K_{(2)}=\sigma .002 \times E\left(k s i(i n)^{1 / 2}\right)
\end{aligned}
$$

and

$$
K_{(3)}=0.57 \sigma_{Y 1}\left(k s i(i n)^{1 / 2}\right) \text {, }
$$

where $\sigma_{Y 1}$ and $\sigma_{Y 2}$ are static yield stress in ksi at the precracking temperature and at the Charpy slow-bend test temperature, respectively, and $E$ is the elastic modulus in psi. Table 5 shows values used for these constants and results of the $K$ calculations for each of the three materials. The smallest of these calculated $K$ values is called $K$ smallest. Then, loads at the start of precracking are computed to give the following proposed values of $K_{f}$ maximum (the value at the start of precracking in a constant-deflection machine): $K$ smallest, $(2 / 3) \mathrm{K}$ 
smallest, and $(1 / 3) \mathrm{K}$ smallest. These $K_{f}$ maximum values are coded 3,2 , and 1 , respectively, for purposes of computer sorting and analysis of data within each material. This is shown in table 7 which gives the fatigue precracking levels, and their codes used for sorting and analysis of data within a material. While three levels (coded 3,2, and 1) are indicated (in the table) for analyses within each material, a total of 4 levels are indicated for combined materials: Aluminum and Steel have levels 3,2 , and 1 , and Titanium has levels 2, 1 , and 0 . This coding became necessary for combined results because the actual $k_{f}$ maximum levels used for Titanium are different from (lower than) the proposed $K_{f}$ maximum levels. The highest actual level for Titanium is $20 \mathrm{ksi}$ (in) ${ }^{1 / 2}$, which is nearly equal to $(2 / 3) \mathrm{K}$ smallest, the proposed code 2 ; the next actual level for Titanium is nearly equal to $(1 / 3) \mathrm{K}$ smallest, which is the proposed code 1; and the lowest actual level for titanium is much lower than any other levels used in these tests. Thus, for combined materials, the analysis requires four levels, coded $3,2,1$, and 0 .

Further, as noted in table 7, for Steel the three actual levels are slightly higher than the proposed levels, on average. In addition, for Steel specimens, $K_{f}$ maximum was measured at the finish of precracking, whereas levels of $K_{f}$ maximum for Aluminum and Titanium were measured at the start of precracking. In the precracking machines used for this Phase I program, K decreases slightly as crack length increases, so that $K_{f}$ at the finish of precracking is slightly lower than that at the start. Thus, for a short crack length, $K_{f}$ at the start of precracking would be slightly greater than $K_{f}$ "maximum" tabulated for the Steel; and for longer cracks, $K_{f}$ maximum at the start of precracking is greater still. Thus, actual $K_{f}$ maximum leveis for each material represent 
different fractions of the $K$ smallest computed for the proposed levels. These fractions are called the $K_{f}$ ratio and they are greatest for the Steel specimens and least for the Titanium specimens, and they are grouped into 3 levels for each material and into 4 levels for combined materials.

\subsection{Crack Size Factor}

The test matrix gives three levels for the crack-size factor (a) used in calculations. These levels of $\bar{a}$ are coded as follows:

Code 1: $\bar{a}=2.5$ to $3.6 \mathrm{~mm}(0.097$ to $0.140 \mathrm{in})$

Code 2: $\bar{a}=3.6$ to $4.6 \mathrm{~mm}(0.1405$ to $0.180 \mathrm{in})$

Code $3: \bar{a}=4.6$ to $6.1 \mathrm{~mm}(0.1805$ to $0.242 \mathrm{in})$

The lower bound for Code 1 was established as follows. After. testing had been completed, it was observed that a crack was never initiated in some specimens fatigue cycled at the lowest level of $k_{f}$ maximum; further, during a preliminary screening of the data, results for specimens with $\bar{a}$ less than $2.48 \mathrm{~mm}(0.097 \mathrm{in})$ were found to be more highly variable and in this respect inconsistent with the data for specimens with $\bar{a}$ between 2.48 and $6.15 \mathrm{~mm}(0.097$ and $0.242 \mathrm{in})$. Thus a lower limit on and $2.48 \mathrm{~mm}(0.097 \mathrm{in})$ was set for purposes of this analysis. Data for specimens below this limit are not included here. No upper limit was warranted for $\bar{a}$.

\subsection{Actual Number of Tests Conducted}

The actual number of tests conducted for each test condition is given in table 2. The two replicate specimens specified in the proposed test matrix were actually tested except for selected cases, especialiy those involving $K_{f}$ code 1 , the lowest stress-intensity level ( $K$ smallest $/ 3$ ). The $k_{f}$ code 1 tests actually conducted include only about 
half of the proposed tests; of the 9 replicate tests proposed for each material, actual replicate results include only one for Aluminum, three for Titanium and eight for Steel. These deficiencies are reportedly due to difficulties commonly encountered in the process of precracking at very low $K$ levels in tough materials. Further, a total of 54 specimens were proposed for tests of each material, and while 51 specimens of the Steel were tested, the number of specimens tested for the other materials was lower--43 Aluminum and 44 Titanium. The deficiencies in the numbers of tests for each of these materials are mainly in the $K_{f}$ code $I$ level, and the analysis of the results for $K_{f}$ code 1 are adversely affected by these deficiencies.

\section{Test Procedures}

Precracked Charpy specimens were tested in three-point bend, using a bend test fixture with the geometry and dimensions recommended in ASTM Designation E 23-72 for Charpy impact testing. No movable support pins are used in this fixture, which uses two anvil blocks to provide support at a fixed span. The cross-head speed was $2.5 \mathrm{~mm} / \mathrm{min}(0.10 \mathrm{in} / \mathrm{min})$. Load and displacement were measured and plotted. The load was taken from the load cell of the test machine and the displacement was measured using a transducer (LVDT) placed between the top and bottom plates of the bend test fixture, as shown in figure 2. Therefore, while the measured displacement represents the displacement of the specimen, the measurement is affected by the compliance of the test machine.

After each slow-bend test, the test response was computed using the raw data obtained from the broken halves of the Charpy specimen and the load-displacement test records. If the specimen was not fractured into two pieces during the test, this was done using liquid nitrogen coolant 
ajter the test. Load $P$, displacement $\delta$, and energy absorption $E$ (area under the $P-\delta$ plot) were measured using a digitizer to trace along the piot of the test record. From the raw data, various fracture toughness test responses were computed. These responses are here designated $K_{Q}^{\prime}, K_{Q-P M}, K_{Q}, K_{J}^{\prime}, K_{J}, K_{d}^{\star}$, and $R_{s b}$, and are computed by methods described in section 4 of this report. As is shown in figure 3 , each response is based on one of three principal measurements, total energy $\left(E_{T}\right)$, energy to maximum load $\left(E_{M}\right.$ or $\left.E_{M}^{\prime}\right)$ or a single value of load $\left(P_{M}\right.$ or $\left.P_{Q}\right)$.

To compute the response $K_{Q}^{\prime}$, the total energy $E_{T}$ (fig. $3 A$ ) is measured. $E_{T}$ is taken to be the area under the curve from the start of test to a load equal to $P_{M} / 10$, where $P_{M}$ is the maximum load. Measurement of energy absorption beyond this level of load was impractical for two reasons, some of the specimens were not completely fractured into two halves during the test and most of the test records had a very broad tail area which could not be recorded without sacrificing accuracy in the record of the more important initial loading behavior. To compute the responses $K_{J}, K_{J}^{3}$, and $K_{d}^{\star}$ (fig. $3 B$ ), several measurements were taken: maximum load $P_{M}$, compliance $D I / P I$, and energy to maximum load, $E_{M^{*}}$. The responses $R_{S b}, K_{Q-P M}$, and $K_{Q}$ (fig. $3 C$ ) require measurement of either the load $P_{M}$, or the load $P_{Q}$ measured by the 5 percent secant method described in Method E 399.

Computations of the above responses also require a measure of the area (A) of the uncracked ligament at the start of the test. This area t.s obtained from the relationship $A=B(W-\bar{a})$, where the nominal specimen width $B$ and thickness $W$ each are set equal to $10 \mathrm{~mm}(0.394 \mathrm{in})$; the crack size factor $\bar{a}$ is an average of the $a_{25}, a_{50}$, and $a_{75}$ crack length 
measurements taken, respectively, at the 1/4-, 1/2-, and 3/4-thickness

(B) locations on the broken halves of the slow-bend tested Charpy specimens. This ligament is seen in figure $I A$ as the distance from the front of the fatigue crack to the back boundary of the specimen.

Hence, raw data taken for each Charpy specimen include $P_{Q}, P_{M}, E_{M}$, $E_{T}, \bar{a}, a_{25}, a_{50}, a_{75}$, and $D I / P 1$. These data are given in Appendix I for all slow-bend test results that were included in this analysis.

For all aluminum and titanium specimens, and for most steel specimens, the load-displacement plots were observed to be of the type (general shape) shown in figure 3 , in which there is no indication of a cleavage initiation event. For some Steel specimens the plots were bimodal as shown in figure 4, indicating a cleavage fracture with rapid machine unloading. During the unloading of the first mode of the bimodal type, the energy of the test machine is released to the specimen and it was not recorded on the test record. Thus, while the area under each of the two modes is included in the measurement of $E_{T}$, this energy of unloading, which contributes to the fracture process, is not included in this measured value. The bimodal load-displacement plot is observed only for steel specimens with crack size less than $3.56 \mathrm{~mm}(0.140$ in), i.e. small crack lengths. The $E_{T}$ values used in this analysis were not corrected to take machine unloading into account; as the analysis had been nearly completed when this was discovered, time constraints precluded this correction.

4. Calculation of Response from Charpy Test Results

Raw data taken in precracked slow-bend Charpy tests are not directly used to assess material properties. Rather, data are converted to responses of fracture toughness, designated by the symbol $k$, or 
specimen strength ratio, $R_{S b}$. These responses are calculated by various methods given below. The computed $K$ and $R_{s b}$ results are given in Appendix Table II for all specimens included in this analysis.

Relationships used to compute responses of $K$ are:

$$
K_{Q}=\left(P_{Q} S / B W^{3 / 2}\right) f(a / W),
$$

where $S=1.574$ and

$f(a / W)=3(\bar{a} / W)^{1 / 2} \frac{\left[1.99-(\bar{a} / W)(1-\bar{a} / W)\left(2.15-3.93 \bar{a} / W 2.7 \bar{a}^{2} / W^{2}\right)\right]}{2(1+2 \bar{a} / W)(1-\bar{a} / W)^{3 / 2}}$

after ASTM Method E 399 [5],

$$
K_{Q-P M}=\left(P_{M} S / B W^{3 / 2}\right) f(a / W),
$$

which is the same as the equation for $K_{Q}$ but maximum load $P_{M}$, rather than $P_{Q}$, is used;

$$
\left.K_{Q}^{\prime}=\left[0.5 E E_{T} / A\left(I-\mu^{2}\right)\right]^{1 / 2} \text {, after Rona }\right] d[6] \text {, }
$$

where:

$$
\begin{aligned}
& E=\text { Young's modulus; } \\
& E_{T}=\text { total energy under the load-deflection trace; } \\
& A=\text { area of uncracked ligament at the start of the test } \\
& \quad(=B(W-\bar{a})) \text {; and } \\
& \mu=\text { Poisson's ratio. } \\
& \qquad \quad K_{J}=\left[2 E E_{M} / A\left(1-\mu^{2}\right)\right]^{1 / 2} \text {, after Rice }[7],
\end{aligned}
$$

where $E_{M}=$ energy to maximum 1oad, under the load-deflection trace. 


$$
K_{j}^{\prime}=\left[2 E E_{M}^{\prime} / A\left(1-\mu^{2}\right)\right]^{1 / 2} \text {, after Rice }[7] \text {, }
$$

where $E_{M}^{\prime}$ is $E_{M}$ corrected for the compliance of the test machine: $E_{M}^{\prime}=$ $E_{M}-P_{M}^{2} C_{m} / 2$; where $C_{m}$ is machine compliance, after EPRI procedures $[8,9] ; C_{m}=C-C_{s}$, with $C$ and $C_{s}$, respectively, representing experimental and specimen (theoretical) compliance values. Measured values of $C$ are given as D1/PI in Appendix Table IC.

$$
K_{d}^{*}=\frac{6 Y^{*}(\bar{a})^{1 / 2} p^{\star}}{B W}
$$

where

$$
\begin{gathered}
\gamma^{*}=1.93-3.07(\bar{a} / W)+14.53(\bar{a} / W)^{2}-25(a / W)^{3}+25.8(a / W)^{4} \\
p^{*}=\left[2 E_{M}^{\prime} / C_{s}\right]^{1 / 2} .
\end{gathered}
$$

It is noted that $K_{d}^{*}$ can also be computed using $P^{*}$ in place of $P_{Q}$ in Equation 4. The lower bound (or equivalent-energy) procedure ( $\left.K_{d}^{*}\right)$ arises from concepts developed by Witt [10].

Responses of strength ratio in slow-bend testing, $R_{s b}$, were computed using the equation:

$$
R_{S b}=6 P_{M} W / B(W-\bar{a})^{2} \sigma_{Y} \text {, }
$$

after Method E 399 [5].

Responses computed using equations (4) through (10) are used here to determine statistically whether or not the level for each of the four factors significantly affects the test result. The accuracy of a Charpy test response is assessed, as described in Section 5.1 .3 for each of 
the various fracture toughness measures of having the symbol $K$. This is done using an appropriate reference value of $\mathrm{K}_{\mathrm{Ic}}$ for each material. The reproducibility is assessed, as described in Section 5.1.2, using replicate responses.

\section{Statistical Tests}

The controlled variables, called factors in this analysis, are notch preparation (NP), fatigue-load at the start of precracking ( $K_{f}$ maximum), and original crack size (a) and material. The goals of this experiment do not include between material differences. Material-to-material differences are known to exist and in this analysis this variable is not considered as a factor in the analysis. In the proposed test matrix, each factor is tested at three levels only; however, for the factors $\bar{a}$ and $K_{f}$ maximum, many more than three levels were actually tested. A variety of analytical methods are used here to determine whether or not statistically significant difference exists among the levels of a factor. These include (1) the Kruskal-Wallis (KW) test, (2) multiple linear regression (MLR) analysis, and (3) graphical analysis of variance. The results of both the KW test and the MLR analysis is a Cumulative Probability Value (CPV) which corresponds to a percent point of the null distribution. The two tests are not identical and were run because they are sensitive to different aspects of the same problem. To determine whether a factor is significant, the MLR analysis is conducted using the individual responses. The $\mathrm{KW}$ test used ranks of these responses and each factor is subdivided into three levels to test whether the levels are significant. These differences are expected to give rise to differences in the CPV results for the two tests.

In this analysis, when either of these tests indicates a factor or its levels to be significant, then graphical analysis is used to further describe the effect. 


\subsection{Kruskal-Wallis Test}

One procedure used here to carry out the test of significance is based on the Kruskal-Wallis [1I] test statistic, H. The Kruskal-Wallis test statistic $H$ can be shown to be equivalent to the usual 1-way analysis of variance statistics, with the observations within a given treatment (or level) replaced by their ranks. (To rank the data, the minimum observation of the set is replaced by a 1, the next larger observation is replaced by a 2, etc.) This transformation to ranks allows one to validly carry out the usual analysis of variance (ANOVA) test for equivalence of means without regard to the actual distribution of the data. In statistical terms, the test procedure is essentially a distributionfree analysis of variance.

The $H$ test statistic is used in this analysis, instead of the usual ANOVA, because it is a distribution-free test and so the validity of the conclusions is not dependent on the distribution of the data. In particular, inasmuch as the usual ANOVA assumes the data to be normally distributed, and inasmuch as inspection of the data reveals that such a normality assumption is not likely to be valid in this case, then the application of a distribution-free test appears to be the simplest and most reasonable way to proceed.

Under the null hypothesis of no effect on the result by the various levels of a factor, the null distribution for $\mathrm{H}$ can be determined strictly from theoretical considerations. The test statistic $H$ is then calculated from the data and compared with this theoretical null distribution of $H$. Calculated values of $H$ which fall out in the extreme regions of the null distribution are deemed to be indicative of a false null hypothesis-thus, the levels within a factor are concluded to be significantly 
different. Calculated values of $\mathrm{H}$ which occur in the "middle" or "body" of the null distribution are deemed to be typical and they give no evidence that the null hypothesis is false. Thus, the levels within a factor are concluded to be not significantly different from one another.

Associated with any given value of the Kruskal-Wallis test statistic, $H$, is a cumulative probability value (CPV). The CPV is arrived at from a given value for the $H$ statistic in the following manner: In forming the nuil hypothesis $H_{0}$ that all levels of a factor yield an equivalent response, it follows that when $H_{0}$ is true, the $H$ statistic has a distribution which can be theoretically determined. To be specific, when the null hypothesis is true, the distribution of the $H$ statistic has been found to be very closely approximated by a $x^{2}$ distribution. Thus, for a given value of the $H$ statistic, the cumulative probability value (CPV) associated with this $H$ value can be found by a simple table look-up in the appropriate $x^{2}$ table. The resulting probability value, which is noted from the table, is the area (= probability) under the null distribution density function from the observed point (i.e., from the $H$ value) all the way back to $-\infty$. If the null hypothesis $H_{0}$ is true, one would expect cumulative probability values (CPVs) generally between 0.0 and 0.90 . If $H_{0}$ is false, one would hope to obtain CPVs larger than 0.90. In the present analysis, all cases with $\mathrm{CPV}>0.90$ will be discussed and the values are expressed in percentage points (i.e., 90 percent rather than 0.90).

If the null hypothesis $H_{0}$ of no difference between levels of a given factor is true, then the distribution of the $H$ statistic is theoretically determinable. And so (if $\mathrm{H}_{0}$ is true), the observed value 
of $\mathrm{H}$ should behave like a single random drawing from the of the theoretical distribution of $H$. The "body" of such a distribution is that region between the 0 percent point and the 90 percent point--all values of $H$ which fall in this region will yield CPVs between 0.0 and 0.90 . Values of $H$ which fall out of the "most likely region" are rare and imply that the validity of $H_{0}$ is not supported by the data. These larger values of $H$ beyond the 90 percent point will, of course, yield CPVs larger than 0.90 .

This CPV is reported here as the result of a test for the equality of the levels within a factor. The CPV is rather simply related to the probability of erroneously concluding that the difference between levels is significant. If this value is significant at the 10 percent level, only 10 percent of the time will it be erroneous to conclude that a significant difference exists.

For example, when a factor has a reported CPV of 95 percent there is a 5 percent chance of erroneously rejecting the null hypothesis when, in fact, it is true; thus, at a probability value of 95 percent, the difference between the levels of a factor is sajd to be significant at the 5 percent level. It is noted that significance levels commonly used for hypothesis testing are 1 , 5, or 10.

\subsubsection{Significance}

For each factor, $X$, it is of interest to test whether the various levels of $X$ give the same result or a significantly different result. If the different levels do not (within random error) give the same value, the factor is said to be statistically significant. In this report, a test of significance is applied independently to data sets representing each of the materials tested and to data representing all materials (of Phase I) combined into a single set. The result of the test of significance is a determination of whether the levels of a factor are significantly different. 
The parameters used to conduct the KW statistical test are the standard deviation for replicate responses, $s$, the individual test responses, $y_{i}$, and the mean response, $\bar{Y}$. Responses derived from these three parameters are specimen strength ratio $R_{s b}$, and percent relative deviation (\%RD) from reference $K_{I C}$ values are given for each of several measures of fracture toughness (Section 4 ) designated $K_{Q}^{\prime}, K_{Q-P M}, K_{Q}, K_{j}^{\prime}$, $K_{\mathrm{J}}$, and $K_{\mathrm{d}}^{*}$

When the test of significance indicates that significant differences exist among the responses for the various levels of a factor, the question becomes which level is best. For the responses given above, low values of $s$ and $|\% R D|$ indicate, respectively, better reproducibility and more accuracy. Thus, they are considered better than high values of $s$ and |\%RD|; therefore, the best level can be determined for computed responses of $K$ by selection of the level with the lowest values of either $s$ or |\%RD|. However, for the computed values of specimen strength ratio, $R_{s b}$, the best level can be determined only from the reproducibility parameter $s$, because no reference values of $R_{S b}$ (from which to make a determination of accuracy) are available for this analysis. Hence, for $R_{s b}$ responses, the parameters $y_{i}$ and $\bar{Y}$ are used only to determine of the significance of differences (in the $R_{s b}$ responses) among the levels of each factor, and the question as to which level is most accurate cannot be addressed without reference values of $R_{s b}$

The requirement of replicate testing (see table 1) was not met for every combination of levels and factors given in the test matrix (table 2). In addition, reference data are not available for all of the cal- 
culated test results, as reference values of $R_{s b}$ are not available.

Thus, the analysis is somewhat incomplete whenever these requirements for replicates and reference values were not met.

\subsubsection{Reproducibility}

Reproducibility of the test results is estimated from replicate responses. Let $y_{j}$ denote the individual response for a group of replicate specimens. A mean response, $\bar{Y}$, and a standard deviation, s, are computed for each set of replicates in accordance with the formulae:

$$
\bar{Y}=\sum_{1}^{N}\left(y_{j}\right) / N,
$$

and

$$
\left.s=\sum_{1}^{N}\left(y_{i}-\bar{Y}\right)^{2} /(N-1)\right]^{1 / 2} \text {, }
$$

where $N=$ the number of responses in the group (see Table 2). For the test of significance, a CPV is computed from a data set for each factor. The set includes the standard deviation, s, responses and their corresponding levels for one of the factors.

In this way, reproducibility evaluations are made for each material and for data combined for more than one material. The response parameter in each case is the value of $s$, converted to rank within a material. For combined data, this same rank (of $s$ within a material) is the response parameter. The variance of data for each material to be combined is different, i.e., the pooled $s$ for all responses of a material differ for the various materials evaluated. In the test of 
significance, each s response is assigned a rank that depends upon performance within one of the materials, so that the effects of differences among the variances of the three materials are effectively el iminated, when the CPV is computed.

\section{1 .3 Accuracy}

The test of significance is an estimate of the accuracy of the responses for each level of a factor whenever the CPV is obtained from computed estimates of $K$ for which reference $K_{I c}$ values are available. The estimator of accuracy used here is called the percent relative deviation (\%RD). This estimator of accuracy is based upon the difference between a value of fracture toughness, $K$, computed by one of the described methods (Section 4) used for precracked Charpy specimens, and the reference value $\left(K_{I C}\right)$ computed in accordance with ASTM Method E 399 [5] for large compact tension specimens. The \%RD is this difference expressed as a percentage of $\mathrm{K}_{\mathrm{Ic}} \mathrm{c}^{\circ}$

The \%RD has an average in studies of this type. It can sometimes be an absolute measure that can be used to compare directly the results of one material (with one level of $\mathrm{K}_{\text {IC }}$ ) with those of another material (with another level of $\mathrm{K}_{\mathrm{IC}}$ ); in these instances it would be a measure of the accuracy of the predicted response. The formula for relative deviation is

$$
\% R D=\left(K-K_{I C}\right) 100 / K_{I C} .
$$

Thus, the absolute value of relative deviation is a measure of the departure of the computed $K$ from the reference $K_{I c}$, and responses of lower absolute values of \%RD are considered to be better in accuracy. 
It is noted that when \%RD is negative, $K$ is smaller than $K_{I C^{*}}$ Further, the test of significance used on this analysis will not yield the same result for the algebraic value of \%RD and for the absolute value of \%RD. In this report, tests of significance are conducted using the algebraic value of a response rather than the absolute value. This is done because most of the responses evaluated were found to be linearly related to crack length and information would be lost to the test if the absolute values were used.

The test of significance is conducted independently for each of two response parameters: $y_{i}$, the individual response, and $\bar{\gamma}$, the mean response for replicates. Both of the tests (one on the individual observation $y_{j}$ and another on the average $\bar{Y}$ of the data over replications within a level) were conducted so as to assure that the conclusions of the analysis were not dependent an a single approach. This follows a general principle of data analysis which states that perturbations in the analysis should be introduced whenever possible so as to assess the sensitivity of the conclusion to various facets of the analysis. The ultimate objective is to arrive at conclusions which are simple manifestations of the data "speaking for themselves" and devoid of any implicit bias introduced by the method of analysis. This objective is best attained by the aforementioned analytic perturbations--approachdependent results will yield different conclusions for different 
perturbations; approach-independent results will yield substantially the same conclusions regardless of the particular perturbation.

The accuracy of responses for combined materials is given a test of significance in a manner similar to that described earlier for the reproducibility responses, except that both replicated and nonreplicated responses are included in the data set and two tests of significance are made. The response for one test is the rank of $y_{i}$ within a material and the response for the other is the rank of $\bar{Y}$ within a material.

\subsection{Multiple Linear Regression}

A procedure based on linear regression may also be used to complement the Kruskal-Wallis analysis. It is important to carry out alternative analyses (such as the regression procedure discussed in this section and the graphical procedure to be discussed in the following section) so as to assure that conclusions are not approachdependent. Conclusions which do not hold up over all three different approaches would lead one to suspect their validity; alternatively, a consistency of conclusions over the three separate approaches is highly supportive of their validity.

The first step in the regression approach consisted of fitting the response versus $\bar{a}$ as described by the model:

$$
y=\beta_{0}+\beta_{1} \bar{a} .
$$

Due to results from the Kruskall-Wallis test, $\bar{a}$ was chosen as the first factor of interest. After this linear fit was performed, the residual standard deviation was computed and noted. At this point, there exist 
various tests that could be applied to determine if $\bar{a}$ itself is significant. The simplest such test is to note whether the slope $\beta_{I}$ is significantly nonzero. A second test is to compare the 1-factor residual standard deviation with the residual standard deviation gotten by fitting the model:

$$
y=\beta_{0}+e
$$

If a significant reduction has occurred, then $\bar{a}$ is interpreted as being significant.

The next step was to augment the 1-factor model to a 2-factor model as follows:

$$
y=\beta_{0}+\beta_{1} \bar{a}+\beta_{2} K_{f} .
$$

The $K_{f}$ factor was chosen again from Kruskall-Wallis test results. The residual standard deviation for this 2-factor model was computed. The appropriate test of significance was then carried out to determine if a significant reduction occurred in the residual standard deviation in going from the 1-factor model to the 2-factor model. Such a significant reduction would be interpreted as the second factor $\left(K_{f}\right)$ being significant.

The final step was to similarly augment the 2 -factor model to a 3-factor model:

$$
y=\beta_{0}+\beta_{1} \bar{a}+\beta_{2} K_{f}+\beta_{3} N P .
$$


As before, the residual standard deviation was computed and compared to the 2-factor residual standard deviation. A significant reduction would imply the significance of the notch preparation factor.

\subsection{Graphical Analysis}

The graphical approach is a valuable complement to the KruskallWallis and regression procedures. The rationale behind the graphics approach is multifold: First of all, it allows one to use the eye's built-in pattern recognition capabilities to confirm or explain significance or nonsignificance of a factor. Secondly, the graphical approach is not sensitive to one particular aspect of the data set, but rather incorporates the entire data set--each point individually--and so it uncovers not only what we suspect, but also what we may not suspect. A third point is that outliers are most easily flagged via a graphical approach. Outliers stand out on a plot and are easily noticeable. Subsequently, they may be confirmed as such by subsequent rigorous statistical tests. A fourth advantage of the graphical approach is that it is assumption free--the validation of conclusions and suspicions unearthed via graphics are not dependent on some underlying statistical assumptions, because, by and large, no assumptions are made in employing a graphical analysis. Fifth, the use of graphics avoids the potential problem of reducing a large data set to a few statistics--such few statistics must necessarily be sensitive to only certain aspects of the data and will be insensitive to many other aspects of the data. Such statistical selectivity has the net result that some information is emphasized, but most information in the data set is filtered out and ignored. Statistics for summary purposes has its place, but for analysis purposes, a properly constructed plot will frequently be more 
informative. The final advantage of the graphical approach is that of communication. Whereas the use of the Kruskall-liallis and regression procedures of the analysis may not be fully understood by some researcher, a properly constructed plot to emphasize the significance of a factor is easily understood by all.

All in all, the graphics approach is for many reasons a valuable one--its application to the Charpy data served as a useful complement to the Kruskall-Wallis and linear regression approaches.

\section{Results}

The results indicate that: (1) All seven computed responses are linearly related to crack size and the sensitivity to crack size varies with the choice of response parameter and with material. (2) Precracking at either very high or very low levels of stress-intensity factor, $k_{f}$, are to be avoided. (3) For the three methods of notch preparation used in this study, no significant effects (of notch preparation) on the responses were observed.

In the presentation to follow, anomalies in the test data are described before these results are developed. The anomalies include departures from the proposed experimental design. Reasons are given for. elimination of selected test data from this analysis. The method of analysis using the $\mathrm{KW}$ test of significance is then further described by application to the problem of determining whether the levels of three factors are significantly different for the response $R_{s b}$. The results of the $\mathrm{KH}$ test are then presented for all other responses. The presentation describes results for $R_{S b}$ in detail and results for various responses of $\mathrm{K}$ more succinctly. Next, sections are devoted to the results 
for each of the factors, crack size $k_{f}$ maximum, and notch preparation. Finally, the sensitivity to crack size is discussed for the responses.

\subsection{Anomalies in the Data}

This analysis of the Phase I slow-bend test data led to conclusions that some of the data submitted for analysis should not be included in determinations of the effects of the levels of the factors. Before dis: cussion of the test results, the data excluded from the analyses are mentioned here.

A preliminary analysis of the data indicated that responses computed for test specimens with crack size less than $2.46 \mathrm{~mm}(0.097 \mathrm{in})$ should be excluded from the analysis because the variability of these responses was greater than that for specimens with larger crack sizes. These excluded specimens include some that were reported to have crack size of $2.00 \mathrm{~mm}(0.079 \mathrm{in})$ and thus were acknowledged by the experimentalist to have been uncracked after the completion of the precracking process. Others had reported crack sizes up to $2.18 \mathrm{~mm}(0.086 \mathrm{in})$. It was concluded that these excluded data would have confounded the test results. Therefore, specimens with crack sizes less than $2.46 \mathrm{~mm}(0.097 \mathrm{in})$ were excluded from the analysis. It is noted that the depth of the machined notch is about $2.0 \mathrm{~mm}$, and this is about $0.5 \mathrm{~mm}$ less than the cut-off established for the present work. Thus, a minimum of $0.5 \mathrm{~mm}$ of fatigue srack growth was established here as a limit below which variability of the response increased greatly. From this experience, it is recommended that a minimum crack extension equal to $0.5 \mathrm{~mm}$ (a CVN crack size equal to about $2.5 \mathrm{~mm}$ ) may be required as a practical measure to assure that fatigue crack initiation is properly detected and that the crack front has developed across the entire front of the $V$ notch of a Charpy specimen. 
In addition, during a preliminary analysis of data, one specimen of Aluminum and one of Steel behaved as outliers and the discrepancies could not be resolved with the experimentalist, so these two specimens were omitted.

Data for Steel specimens with the smallest crack size factor (a code 1 ) were not included in the analysis for the response $K_{Q}^{\prime}$. For reasons given under Test Procedures, the total energy, $E_{T}$, for many of these specimens was in error. The response $K_{Q}^{\prime}$ is the only response that is based on total energy. Therefore, $K_{Q}^{\prime}$ is the only response for which it was necessary to omit the data for Steel specimens of $\vec{a}$ code 1 .

Titanium data were derived from four sets of Charpy specimens, taken from each of four compact tension specimens (CTS). See table 4. Charpy specimens taken from one of the four CTS, the one coded $W$, were anomalous in several respects and were omitted from determinations of the significance of and effects of the levels of the factors. ApparentIy, the code $W$ Charpy specimens were not randomized before being selected for precracking, as they were all precracked at a single level of $K_{f}$ maximum. This is shown in figure 5 , which is a plot of the computed $R_{s b}$ response as a function of $K_{f}$ maximum. The plot characters $(R, T, L$, and $W$ ) represent the CTS specimen from which the Charpy specimens were taken. All W specimens are shown to have been precracked at $K_{f}$ code 3 , the highest level of $K_{f}$ maximum in this plot. None of the othar Titanium specimens were precracked at this level. In addition, it is seen that for $R_{s b}$ data, the mean and the variance of these code $W$ results are significantly different (smaller than) those for the $R, T$, and $L$ data, which are plotted at lower levels of $\mathrm{K}_{\mathrm{f}}$ maximum, codes 1 and 2 ; large differences (between mean and between variance) were also observed for most of the other 
computed responses of $K$. Further, as indicated in table 5, the CTS coded $W$ is the only Titanium CTS that failed the validity requirements of ASTM Method $E$ 399, and this CTS has the lowest fracture toughness $\left(77.4 \mathrm{ksi}(\mathrm{in})^{1 / 2}\right)$ among the four CTS of Titanium tested. It was concluded that for Titanium, the code $W$ specimens and therefore the Code $3, K_{f}$ maximum level should be excluded here, in determinations of the significance of the levels of a factor.

In developing an understanding of the results for the factor $K_{f}$ maximum, the reader is asked to bear in mind that, contrary to the original experimental design with its three proposed $K_{f}$ ratios, a wide range of actual $K_{f}$ ratios $\left(K_{f}\right.$ maximum/K smallest) were used in this test program. This range is illustrated in figure 6, which is a plot of the computed responses \%RD of $K_{j}$ as a function of $K_{f}$ ratio. Steel specimens are precracked over a wide range of ratios within each of three proposed "discrete" levels of the factor $K_{f}$ maximum. The

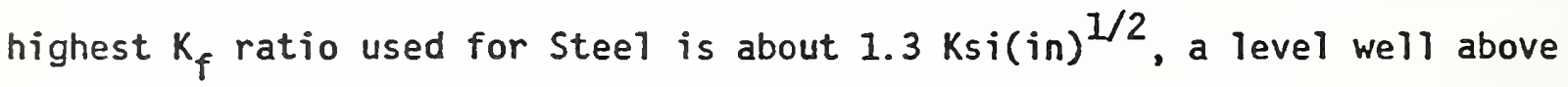
the proposed Code 3 level of 1.0 . These ratios for Steel are measured at the finish of precracking (see table 7). Discrete levels of the ratio are shown for Aluminum $(0.33,0.67$, and 1.0$)$ and for Titanium $(0.20$, and 0.40$)$, and these ratios were measured at the start of precracking. Due principalyy to brinelling at the load points of the specimen, the actual $K_{f}$ maximum at the finish is expected to be slightly lower than these indicated levels for Aluminum and Titanium. Thus, the range of stress-intensity ratios used in precracking the three materials varies from less than 0.20 to more than 1.3 , and the levels for only two of the materials are discrete and are measured at the start of precracking.

\subsection{Results of KW Test of Significance for $R_{s b}$ Responses}

The CPV results of the KW tests of significance conducted for the $R_{S b}$ responses are presented as table 8 and described here to facilitate reader 
understanding of the method of this analysis. Included are the results for Aluminum, all Titanium (including the Code $W$ specimens), Titanium (including only the $R, T$, and $L$ specimens), and Steel. In addition, results for the combined materials, Aluminum. Titanium $(R, T, W, \& L)$, and Steel are presented.

In summary, these cumulative probability results indicate that for the factor NP, the level of the factor is not significant for any of the three ilaterials; for the factor $k_{f}$ maximum, the level is significant for steel and possibly significant for Titanium; and the factor $\bar{a}$ is significant for all three materials tested. In general, the combined results tend to reflect any significant effect that is found for one or more of the individual materials.

The conclusion that the level of the factor NP does not significantly affect the $R_{s b}$ responses for any of the three materials tested is supported by results given in table 8 . The highest cumulative probabilities are $69 \%$ for the individual response $\left(y_{i}\right), 61 \%$ for the mean response $(\bar{Y})$ and $78 \%$ for the reproducibility parameter $(s)$. Thus, the highest value in the analysis of the factor NP, is $86 \%$. This indicates that even if the null hypothesis is true (that the factor NP for Steel has no effect on test result $R_{s b}$ ), we would on the average erroneously reject that hypothesis $14 \%$ of the time. Stated another way, on the average when the null hypothesis is true, then $14 \%$ of the time the calculated test statistic will exceed the tabulated $86 \%$ point of the null distribution for the factor NP, using the results for reproducibility of $R_{S b}$ responses for Steel. Inasmuch as commoniy used significance levels for hypothesis testing are 1, 5, and 10\%, then it is concluded that the three levels of the factor NP are not significantly 
different from one another on the basis of either the level of the response, $y_{j}$ or $\bar{Y}$, or the reproducibility of the response, $s$. Thus it is concluded, on the basis of a distribution-free analysis of variance, that the levels of the factor NP do not significantly affect the $R_{\text {sb }}$ response for the materials tested.

The conclusion that the level of the factor $K_{f}$ maximum is significant for Steel and possibly significant for Titanium is obtained from the CPV given in table 8. For Steel, the response parameters $y_{i}$ and $\bar{Y}$. are, respectively, $98 \%$ and $96 \%$, indicating that the effect on the response $R_{S b}$ is significant at the $5 \%$ confidence level. The CPV for the reproducibility parameter $s$ is only $25 \%$; thus, reproducibility of $R_{s b}$ responses for Steel is considered to be not affected significantly by the level of the factor $K_{f}$ maximum.

For Titanium, only 2 levels of $\mathrm{K}_{\mathrm{f}}$ maximum are tested for the RTL specimens used in the $\mathrm{KW}$ test of significance. Their CPV results are $50 \%$ for $y_{i}, 21 \%$ for $\bar{Y}$, and $90 \%$ for $s$. The $y_{j}$ and $\bar{Y}$ results clearly indicate that the response is not affected significantly by the level of the factor $K_{f}$ maximum, but the value of $90 \%$ for $s$ is marginal, being significant at only the $10 \%$ confidence level. The possible effect of the level of $K_{f}$ maximum on the reproducibility of $R_{s b}$ responses therefore requires clarification from a more thorough analysis, which is presented later.

When Code $W$ specimens of Titanium are included in the analysis of either "all Titanium" data or combined data for the three materials, the conclusions given above for Titanium are contradicted, and this points up the impropriety of the use of the Code $W$ data. For all Titanium 
data, the CPV exceeds 94 percent for each of the parameters, $y_{j}, \bar{Y}$, and $s$. These data supplement what was said earlier concerning the exclusion of Code $W$ specimens from the Phase I program and this analysis. For the combined data set, the CPVs for the parameters $y_{i}$ and $\bar{Y}$ exceed $90 \%$ in support of the trend for steel.

\subsection{Results of KW Test of Significance for All Responses}

The results of the KW tests conducted for each of the responses $R_{s b}, K_{Q}^{\prime}, K_{Q-P M}, K_{Q}, K_{j}^{\prime}, K_{J}$, and $K_{d}^{\star}$ are presented as Appendix Tables III through $V$ for the factors $\bar{a}, K_{f}$ maximum, and $N P$, respective1y. In these tables are given the results for each of the materials and for the combined materials. The Code $W$ data for Titanium are excluded from the analyses of the Titanium (RTL) data, from the analyses given for Combined Materials and from the findings of this report of the Phase I program.

In general, the results of the $\mathrm{KW}$ tests of significance indicate that

(I) The level of the crack-size factor $\bar{a}$ is significant for all three materials and for almost every computed response. This is evident from the results of both the individual response parameter $y_{i}$ and from the mean response parameter $\bar{Y}$.

(2) The level of the stress-intensity factor used in precracking, $K_{f}$ maximum, is significant for one or more responses for each material, but the significance levels are generally not as high as for the crack-size factor.

(3) The level of the notch preparation factor NP is not significant.

(4) For selected cases, the reproducibility parameter is significant for the factors $\bar{a}$ and $K_{f}$ maximum. 


\subsection{Effects of Crack Size and Material}

Responses computed from slow-bend tests of precracked Charpy specimens are shown to be linearly related to crack size. With increases in normalized crack size, responses of $R_{s b}$ increase and responses of $k$ decrease. The relationship between response and crack size depends on the choice of response parameter and on the material. In this section, these relationships will be illustrated. In Section 6.7, the sensitivity of the response to crack size will be examined as a function of response parameter and material.

The predominant effect of crack size on the test responses is illustrated by selected plots presented as figures 7 through 12. In general, the responses of $K$ (or \%RD of $K$ ) decrease roughly linearly with increases in normalized crack size, as shown in figure 7 , which is a plot of the responses of \%RD of $K_{j}^{\prime}$ for Aluminum specimens. The plot characters $\left(1,2\right.$, and 3 ) used here represent the levels of the factor $K_{f}$ maximum to be discussed later. Figure 8 is similar to figure 7 , except that the data is for the response $R_{s b}$ and a regression line is shown to illustrate the expected value of response $R_{s b}$ with increases in normalized crack size. The effect of the response parameter is illustrated further in figure 9, a plot of the regression results for Aluminum for each of the seven responses of \%RD as functions of normalized crack size. Further, in table 9, results of regression analyses used for these plots are given, for all three materials. The function \%RD of $R_{s b}$ used in figure 9 and table 9 was computed using an arbitrary reference chosen to be the mean $R_{s b}$ response, $\bar{R}_{s b}$, computed for each material. Thus, each $R_{s b}$ response was converted to a \%RD of $R_{s b}$ so that the results of regression analyses of $R_{S b}$ responses could be expressed in terms that 
would facilitate comparison with the \%RD of $K$ values (see Eq. 13) used in analyses of all other responses computed from Charpy test results. This conversion is especially useful in the analysis of sensitivity to crack size. Figure 9 and table 9 each illustrate that both the siope and the magnitude of the response are functions of the response parameter. In the figure, $R_{s b}$ is the only response with a positive slope. Further, the magnitudes of the responses of $K$ are shown to decrease roughly in the order $K_{J}, K_{j}^{\prime}, K_{d}^{*}, K_{Q}^{\prime}$, $K_{Q-P M}$, and $K_{Q}$. However, the magnitude is dependent on the material; and the order indicated above for Aluminum is, to some extent, a function of material, as well as crack size. The sensitivity of the response to crack size is discussed in Section 6.7.

The effect of material is illustrated in figures 10 through 12 and in table 9. From the regression results, given in the figures and in the table, it is seen that at any crack length, the magnitude of the expected response (\%RD of $K$ or $R_{S b}$ ) is much greater for Steel than for Aluminum or Titanium, and this effect is especially marked for all of the $K$ responses. This result opens to question the validity of the reference value of $\mathrm{K}_{\mathrm{Ic}}$ used for this Steel. As was shown earlier among the CTS results used to obtain $K_{I c}$ reference values (table 4 ), the Steel failed to meet the thickness requirement, whereas the Aluminum and the Titanium both passed this requirement. Hence, this $K_{I C}$ for Steel is unique among the $K_{I c}$ reference values used in this analysis.

\subsection{Effect of $K_{f}$ maximum}

The results, as summarized in table 10, indicate that precracking at levels of $K_{f}$ maximum outside the range of 0.4 to 0.9 times $K$ smallest is to be avoided, as either the magnitude or the variability of computed responses of $k$ or $R_{s b}$ may be greater than that for responses for specimens precracked 
within this range. These observed effects of the level of $k_{f}$ maximum are somewhat dependent on the response parameter and are generally dependent on crack-size factor. For example, $R_{s b}$ is the only response with greater variability at high $\mathrm{K}_{f}$ ratio. Furthermore, the results are based on limited data and they may be dependent on the material, as each material was not tested over the same range of $K_{f}$ ratios ( $K_{f}$ maximum/K smallest), and data are sparse for some combinations of coded $\bar{a}$ and $K_{f}$ levels. The range of $K_{f}$ ratios for these tests are 0.33 to 1.0 for Aiuminum, 0.20 to 0.40 for Titanium, and 0.33 to 1.3 for Steel. Thus, while conclusions of this analysis are presumed to be generally applicable to all materials tested, this presumption could not be completely tested with the available data.

A summary of significant results, for all seven responses and for the three materials, is given in table $10 . A C P V$ is shown for the $F$ test of the relevant MLR analysis and for each of the relevant parameters $\left(y_{i}, \bar{Y}\right.$ and $\left.s\right)$ of the $\mathrm{KW}$ test. The CPV is given for each significant result and for a few others, included for comparison. In addition, some symbols are presented in this table, to represent the significance. The symbols $S_{y}$ and $S_{s}$ represent those cases in which the $\mathrm{K}_{\mathrm{f}}$ ratio significantly affects the magnitude and reproducibility, respectively, of the response. The symbor "?" is used in selected cases to indicate a questionably significant result. For each case in which one of these symbols is indicated, in either Column $A$ for the magnitude of the response, or Column C for the reproducibility of the response, graphical analysis was conducted to further establish, illustrate, and describe the effect. The combined results of these methods of analysis gives a final result indicated in Column $B$ (for the effect of $K_{f}$ on the 
magnitude of the response) or in Column D (for that of the reproducibility). Results are illustrated in figures 13 through 16.

\subsubsection{Aluminum}

Results for aluminum specimens indicate that for $\bar{a}$ codes 1 and 2 , at a $K_{f}$ ratio less than 0.4 the magnitude of the response is greater than at higher $K_{f}$ ratios. As is indicated in table 10 column $B$, the magnitudes for all responses except $R_{s b}, K_{Q}$, and $K_{Q}^{\prime}$ are significant. This effect of a low $K_{f}$ ratio is jllustrated in a plot given as figure 13, in which data for $\% R D$ of $K_{j}^{\prime}$ are plotted against the $K_{f}$ ratio. The plot characters represent coded crack length. For each crack size shown, the response for specimens precracked at a ratio of 1.0 is similar to that at a ratio of 0.67 , but for specimens precracked at a ratio of 0.33 the magnitude of the response increases for $\bar{a}$ codes 1 and 2. This plot typifies and represents four of the five significant responses for Aluminum specimens; these are $K_{Q-P M}, K_{J}^{\prime}, K_{J}$, and $K_{d}^{*} A$ graphical analysis for the other significant response, $K_{Q}$, indicates that this effect is perhaps significant but only for à code 1 . For $\bar{a}$ code 2 specimens, responses of $K_{Q}$ for specimens precracked at a $K_{f}$ ratio of 1.0 have greater magnitude than those precracked at ratios of either 0.67 or 0.33 . Thus, for Aluminum specimens, $K_{Q}$ responses are unique among the seven responses, and the other significant responses behaved as shown in figure 13.

\subsubsection{Titanium}

Results for titanium specimens indicate that the factor $K_{f}$ maximum is significant for all seven responses and on the basis of limited available data for six of these responses and for $\bar{a}$ codes 1 and 2 only, it is concluded that responses for specimens precracked at a very low $k_{f}$ ratio of 0.20 may have greater variability than the variability for 
specimens precracked at a ratio of 0.40 . These findings are summarized in table 10 columns $C$ and $D$. For Titanium specimens, data is available only for two levels of the $K_{f}$ ratio and at the lowest level $(0.20)$ the data are sparse for specimens of $\bar{a}$ code 1 and very sparse for those of $\bar{a}$ code 3. Thus, the conclusions are somewhat tentative.

The results indicate that for $\bar{a}$ code 2 at a $k_{f}$ ratio of 0.20 , responses are more variable than at a $K_{f}$ ratio of 0.40 . This is true for five of the responses, including $R_{s b}, K_{Q-P M}, K_{j}, K_{j}^{\prime}$, and $K_{d}^{*}$, and for each of these responses it appears that the effect may be significant even for specimens of $\bar{a}$ code 1 , for which the data are sparse. For a sixth response $K_{Q}^{\prime}$, this effect clearly is significant only for $\bar{a}$ code 2 . The result for the seventh response $K_{Q}$ is significant but markedly different from that of the other responses. At a $K_{f}$ ratio of 0.20 , the magnitude of $K_{Q}$ responses is smaller for $\bar{a}$ codes 1,2 , and 3 , and the variability is greater for $\bar{a}$ code 2 specimens but smaller for $\bar{a}$ code 1 specimens. Thus, $K_{Q}$ responses behave uniquely (in both $S_{S}$ and $S_{y}$ of table 10) amongst these seven responses. The unique behavior observed for the response parameter $K_{Q}$ for both the Aluminum and the Titanium specimens, as discussed in this section, give the authors pause and we note that in a previous work [14], the parameter $K_{Q}$ (based on the same $5 \%$ secant intercept used in the present work) was found to be an inappropriate parameter for evaluations of fracture toughness in subsized specimens of a heat of 4340 steel at a yield strength of $180 \mathrm{ksi}$. It is concluded that $K_{Q}$ may be an inappropriate parameter for evaluations of the fracture toughness using Charpy tests conducted under conditions used in this study. These conditions give a load-displacement trace of the type shown in figure 3 , in which there is no indication of à cleavage initiation event. 
The general behavior described for the other significant responses is illustrated in figure 14, a plot of data for response \%RD of $K_{j}^{\prime}$ versus the $K_{f}$ ratio. In the figure, the increased variability at a ratio of 0.20 is clearly evident for code 2 , it is less clear for code 1 , and for code 3 the data are too sparse for an assessment of an effect. This illustration is consistent with the KW test result of table 10 column $C$, which indicates that the CPV for the reproducibility parameter $s$ of the KW test equals $96 \%$ for these coded data. Thus, it is concluded that, on the basis of the available data for Titanium specimens of $\bar{a}$ codes 1 and 2 , responses for specimens precracked at a very low $K_{f}$ ratio of 0.20 have greater variance than those for specimens precracked at a ratio of 0.40 .

\subsubsection{Steel}

Steel specimens were precracked at $k_{f}$ ratios of from 0.33 to 1.3 (see table 7). However, only a limited number of specimens were precracked at a ratio of less than 0.4 . Hence, the results for Steel are used here for conclusions concerning the general trends for ratios above 0.4. In general, the data for steel specimens indicate that the magnitude of each of the seven responses tends to increase with increases in the $K_{f}$ ratio. This effect is most marked for Steel specimens of $\bar{a}$ code 2 and it indicates that precracking at $k_{f}$ ratios above 0.9 is to be avoided. In addition, for $R_{s b}$ variability of responses may increase at either high or low levels of the $K_{f}$ ratio.

The general tendency for increases in the response with increases in the $K_{f}$ ratio is illustrated by figure 15 , a plot for Steel specimens showing data and a regression line for responses of $R_{s b}$ versus the $K_{f}$ ratio. Table 10 indicates the magnitude of the response is significant. Although the reproducibility parameter in the $\mathrm{KW}$ test (column $\mathrm{C}$ ) does 
not indicate a significant effect, it is apparant from this plot of $R_{s b}$ data that for $\bar{a}$ codes 2 and 3 , variability is decidedly smaller at intermediate levels of the $K_{f}$ ratio. Thus, it is concluded that both the magnitude and the variability of response $R_{s b}$ may be significantly affected by the level of $K_{f}$ ratio for Steel specimens.

The marked effect of $K_{f}$ ratio on the responses of \%RD of $K$ observed for a code 2 specimens is illustrated in figure 16, a plot of codedcrack-length data for response $K_{Q-P M}$ versus $K_{f}$ ratio. Linear regression lines for each of the three coded crack lengths are shown in order to facilitate comparisons of the effects of the $K_{f}$ ratio for each coded crack size. Significance tests (table 10 ) indicate $S_{y}\left(K_{f}\right.$ maximum has a signficant effect on the response magnitude) for both the $\mathrm{KW}$ tests and the MLR analyses, except for responses based on energy to maximum load $\left(K_{j}, K_{j}^{\prime}\right.$, and $\left.K_{d}^{*}\right)$, for which only the MLR analyses lead to a significant effect of $K_{f}$ maximum. Graphical analyses for these three responses indicate a significant behavior only for $\bar{a} \operatorname{codes} 1$ and 2 . It is noted that for response $K_{Q}^{1}$, data are not available for Steel specimens of $\vec{a}$ code 1 , and the observed effects for the available data (a codes 2 and 3) are similar to the effects illustrated in figure 16 for $K_{Q-P M}$. Thus, it is concluded that the magnitude of each of the seven responses tends to increase with increases in the $k_{f}$ ratio for Steel specimens. This effect is most marked for Steel specimens of $\bar{z}$ code 2 and it is an indication that precracking at $k_{f}$ ratios above 0.9 is to be avoided. In addition, it was shown that for response $R_{s b}$, variability of the response may increase at either high or low levels of the $k_{f}$ ratio, and this is another indication that these extreme $K_{f}$ levels are to be avoided. 


\subsection{Effects of Notch Preparation}

Significant effects of the level of IIP on the responses were observed only for Steel specimens, for three responses $R_{S b}, K_{Q-P M}$ and $K_{Q}^{\prime}$. These effects were supported by results of MLR and graphical analyses, but they went largely undetected by the KW test for significant differences among coded levels of the factor NP. The results indicate that for a hard material, such as the margaging steel used in the Phase I program, razor scratching before precracking may lead to increases in either the variability or the magnitude of the response.

The $\mathrm{KW}$ test results, given as Appendix Table $\mathrm{V}$, indicate that at the 10 percent confidence level the only potentially significant responses are $K_{Q}^{\prime}$ for Titanium $\left(R, T\right.$, and $L$ ) specimens and $K_{Q-P M}$ for Steel specimens. In this table, for Titanium, $y_{j}$ is 92 percent for $K_{Q}^{\prime}$ responses, and for the Steel, $s$ is 96 percent for $K_{Q-P M}$ Graphical and MLR analyses of the Titanium data indicated that there is no effect of NP on the magnitudes of the responses of $K_{Q}^{\prime}$ for Titanium. This eliminates Titanium from further consideration for effects of notch preparation. However, results of graphical and MLR analyses conducted with the data for Steel indicate that NP is significant for responses $R_{s b}, K_{Q-P M}$, and $K_{Q}^{\prime}$. These NP results are summarized in table 11 , which also gives some results for responses $K_{j}^{\prime}$ and $K_{d}^{\star}$, two responses for which significant effects of NP were not found.

The observed significant effect of NP for Steel specimens is illustrated in figure 17, a plot of \%RD of $K_{Q-P M} v s \bar{a} / W$. Results in table 11 indicate that, statistically, $K_{Q-P M}$ responses are affected more greatly than the other two significant responses, $R_{s b}$ and $K_{Q}^{\prime}$. Figure 17 illustrates an effect observed in plots for all three responses, $R_{s b}$, $K_{Q-P M}$, and $K_{Q}^{\prime}:$ Variability of responses for $N P$ code 1 is greater than that for codes 2 or. 3. 
Figure 17 also illustrates two effects observed only for responses $R_{S b}$ and $K_{Q-P M:}$ ( 1 ) the mean and median responses for NP code $I$ are greater than those for codes 2 or 3 , and (2) there exists along the top of the trend band (of each plot) a set of NP code 1 data, with no data there for the other NP codes. Not illustrated in this plot is the observed effect of NP on the magnitudes of the responses of $K_{Q}^{1}$ : The $K_{Q}^{\prime}$ responses are generally smallest for data of NP code 1, and there are NP code $I$ data at the bottom of the plot of for. $K_{Q}^{\prime}$. Thus, for NP code 1 , while the magnitudes of responses of selected specimens are greater for response of $R_{S b}$ and $K_{Q-P M}$, they are smaller for $K_{Q}^{\prime}$ responses; further, NP code $I$ responses for $R_{S b}, K_{Q-P M}$, and $K_{Q}^{\prime}$ are more variable than those for NP codes 2 and 3. Clearly, selected test results of $\mathrm{Np}$-code-1 steel specimens are signficantly contributing to the variability and magnitude of results for responses $R_{S b}, K_{Q-P M}$, and $K_{Q}^{\prime}$ for steel.

Our interpretation of these findings is that some Steel specimens of NP code 1 (razor scratched) were somehow improperly prepared for the precracking process. The net result of this improper preparation is that something (perhaps an uneven crack front'or perhaps cold work) occurred in the test specimen during precracking. As a result of this, (1) responses that are a function of maximum load $\left(R_{S b}\right.$ and $\left.K_{Q-P M}\right)$ have greater than expected magnitude, (2) the response that is a function of total energy absorbed $\left(K_{Q}^{\prime}\right)$ has smaller magnitude, and ( 3 ) those that are a function of either $P_{Q}$ or energy to maximum load do not appear to be affected by NP. Because these effects of NP were not observed for the softer materials, Aluminum and Titanium, it is further speculated that, in general, the observed effect of NP occurred in this Steel because it is a difficult material to scratch with a razor blade, especially after 
the blade begins to become dull, as it might after being used to scratch several hard steel specimens.

The results given above are believed to be unaffected by the previously discussed effect of the level of $K_{f}$ maximum on the responses for Steel. This was assured by graphical analyses in which the responses for $K_{f}$ code 3 were tagged and counted for each NP and $\bar{a}$ code subdivision. Thus, it is concluded that razor scratching before precracking may lead to increases in either the variability or the magnitude of the reponse for a hard material, such as the maraging steel used in the Phase I program.

\subsection{Sensitivity of Response to Crack Size.}

In this section, the sensitivity of the response to crack size is shown to be a function of the choice of response parameter and of the material. The response parameters most sensitive to crack size are $K_{J}$ and $K_{j}$, both of which are based on energy to maximum load. Among the three materials tested, Steel is most sensitive to crack size and Aluminum is least sensitive to crack size.

Comparisons of the sensitivity of response parameter $R_{s b}$ with that of one of the responses based on \%RD of $K$ is facilitated here in tables 9 and 12 and in figure 9 , by the conversion of data for response $R_{S b}$ to percent relative deviation ( $\% R D$ of $R_{S b}$ ) from an arbitrary reference, the mean $R_{s b}$ for each material, as discussed in Section 6.4. Table 12 contains selected data from table 9. These are data needed to compare the relative sensitivities (of all seven responses) to crack size. Two numbers are given for each combination of response parameter and material. The first of these is the slope, in the relationship between \%RD of response and crack size (eq. 14), and the second is the residual standard deviation obtained from the fit. to equation 14. 
The indicated slopes and residuals lead to the conclusion that responses based either on a single value of load, including $R_{s b}, K_{Q}$, and $K_{Q-P M}$, or on a total energy, $K_{Q}^{\prime}$, are less sensitive to crack size, in comparison with the sensitivities of responses based on an energy to maximum load. The slopes for responses that are based on either a load or total energy are comparatively smal1. They vary from 0.04 to 0.11 . On the other hand, slopes for responses $K_{J}$ and $K_{j}^{\prime}$ are particularly large, ranging from 0.20 to 0.43 . Slopes for response $K_{d}^{\star}$ are intermediate in magnitude ranging from 0.11 to 0.18 . Thus, responses based on energy to maximum load are more sensitive. This is illustrated by regression results for aluminum given as figure 9. In addition, residuals (table 12) for responses based either on a single value of load or on total energy are generally smaller and range from 2.4 to 6.1 , whereas residuals for responses based on energy to maximum load are larger and range from 5.3 to 8.7. Thus, it is concluded that, among the seven responses, $K_{J}$ and $K_{j}^{\prime}$ are most sensitive to crack size, $K_{d}^{*}$ is intermediate in sensitivity to crack size, and responses based on either a single value of load or total energy are least sensitive to crack size and are generally similar to one another in sensitivity to crack size.

The relative sensitivity to crack size is measured by the absolute magnitude of the slope given as $\beta_{1}$ in table 9 . These data indicate that

(1) The three materials tested are similar, but minor differences are present.

(2) The Steel is most sensitive to crack size.

(3) The Titanium and the Aluminum have similar sensitivities to crack size. Table 12 shows the similarities between slopes for most responses of aluminum and those of titanium, and it shows that the slope for most responses is greater for the Steel than for the other materials, with the exception of responses $R_{s b}$ and $K_{Q}^{\prime}$ for which slopes are nearly equal for each of the three materials. 
Table 12 indicates that the residual standard deviation for six of the seven responses is smaller for Aluminum than for either of the other two materials. This is an indication that Aluminum is least variable.

\section{Conclusions}

7.1 Responses computed from slow-bend tests of precracked Charpy specimens are shown to be linearly related to crack size.

7.1.1 With an increase in crack size, the response of $R_{s b}$ increases and the $K$ responses decrease.

7.1.2 At fixed crack size, the magnitude of the \%RD of $k$, for each of six responses, is much greater for the Steel tested than that for the Aluminum or the Titanium, a result that opens to question the validity of the reference value of $\mathrm{K}_{\mathrm{IC}}$ used for the Steel.

7.2 The sensitivity of the response to crack size is a function of both the choice of response parameter and of the material.

7.2. I Among the seven response parameters evaluated here, $K_{J}$ and $K_{j}^{\prime}$ are most sensitive to crack size, $K_{d}^{\star}$ is intermediate, and responses based on either total energy $\left(K_{Q}^{\prime}\right)$ or a single value of load, $\left(K_{Q-P M}, K_{Q}\right.$ and $\left.R_{s b}\right)$ are least sensitive and are similar to one another in sensitivity to crack size.

7.2.2 Among the three materials tested, sensitivity to crack size is greatest for the Steel and least for the Aluminum.

7.3 Preliminary screening of the data used for this analysis led to the conclusion that a lower bound of crack size equal to about $2.5 \mathrm{~mm}(0.098$ in) may be required as a practical measure to assure that fatigue crack initiation is properly detected and that it has developed across the entire front of the $V$ notch of a Charpy specimen. 
7.4 Precracking at levels of $K_{f}$ maximum outside the range of from 0.4 to 0.9 times $\mathrm{K}$ smallest is to be avoided, as either the magnitude or the variability of computed responses of $K$ or $R_{s b}$ may be greater than that for responses for specimens precracked within this range.

7.4.1 Available data for the Aluminum and the Titanium tested indicate that precracking at levels below a $K_{f}$ ratio of about 0.4 is to be avoided, as either the magnitude or the variability of the response may be increased.

7.4.2 Indications that precracking at a low $\mathrm{K}_{\mathrm{f}}$ ratio may increase the magnitude of the response were obtained from results of tests of Aluminum specimens. At a $K_{f}$ ratio less than 0.4 , the magnitude of the response is greater for crack sizes of a codes 1 and 2 . This was observed for four of five significant responses $K_{Q-P M}, K_{J}, K_{J}$ and $K_{d}^{*}$. For the fifth significant response, $K_{Q}$, the magnitude is greater only for $\bar{a}$ code 1 .

7.4.3 Indications that precracking at low $k_{f}$ ratio may increase the variability of the response were obtained from Titanium and Steel specimens. Results for Titanium specimens indicate that the factor $K_{f}$ maximum is significant for all seven responses. On the basis of limited data available for six of these responses and for $\bar{a} \operatorname{codes} 1$ and 2 only, it is concluded that responses for specimens precracked at a very low $k_{f}$ ratio of 0.20 may have greater variability than those for specimens precracked at a ratio of 0.40 . Variability of $R_{s b}$ responses for $\bar{a}$ codes 2 and 3 of Steel specimens is decidedly smaller at intermediate levels of the $K_{f}$ ratio. 
7.4.4 Results for the Steel specimens indicate that the magnitude of the response generally tends to increase with an increase in the $k_{f}$ ratio over the range of ratios of from 0.33 to 1.3 . This effect is most marked for specimens of $\bar{a}$ code 2 , and it is an indication that precracking at very high $k_{f}$ ratios above 0.9 is to be avoided.

7.5 Among the three levels of notch preparation tested, no signficant effects of the level of NP on the response were observed, except for steel. The results indicate that for materials similar to those used inthe Phase I program, similar responses are to be expected from a standard notch that is either razor scratched or EDM sharpened or from a sharply (non-standard) machined notch. The results suggest that for hard specimens (like the steel used here) razor scratching may not be appropriate because hard specimens may be difficult to scratch uniformly.

7.6 The results indicate that the response $K_{Q}$ based on a 5-percentsecant intercept may be inappropriate for characterization of fracture toughness using precracked Charpy tests conducted under conditions used in this study.

\section{Acknowledgments}

The authors would like to thank two NBS workers, Mr. David E. Schwab for extensive computations and programming assistance in the computations of the Kruskal-Wallis Test of Significance and Mr. Sam R. Low for making numerous plots and tables needed for this analysis. In addition, this analysis was made possible through the ASTM Task Group E24.03.03, its chairman Dr. C. Hartbower and the work of participating members, M. W. Brennecke, A. Burnett, C. Curll, R. E. Davies, S. Fisher, and the extensive works of members; T. Ronald and $W$. Server. In a study conducted by G. E. Hicho for Subcommittee E24.02 on Fractography for Fracture Testing, the value of maximum load for specimen S19 was found to contain an error (a transposition of two numbers) and this prompted the authors to recompute and replot all affected results. 


\section{REFERENCES}

[1] Schwabe, J.; et al. Report of Working Group on Instrumented Precrack Charpy Test for Medium Strength Nuclear Pressure Vessel Steels (Parts 1 and 2), HPC-PVRC Joint Task Group on Fracture Toughness Properties of Materials for Nuclear Components--Final Report, Library of Congress No. 77-88087, 1977.

[2] Wullaert, R. A.; Olefield, W.; and Server, W. L. Fracture toughness data for ferritic nuclear pressure vessels--Final Report of Research Project 232-1, Vol. I, II and III, Electric Power Research Institute, NP-121, 1976 April.

[3] NMAB Committee on Rapid Inexpensive Tests for Determining Fracture Toughness. Rapid inexpensive tests for determining fracture toughness; Washington, DC:National Materials Advisory Board, Commission of Sociotechnical Systems, National Research Council, National Academy of Science; 1976.

[4] Aluminum standards and data; New York: Publications Dept., Aluminum Association, Inc., 750 Third Ave., New York, NY 10017; 1976.

[5] ASTM Designation E399-74; Standard method of test for plane-strain fracture toughness of metallic materials, in Part 10, Annual book of ASTM standards. Philadelphia:American Society for Testing and Materials; 1976.

[6] Ronald, T.; Hall, J. A.; and Pierce, C. M. Usefulness of precracked charpy specimens for fracture toughness screening tests of titanium alloys. Metallurgical Transactions 3:1-6; 1972 April.

[7] Rice, J. R.; Paris, P. C.; and Merkle, J. G. Some further results of J-integral analysis and estimates. ASTM STP 536; 1973 July. 231 p. 
[8] Ireland, D. R.; Server, W. L.; and Wullaert, R. A. Procedures for testing and data analysis: task A topical report; Effects Technologies Inc., Technical Report 75-43, 1975 0ctober.

[9] Server, W. L. Impact three-point bend testing for notched and precracked specimens; ASTM Journal of Testing and Evaluation, 1978 January.

[10] Witt, F. J. Equivalent energy procedures for predicting gross plastic fractures; Oak Ridge Nat. Lab., U.S. AEC Report ORNL-TM-3172, 1972.

[1i] Kruskal, W. H. and Wallis, W. A. Use of ranks in one-criterion variance anlaysis; JASA, 47(260):583-618; 1952 December.

[12] Draper, N. and Smith, H. Applied regression analysis. New York:Wiley and Sons, 1956.

[13] Dataplot, An interactive system for graphics, fortran function evaluation, and linear/nonlinear fitting. Proceedings of the Statistical Computing Section of the American Statistical Association; 1978.

[14] Jones, M. H. and Brown, W. F., Jr. The influence of crack length and thickness in plane strain fracture toughness tests; in Review of developments in plane strain fracture toughness testing, ASTM STP 463, Philadelphia:American Society for Testing and Materials; 1970; 81 p. 
$\underline{T a b l e ~} 1$

Proposed Test Matrix

\begin{tabular}{|c|c|c|c|}
\hline \multicolumn{3}{|c|}{ Coded Levels of Factors } & $\begin{array}{l}\text { Proposed Number of } \\
\text { Tests Per Material }\end{array}$ \\
\hline NP & $k_{f}$ & $\bar{a}$ & Al, Ti, Steel \\
\hline 1 & 1 & 1 & 2 \\
\hline 1 & 1 & 2 & 2 \\
\hline 1 & 1 & 3 & 2 \\
\hline 1 & 2 & 1 & 2 \\
\hline 1 & 2 & 2 & 2 \\
\hline 1 & 2 & 3 & 2 \\
\hline 1 & 3 & 1 & 2 \\
\hline 1 & 3 & 2 & 2 \\
\hline 1 & 3 & 3 & 2 \\
\hline 2 & 1 & 1 & 2 \\
\hline 2 & 1 & 2 & 2 \\
\hline 2 & 1 & 3 & 2 \\
\hline 2 & 2 & 1 & 2 \\
\hline 2 & 2 & 2 & 2 \\
\hline 2 & 2 & 3 & 2 \\
\hline 2 & 3 & 1 & 2 \\
\hline 2 & 3 & 2 & 2 \\
\hline 2 & 3 & 3 & 2 \\
\hline 3 & 1 & 1 & 2 \\
\hline 3 & 1 & 2 & 2 \\
\hline 3 & 1 & 3 & 2 \\
\hline 3 & 2 & 1 & 2 \\
\hline 3 & 2 & 2 & 2 \\
\hline 3 & 2 & 3 & 2 \\
\hline 3 & 3 & 1 & 2 \\
\hline 3 & 3 & 2 & 2 \\
\hline 3 & 3 & 3 & 2 \\
\hline
\end{tabular}


Table 2

Actual Numbers of Tests Conducted for Each Level of the Factors and for Each Material.

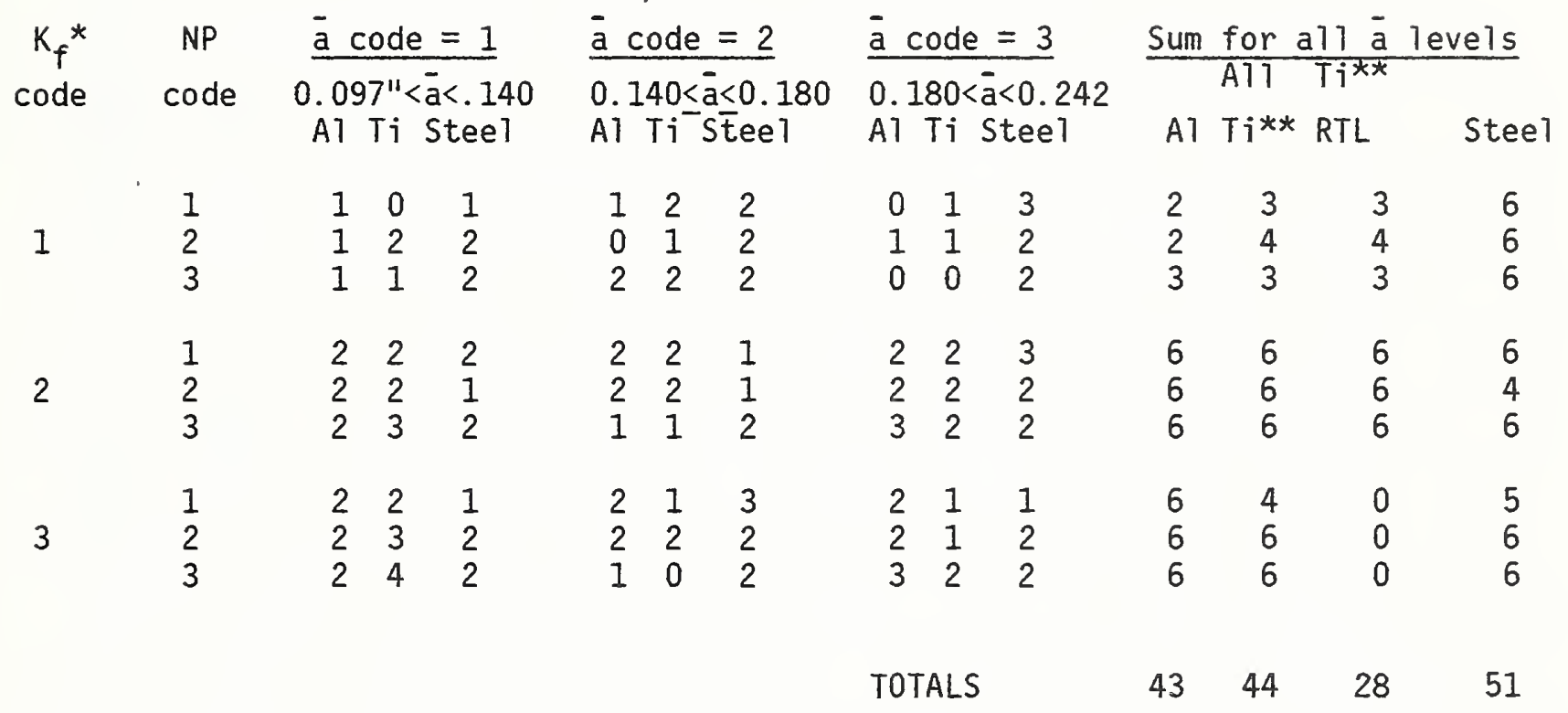

* See Table 7 for codes used in computer analysis.

**Data used in the analyses for Titanium include $R, T$, and $L$ specimens and exclude a11 Charpy specimens prepared from a CTS specimen that was designated $W$. 


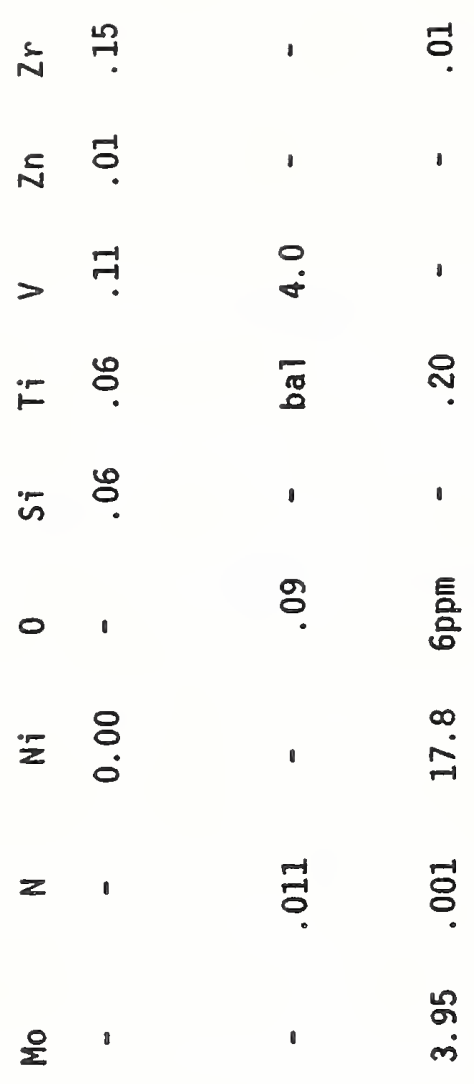

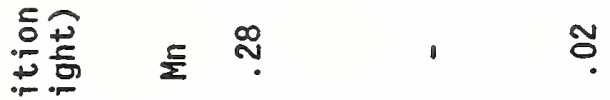

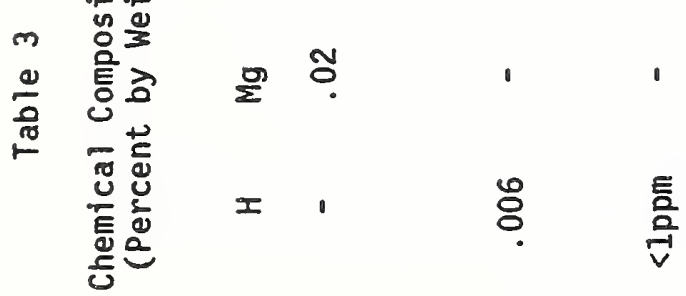

ะ $\stackrel{\infty}{\circ} \stackrel{m}{\longrightarrow}$ ๓

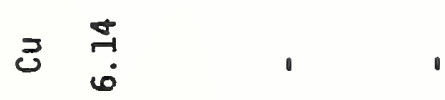

$=\stackrel{8}{0} \quad, \quad \stackrel{\circ}{\circ}$

¿ 1 i

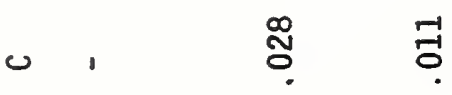

₹

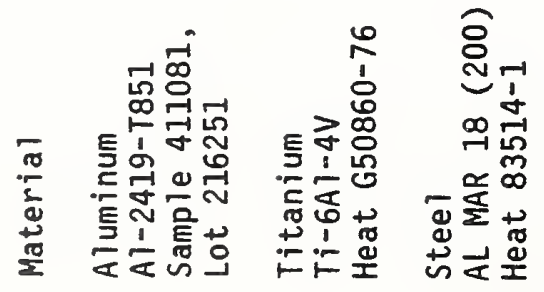




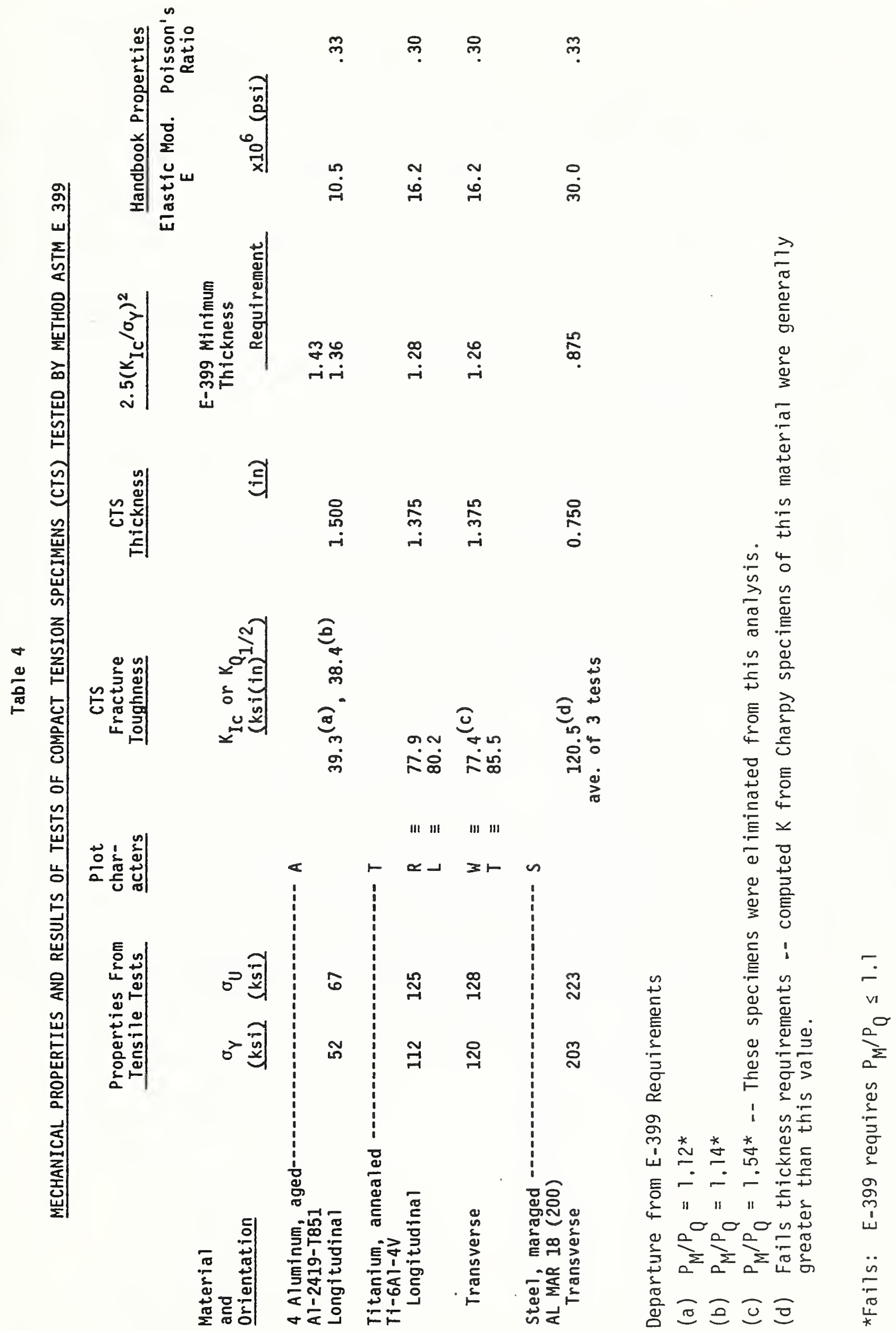


Table 5

\section{Determination of $K$ Smallest}

MATERIAL \&

ASSUMED

PROPERTIES

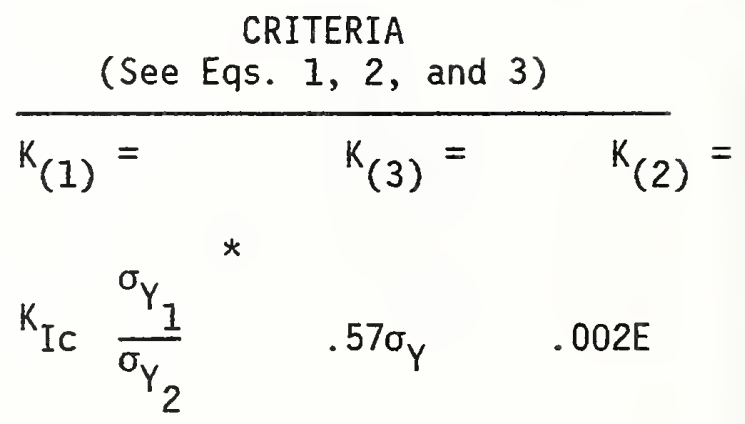

Aluminum

$\sigma_{Y 1}=60 \mathrm{ksi}=\sigma_{Y 2}$
$K_{I C}=40 \mathrm{ksi}(\mathrm{in}) 1 / 2$
$E=10 \times 10^{3} \mathrm{ksi}$

40

34

$\underline{20}$

Titanium

$\sigma_{Y 1}=100 \mathrm{ksi}=\sigma_{Y_{2}}$

80

57

33

$K_{I c}=80 \mathrm{ksi}(\mathrm{in}) 1 / 2$

$E=16.5 \times 10^{3} \mathrm{ksi}$

Stee $]$
$\sigma_{Y 1}=200 \mathrm{ksi}=\sigma_{Y 2}$
$100+$
114
$\underline{60}$
$K I c=100+$
$E=30 \times 10^{3} \mathrm{ksi}$
* $\sigma_{Y 1}$ is the static yield strength at the precracking temperature and $\sigma_{Y 2}$ is the static (slow bend) yield strength at the test temperature. 


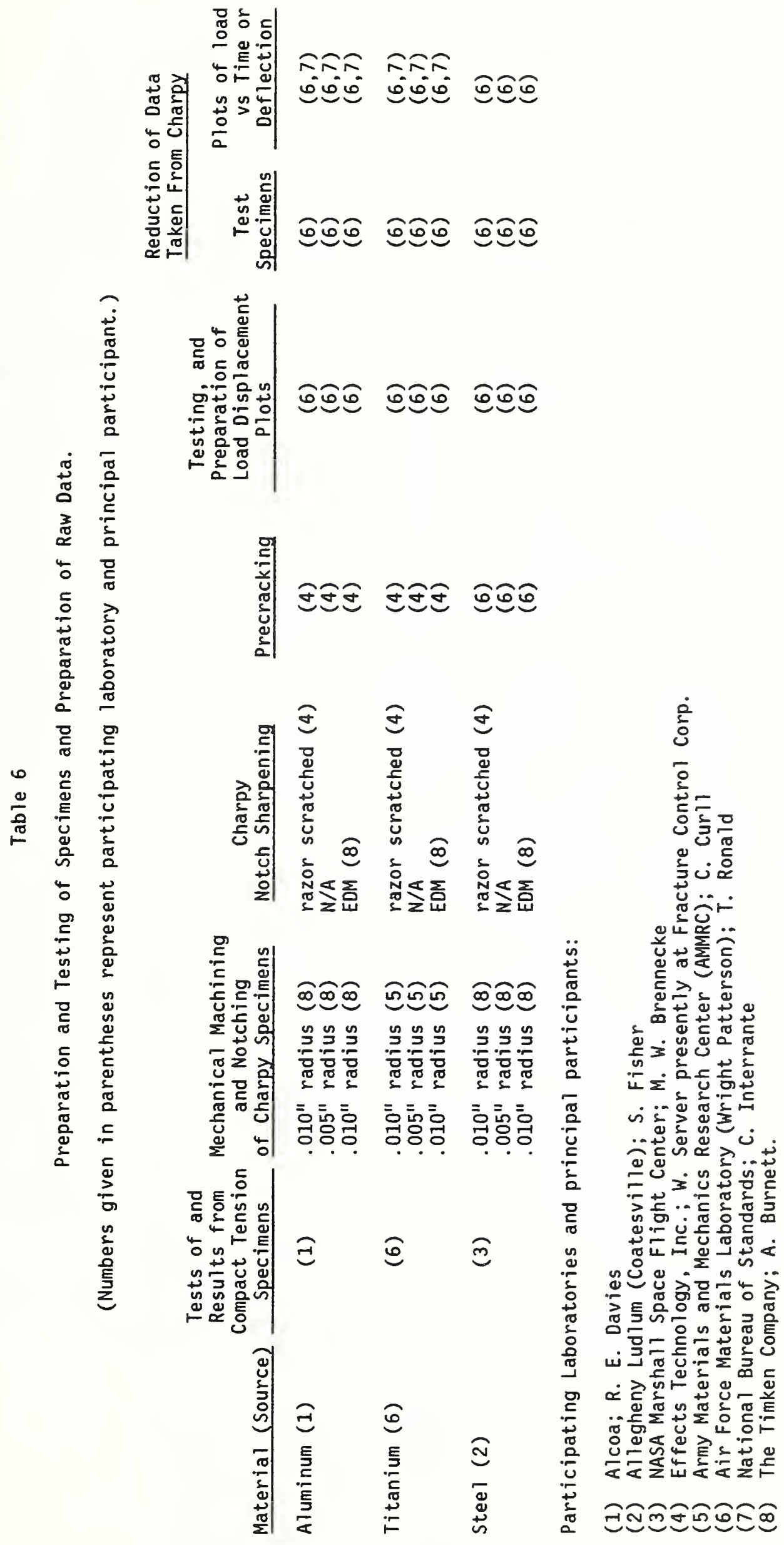




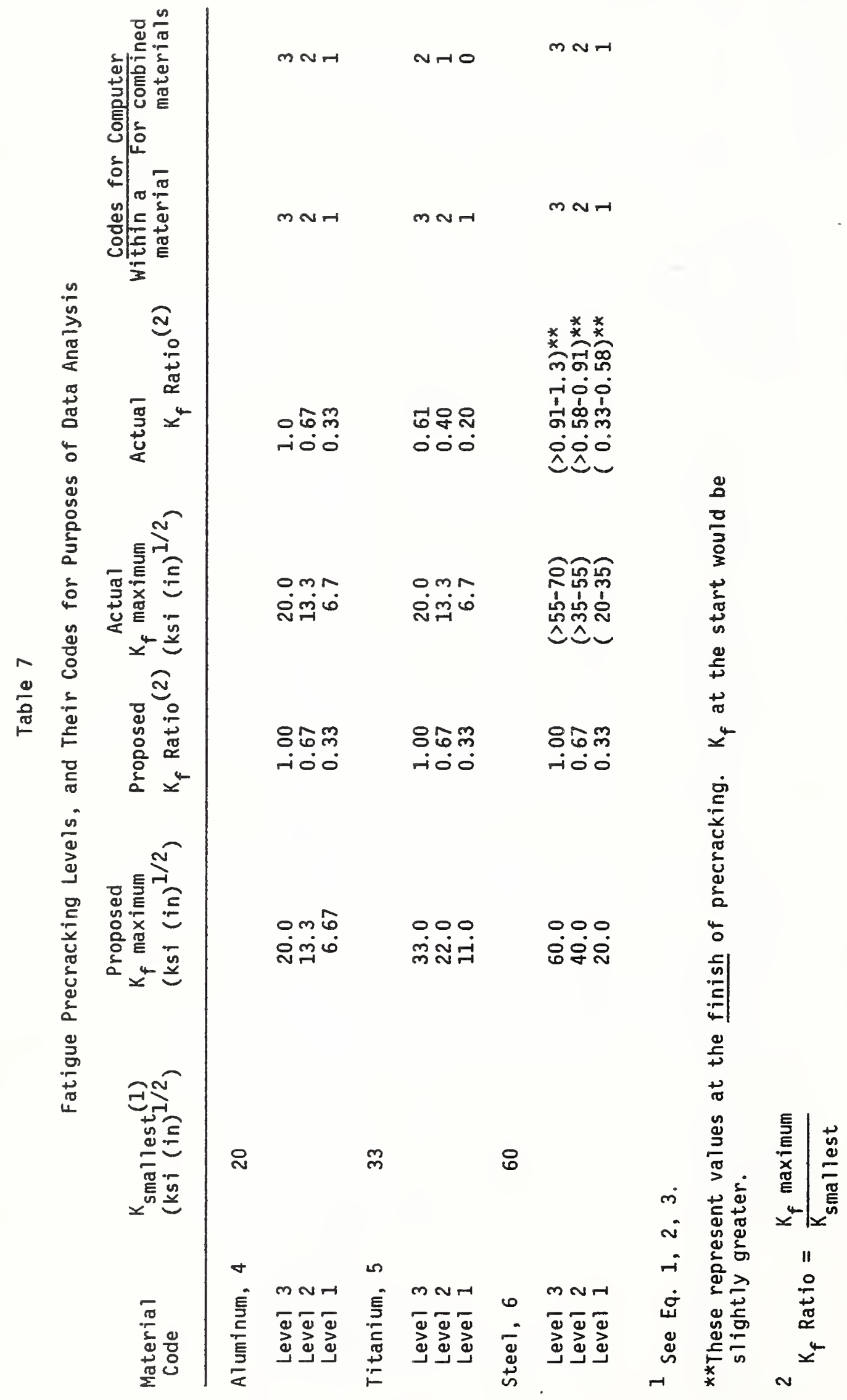




\section{Table 8}

Kruskal-Wallis Test of Significance and Cumulative

Probability Values for Response $R_{s b}$.

Type of

Statistic
Response

Parameter
Cumulative Probability NP
Value for

Material
43 Aluminum

$24 \quad$ Aluminum

$17 \quad$ Aluminum
68.9

61.2

51.3

22.5

44 Titanium, all

24 Titanium, all

7.3

16 Titanium, all

57.2

57.5

25.0

40.9

$11 \mathrm{~T}$ RTL onty

51 Steel

63.5

35.3

77.8

21 Stee
56.9

52.8

70.7

$100.0 * *$

$>99.9$

94.3

49.8

20.9

89.8

98.5

96.0

25.5
$>99.9$

99.4

96.8

Mean responses

s

Combined Materials

Individual Responses Rank* of $y_{i} 122$ A, T(a) 1), \& S 61.3

Mean Responses

Rank* of $Y$

67

A, $T(a 17), \& S 92.7$

99.3

$100.0 * *$

Reproducibi i ity

Rank* of $s$

48

$A, T(a) 1), \& S$

53.5

99.2

$>99.9$

3.5

99.5

\footnotetext{
Rank is assigned within the response for a material

$* *>99.9995$

$$
R_{s b}=6 P_{m} W / B(W-\bar{a})^{2} \sigma_{Y}
$$
}




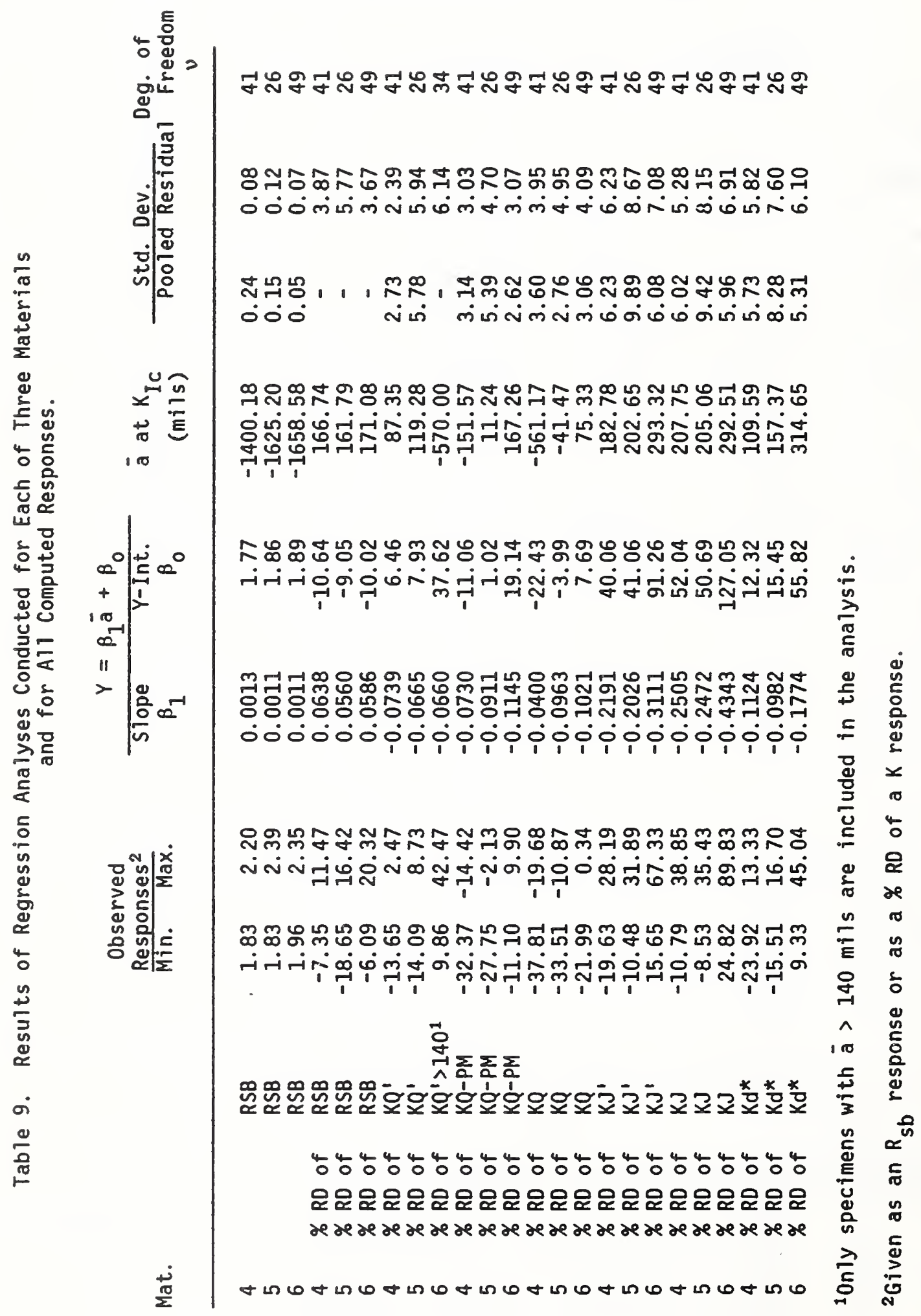




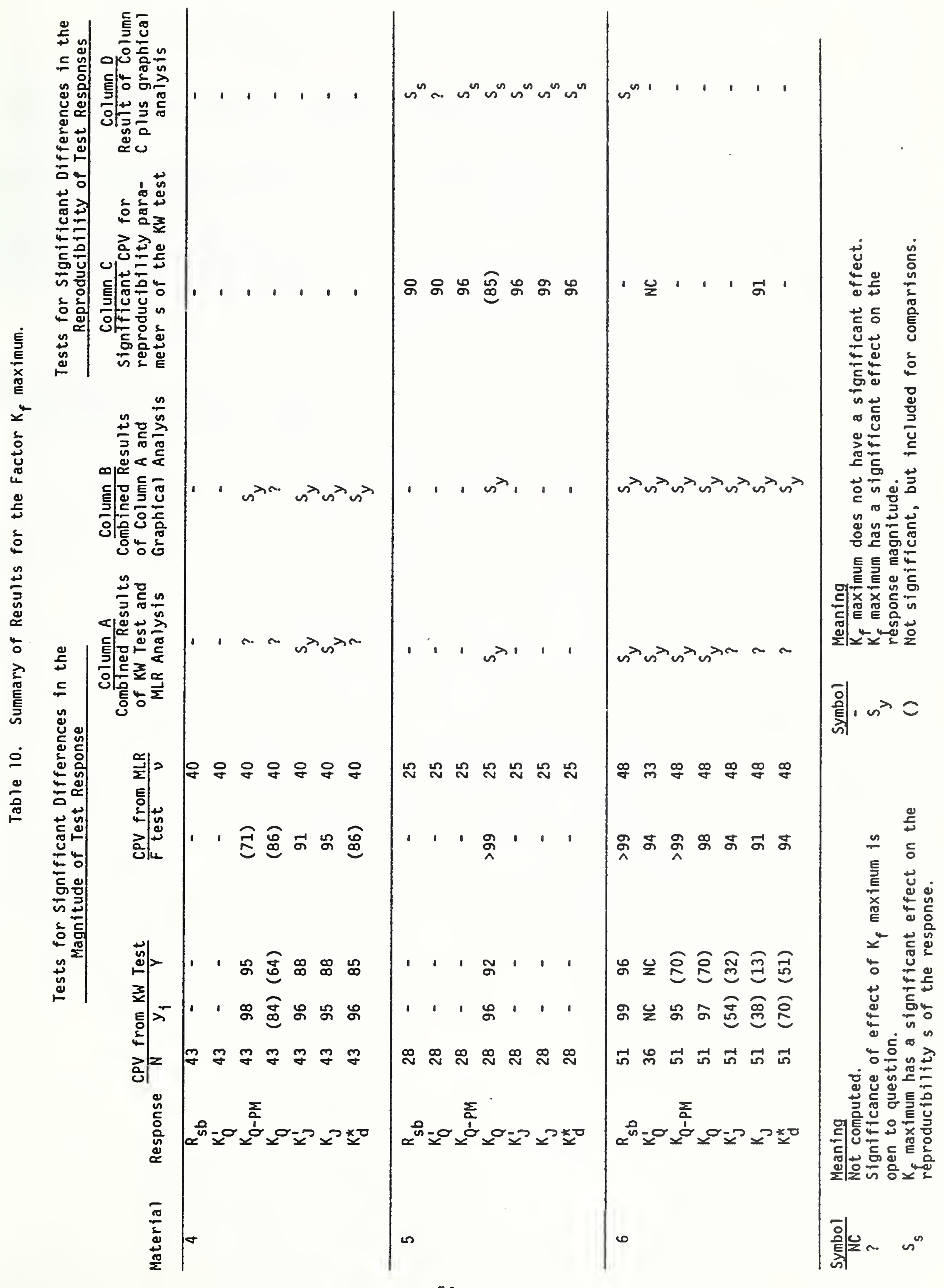


Table 11. Effects of Notch Preparation on Results for Steel Specimens.

\begin{tabular}{|c|c|c|c|c|c|}
\hline \multirow[b]{2}{*}{ Response } & \multicolumn{3}{|c|}{ CPV From KW Test ${ }^{(1)}$} & \multirow{2}{*}{$\begin{array}{l}\text { CPV from } \\
\text { MLR Analysis }\end{array}$} & \multirow[b]{2}{*}{ Findings from Graphical Analysis } \\
\hline & $y_{i}$ & $\begin{array}{r} \\
\end{array}$ & $s$ & & \\
\hline$R_{s b}$ & 70 & 40 & 86 & 95 & $\begin{array}{l}\text { For NP code } 1 \text {, both variability, } \\
\text { and magnitudes of mean and median } \\
\text { responses, are greater than those } \\
\text { for codes } 2 \text { and } 3 \text {. }\end{array}$ \\
\hline$K_{Q-P M}$ & 30 & 18 & 96 & 97 & Same as $R_{s b}$ (above). \\
\hline $\mathrm{K}_{\mathrm{Q}}^{\prime}$ & 80 & 72 & 37 & 94 & $\begin{array}{l}\text { For } N P \text { code } 1 \text {, variability is } \\
\text { greater than, and magnitudes of } \\
\text { mean and median responses are } \\
\text { less than, those for NP codes } \\
2 \text { and } 3 .\end{array}$ \\
\hline$K_{j}^{\prime}$ & 6 & 8 & 58 & 88 & No significant effects of NP. \\
\hline$K_{d}^{*}$ & 18 & 26 & 78 & 89 & No significant effects of NP. \\
\hline
\end{tabular}

(1) Taken from Appendix Table V. 
Table 12. Sensitivity of Responses to Crack Size.

\begin{tabular}{cccccccc}
\multicolumn{8}{c}{ Regression results for \%RD**, taken from table 9.} \\
Material & $R_{s b}$ & $K_{Q}^{\prime}$ & $K_{Q-P M}$ & $K_{Q}$ & $K_{J}^{\prime}$ & $K_{J}$ & $K_{d}^{*}$
\end{tabular}

Slope $\beta_{1}$

$\begin{array}{llllllll}\text { A } & 0.064 & -0.074 & -0.073 & -0.040 & -0.22 & -0.25 & -0.11 \\ \mathrm{~T} & 0.056 & -0.067 & -0.091 & -0.096 & -0.20 & -0.25 & -0.10 \\ \mathrm{~S} & 0.059 & -0.066 & -0.115 & -0.102 & -0.31 & -0.43 & -0.18\end{array}$

Residual Standard Deviation

$\begin{array}{llllllll}\mathrm{A} & 3.9 & 2.4 & 3.0 & 4.0 & 6.2 & 5.3 & 5.8 \\ \mathrm{~T} & 5.8 & 5.9 & 4.7 & 5.0 & 8.7 & 8.2 & 7.6 \\ \mathrm{~S} & 3.7 & 6.1 & 3.1 & 4.1 & 7.1 & 6.9 & 6.1\end{array}$

$\star \star \% R D=\beta_{1} \bar{a}+\beta_{0}$. 
Fig. A

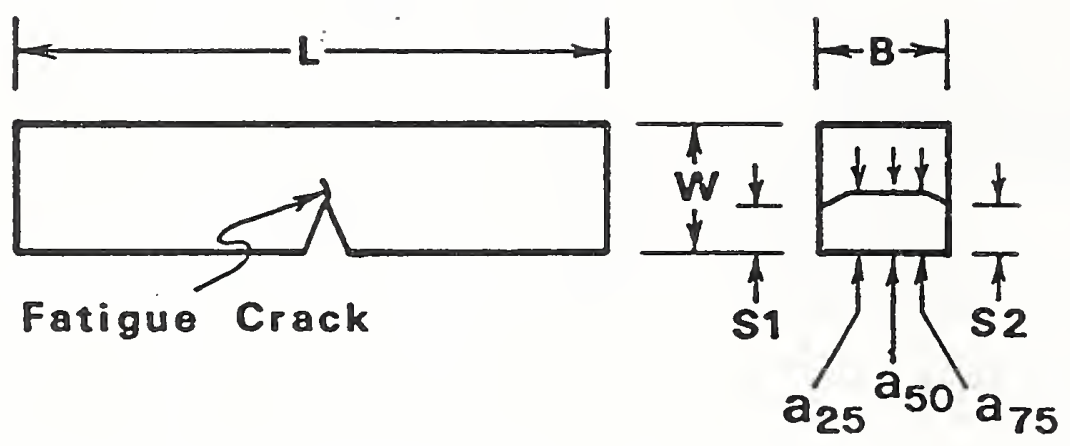

Fig. B

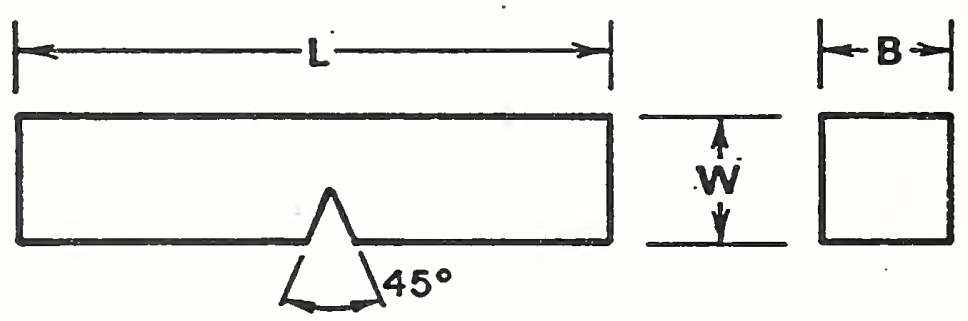

\begin{tabular}{ccc}
$\begin{array}{c}\text { Machined } \\
\text { Root Radius } \\
\text { (mm) }\end{array}$ & $\begin{array}{c}\text { Notch } \\
\text { (in) }\end{array}$ & $\begin{array}{c}\text { Preparation } \\
\text { Code }\end{array}$ \\
\hline .250 & .010 & 1 \\
.125 & .005 & 2 \\
.250 & .010 & 3
\end{tabular}

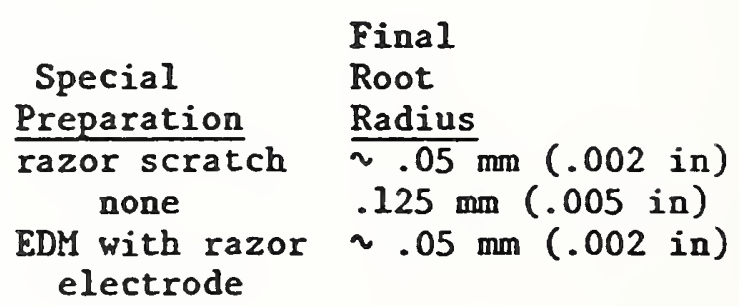



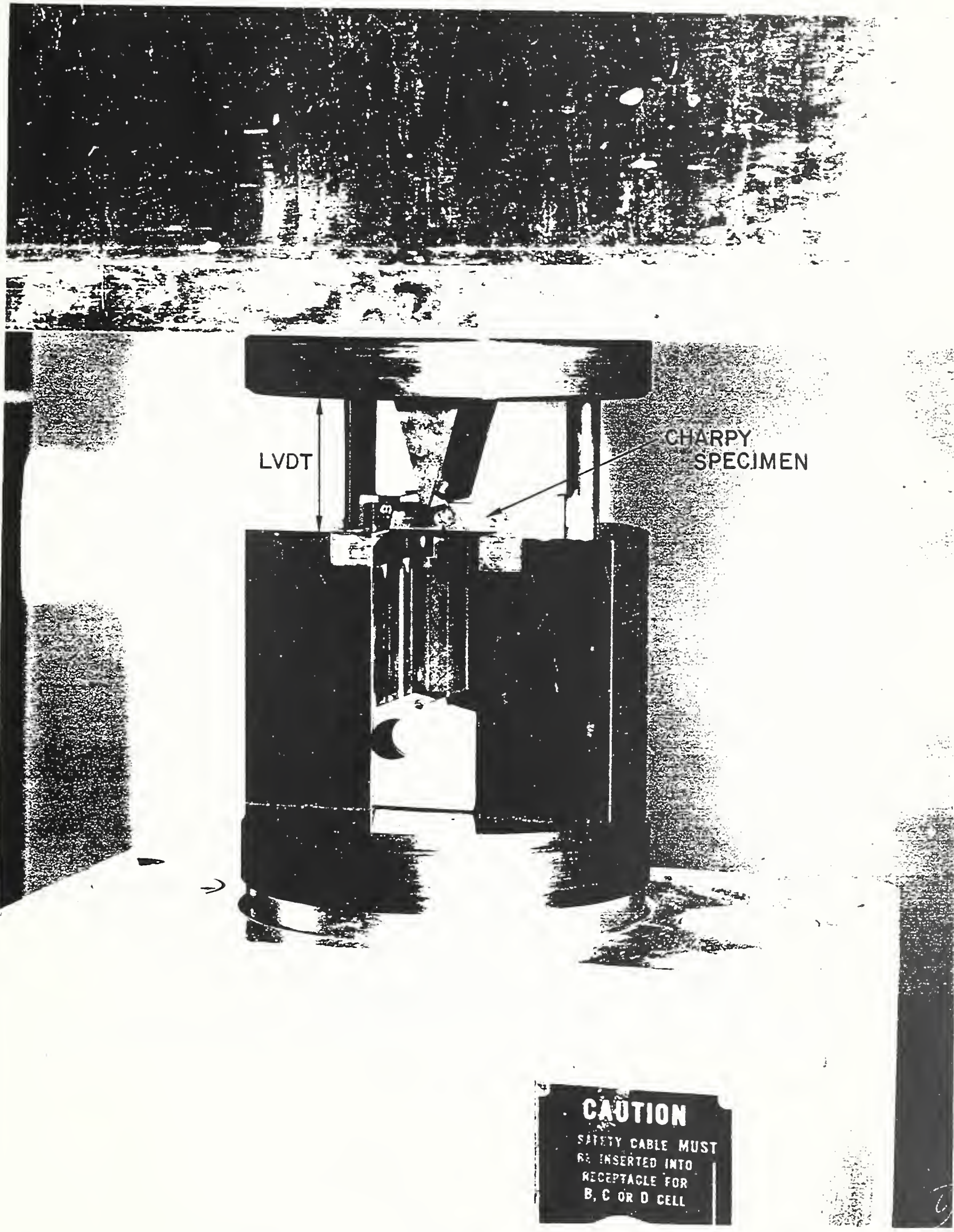
Fig. A Measurement $\rightarrow$ Response

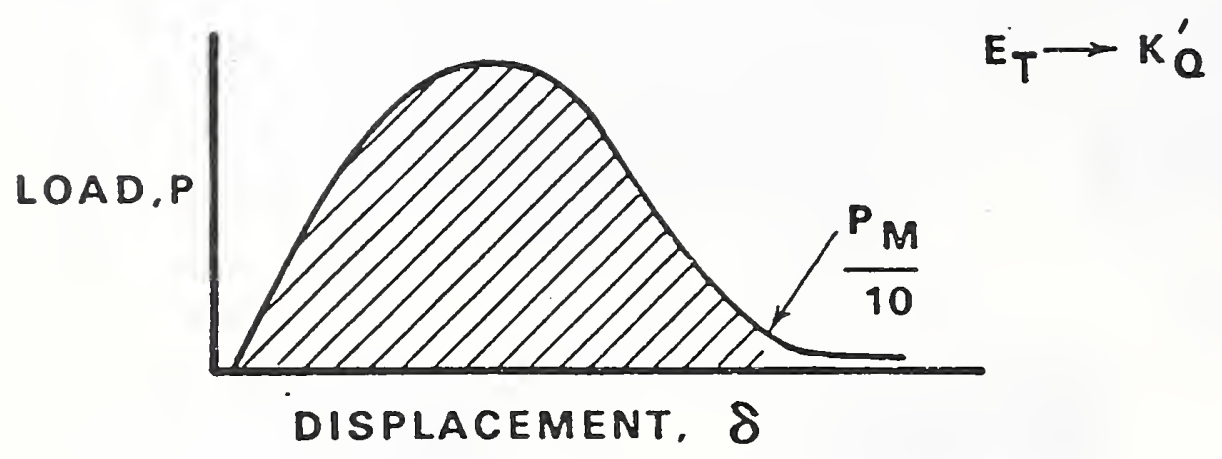

Fig. B

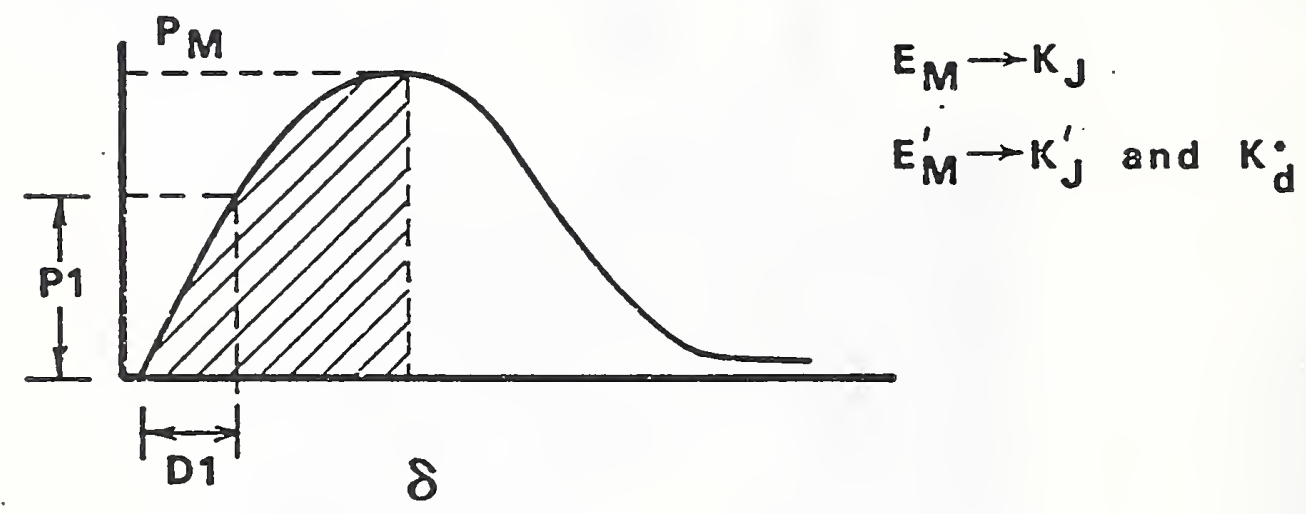

Fig. C

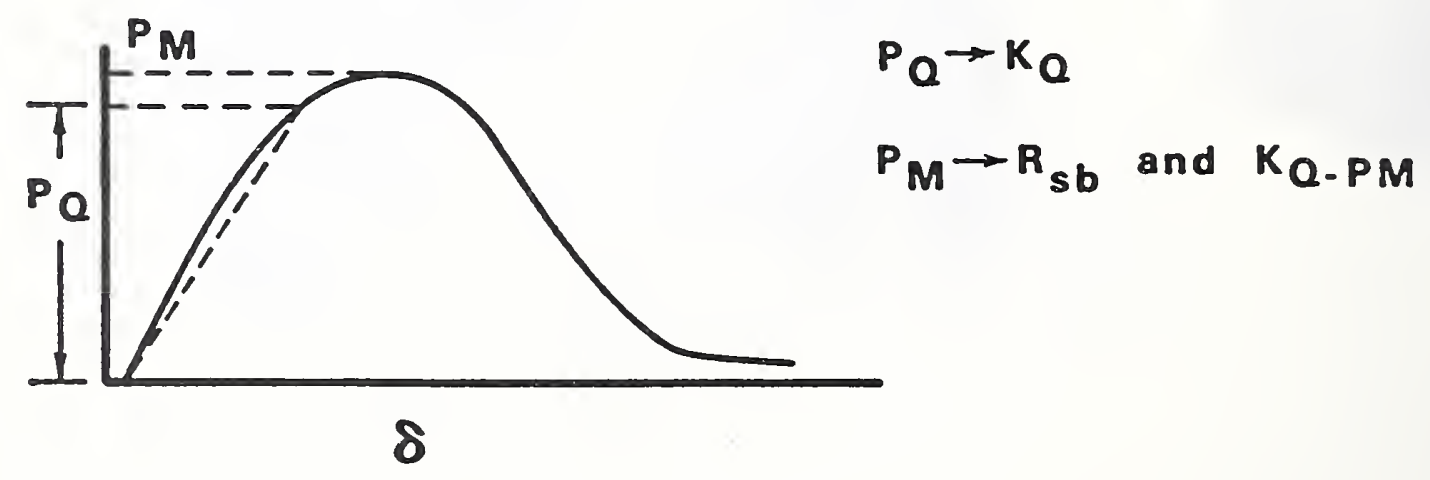

Fig. 3 


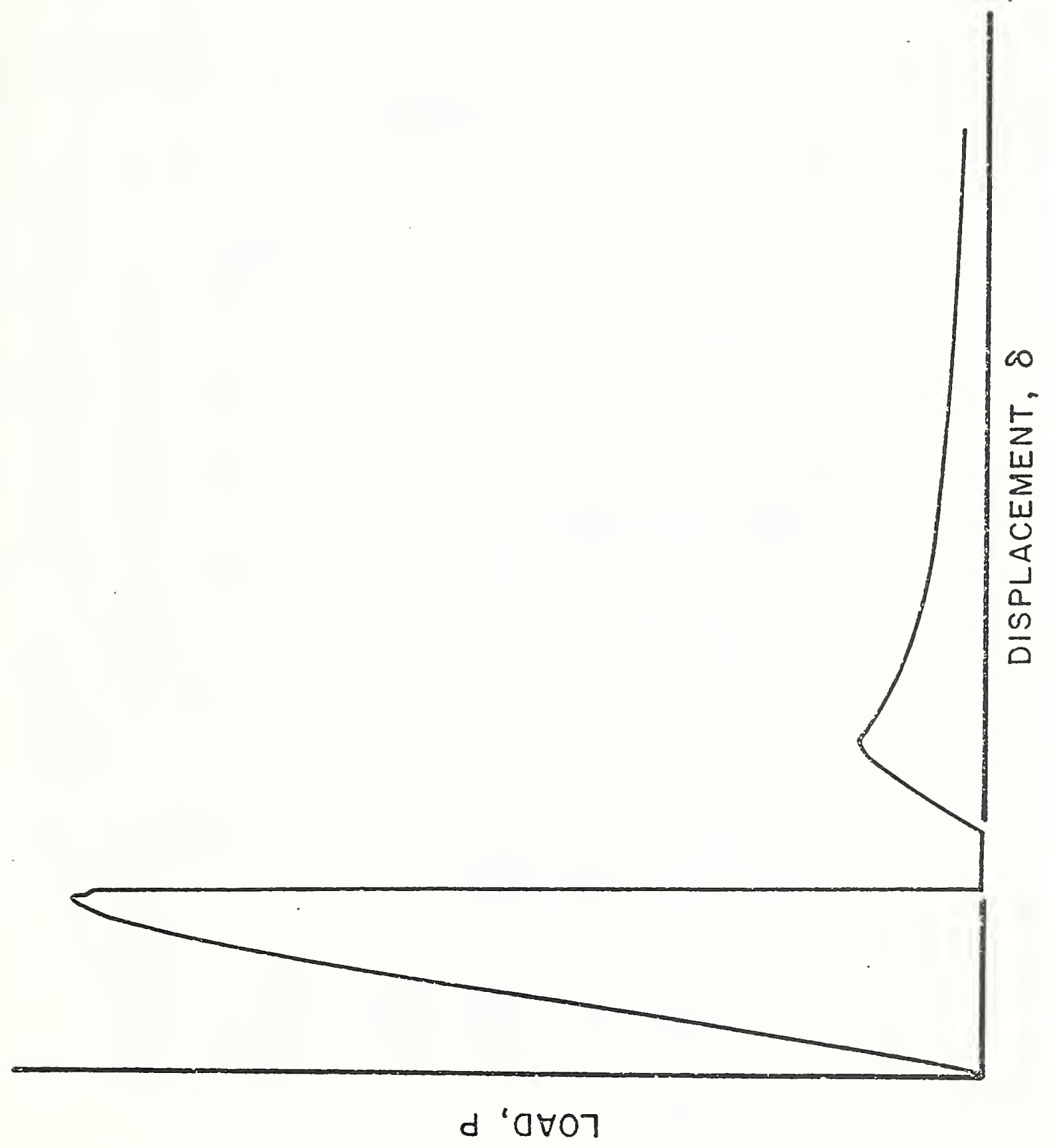




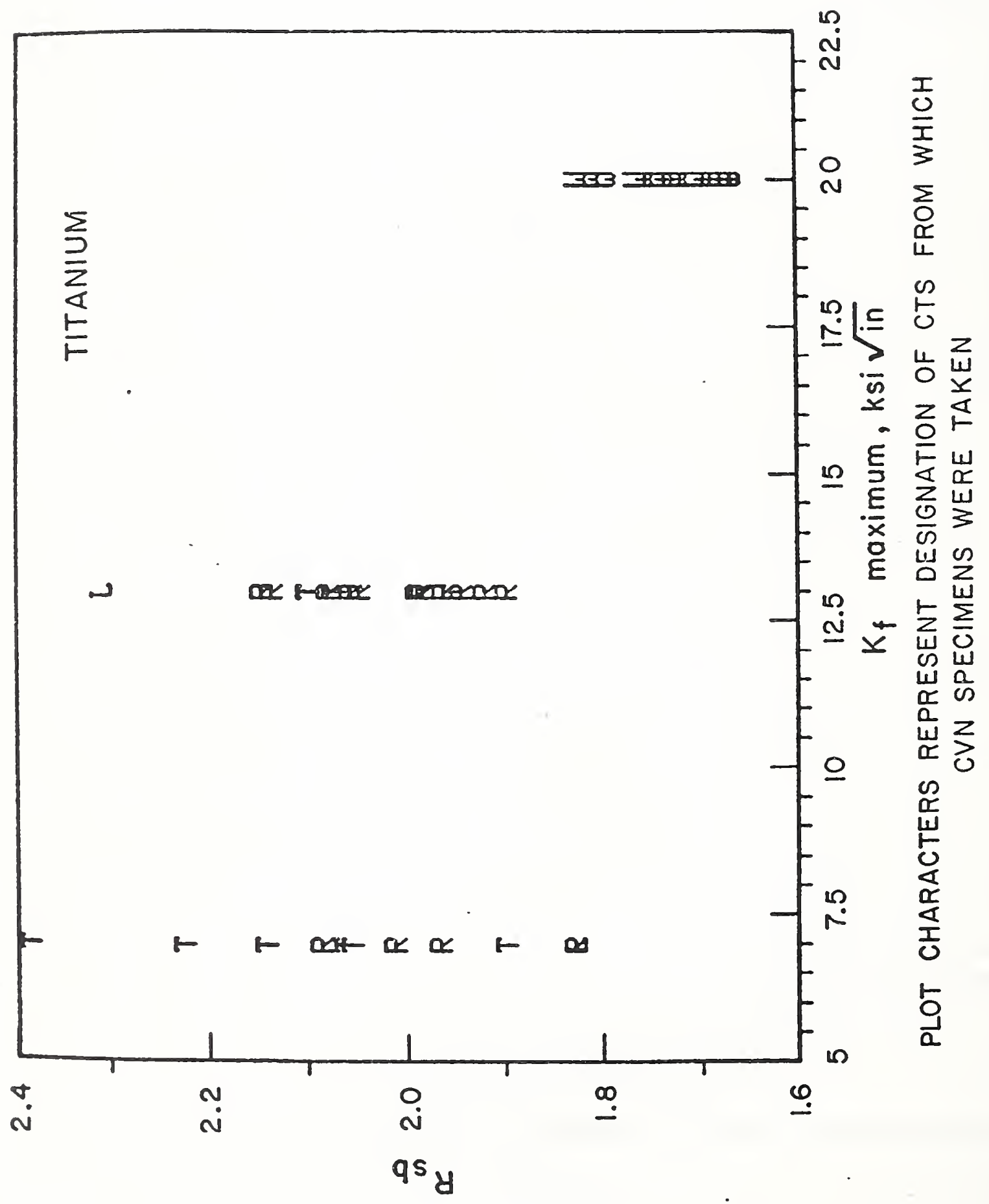




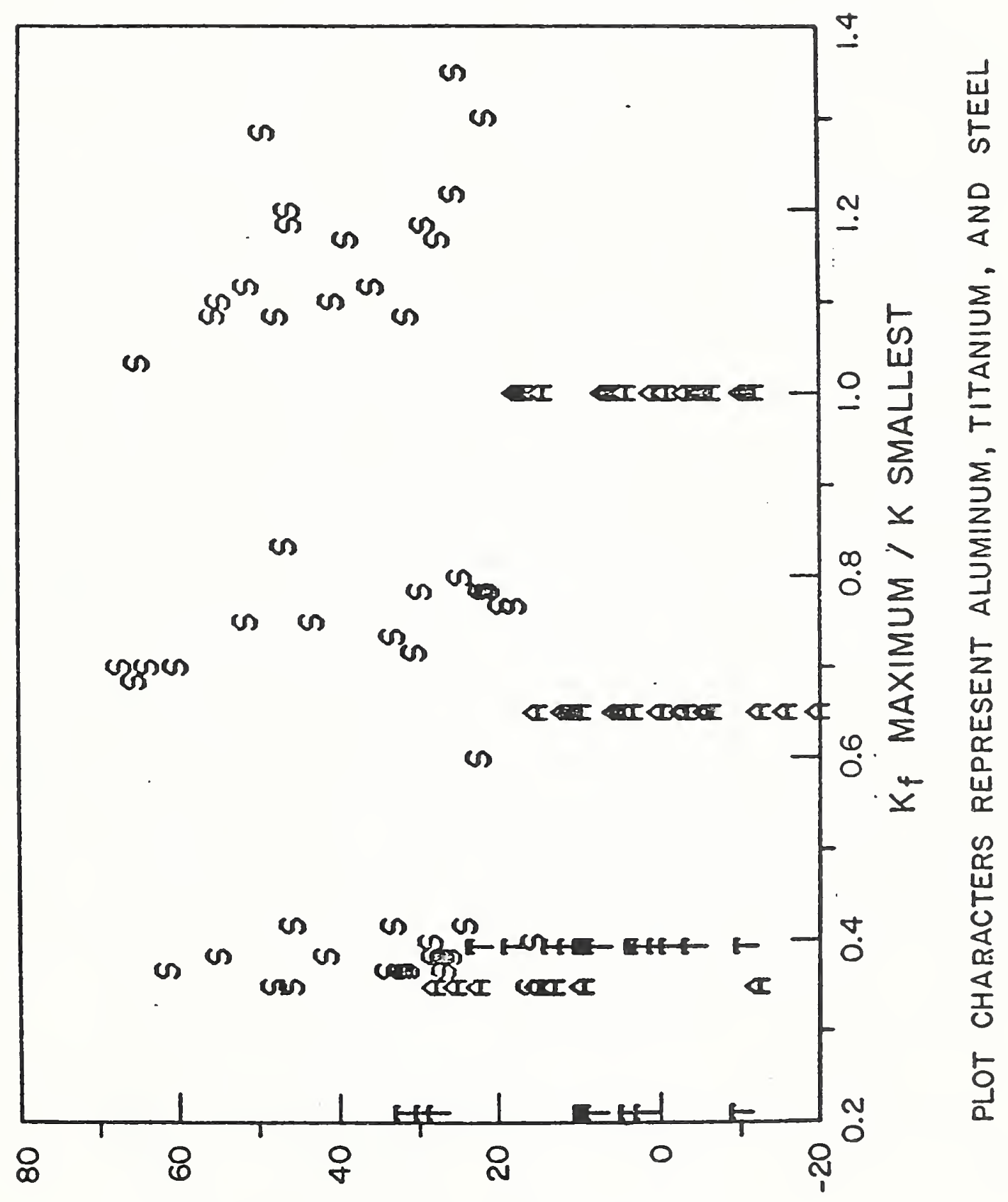

? त्र 10 वप्य 


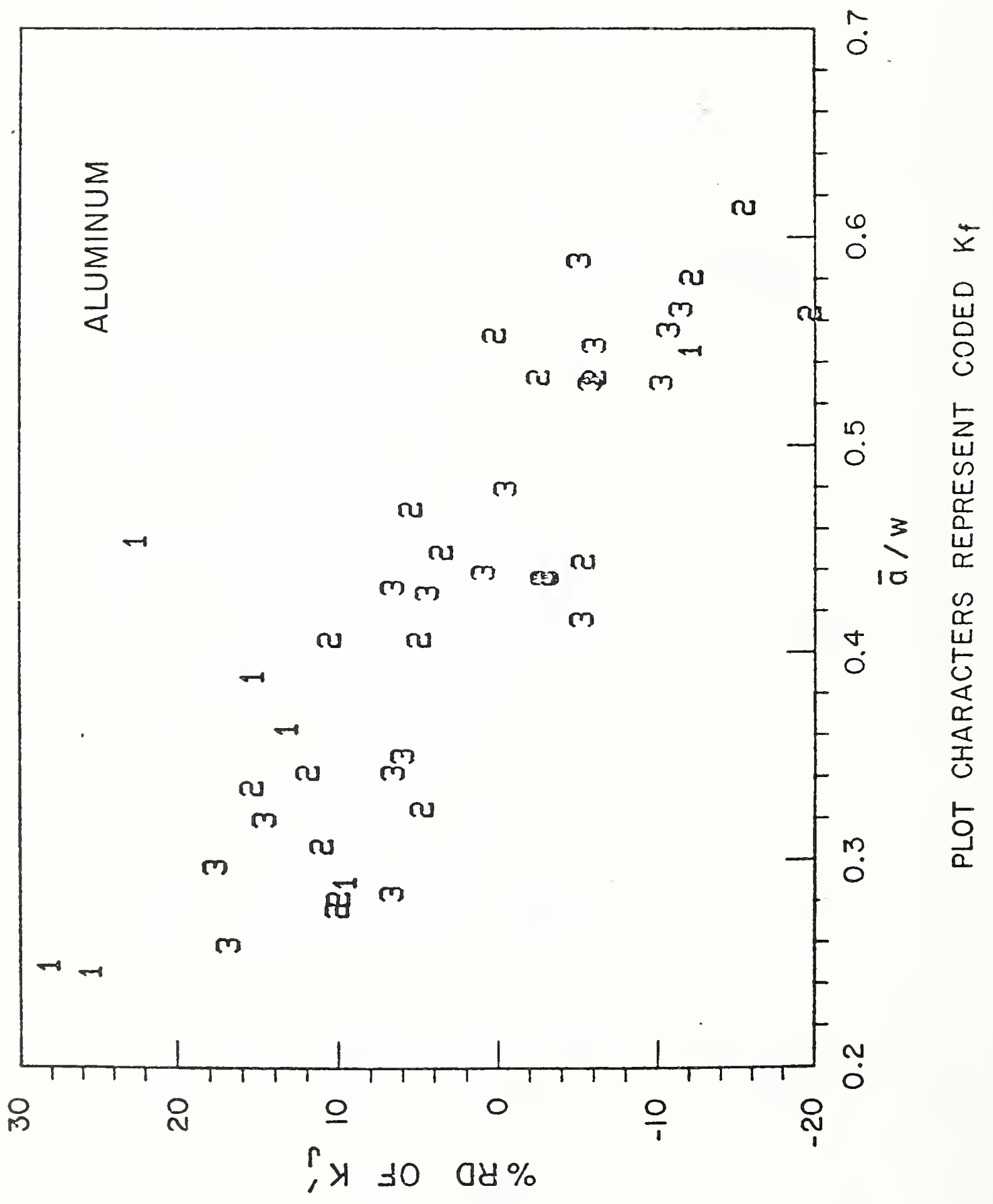




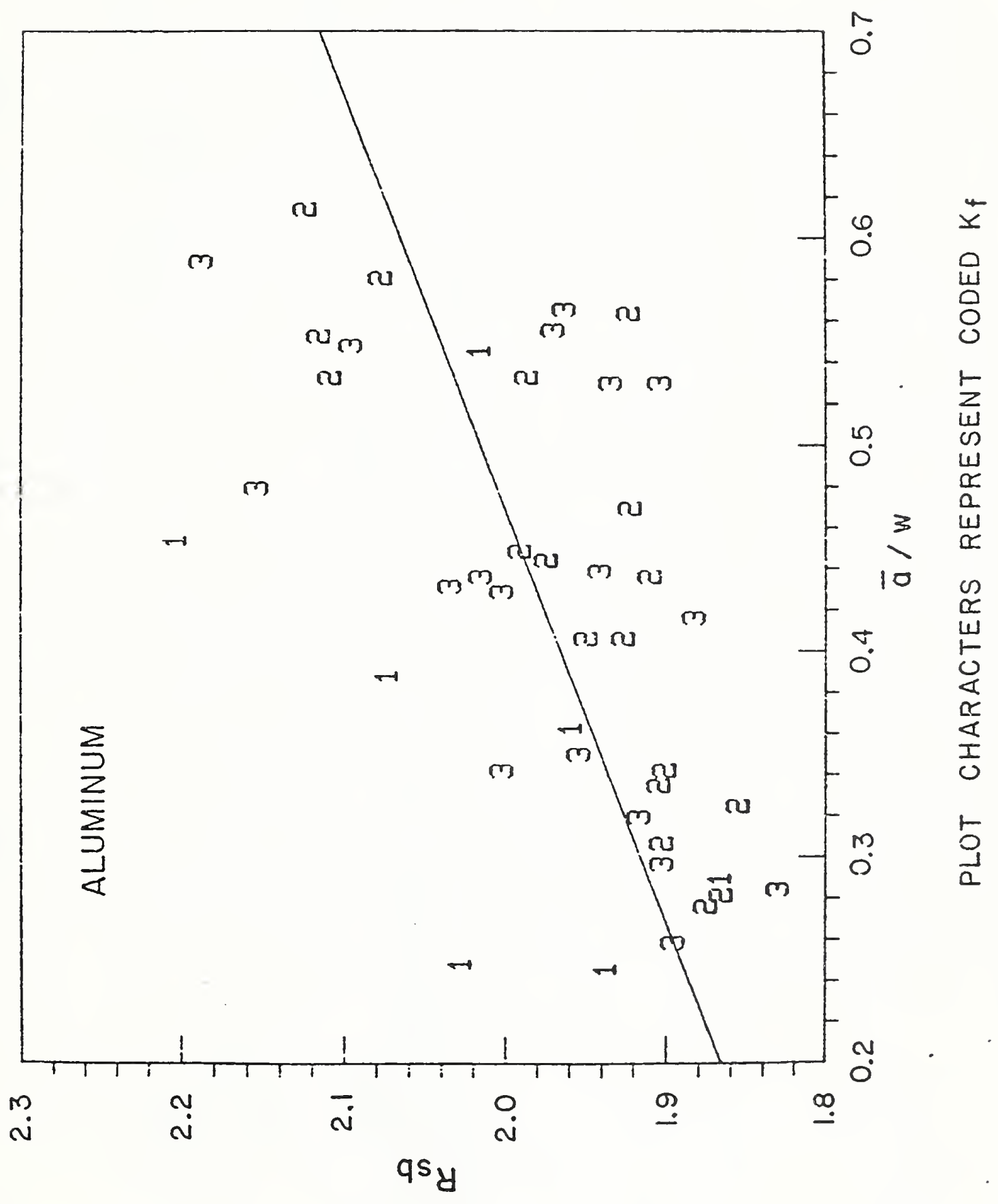




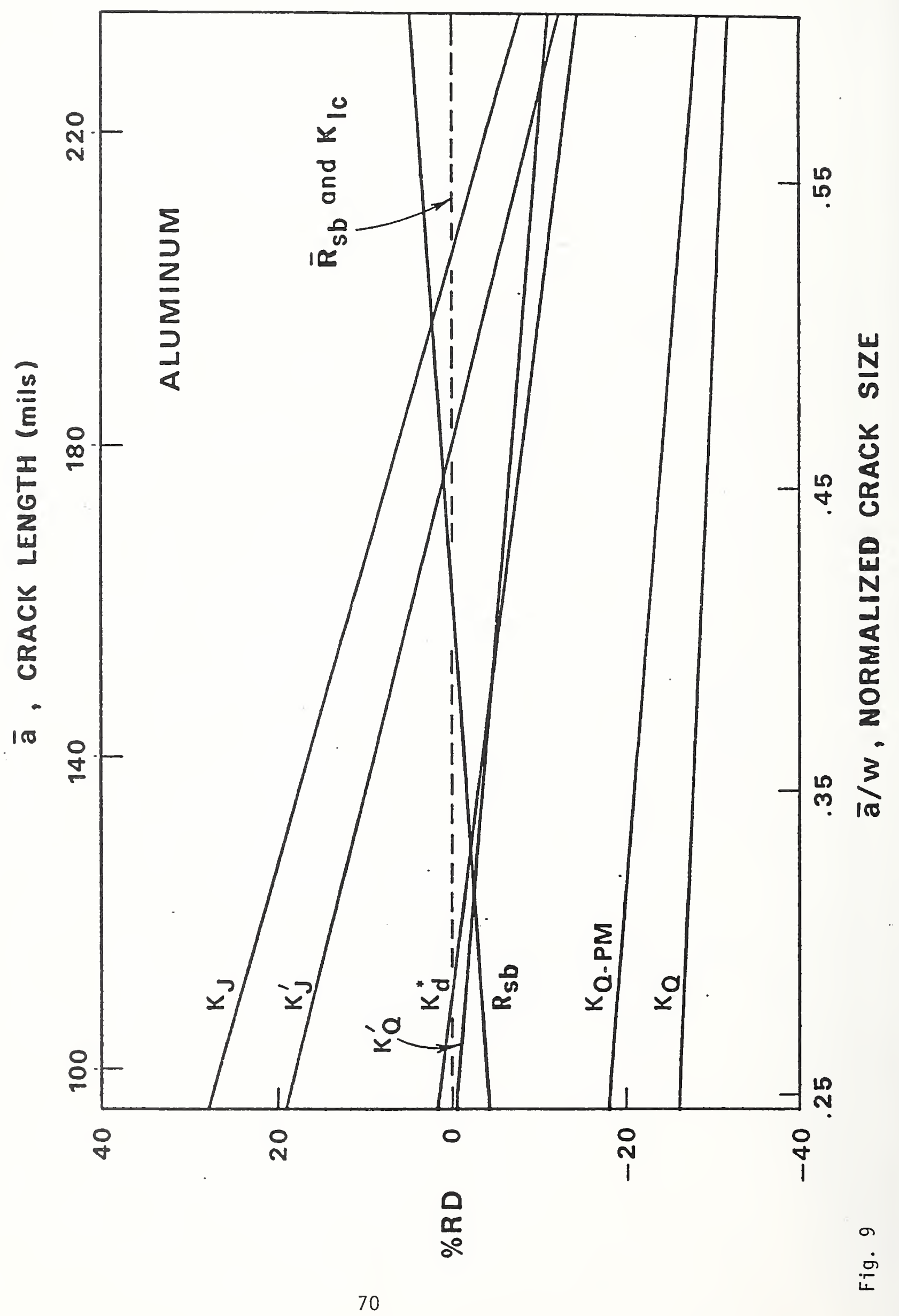




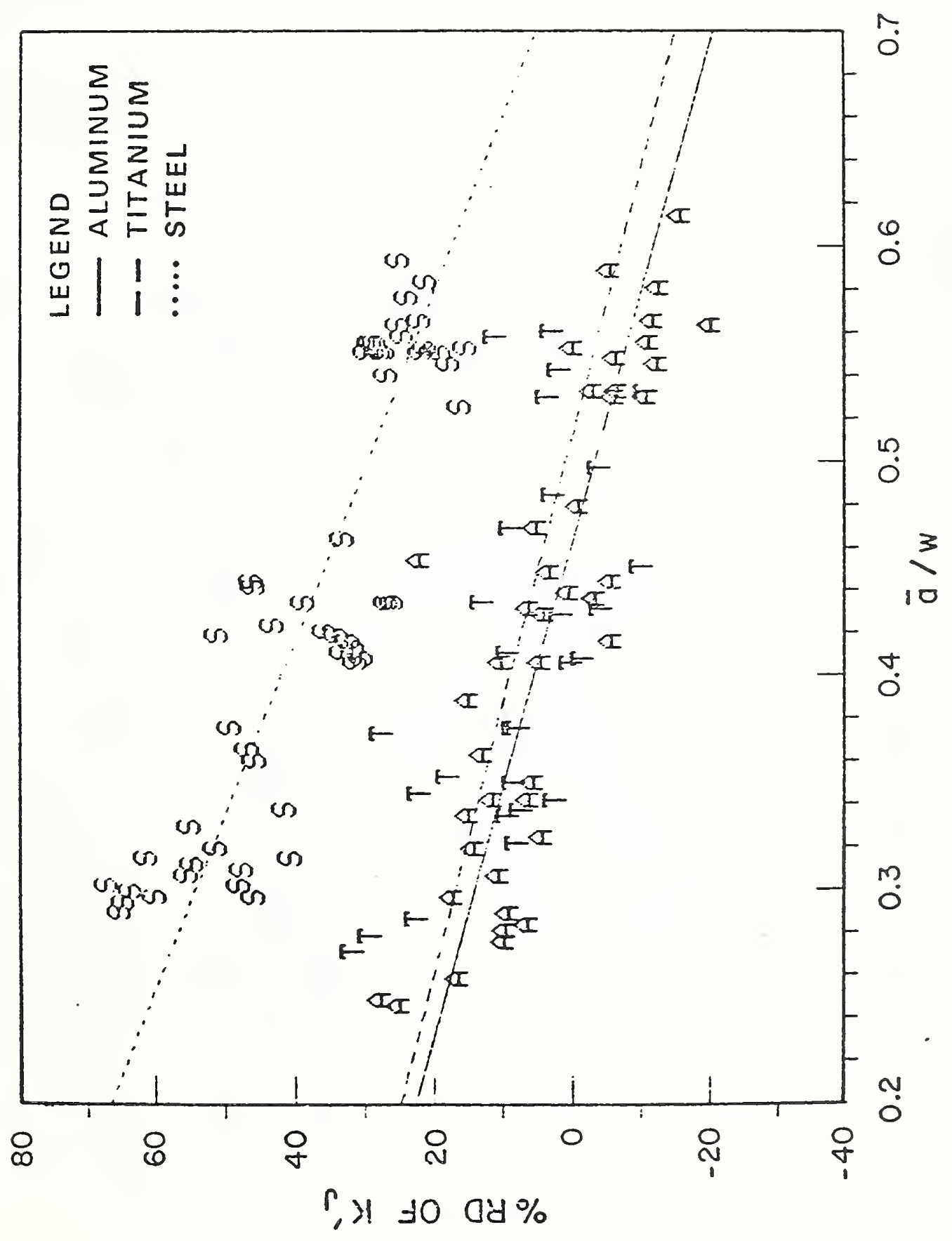




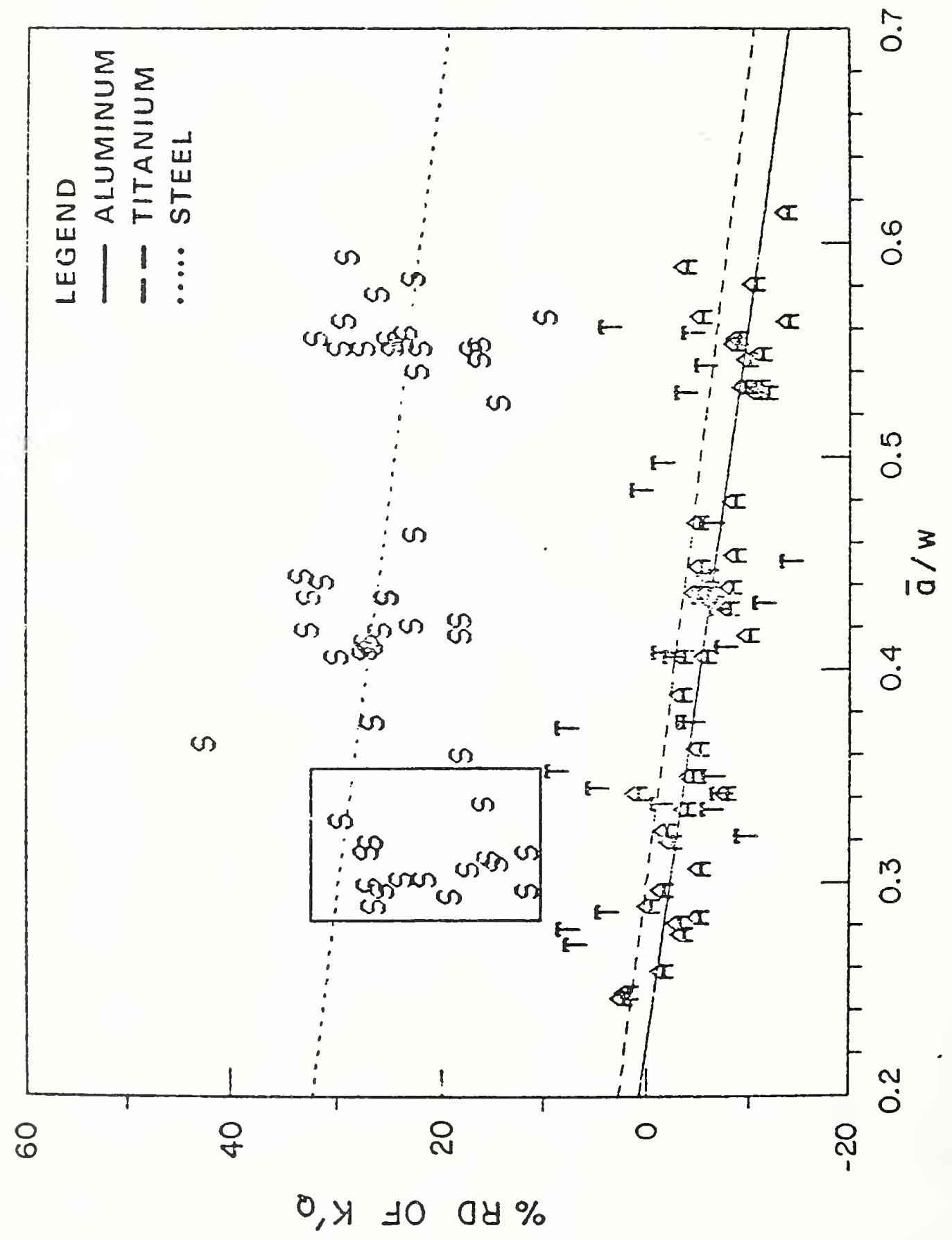




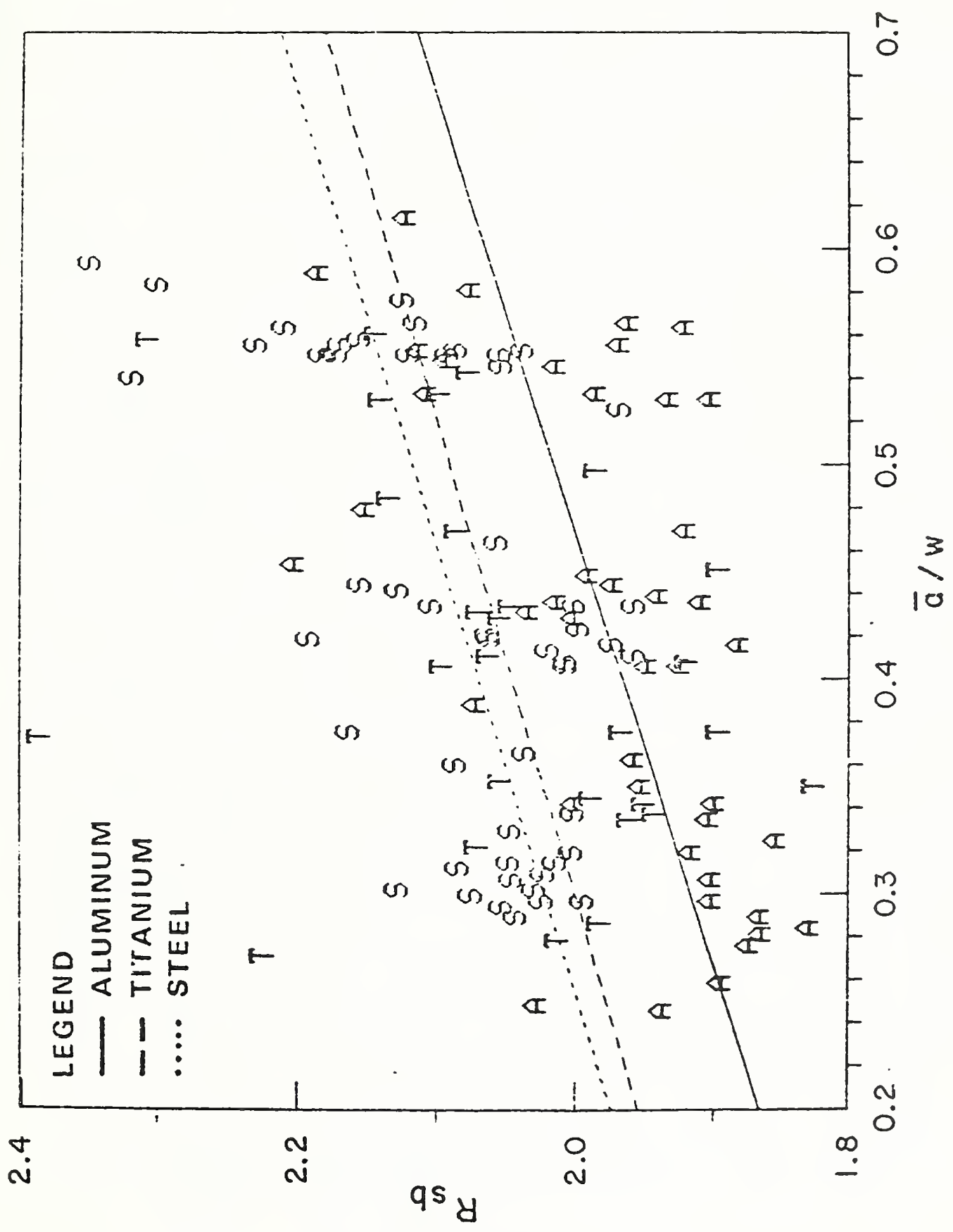




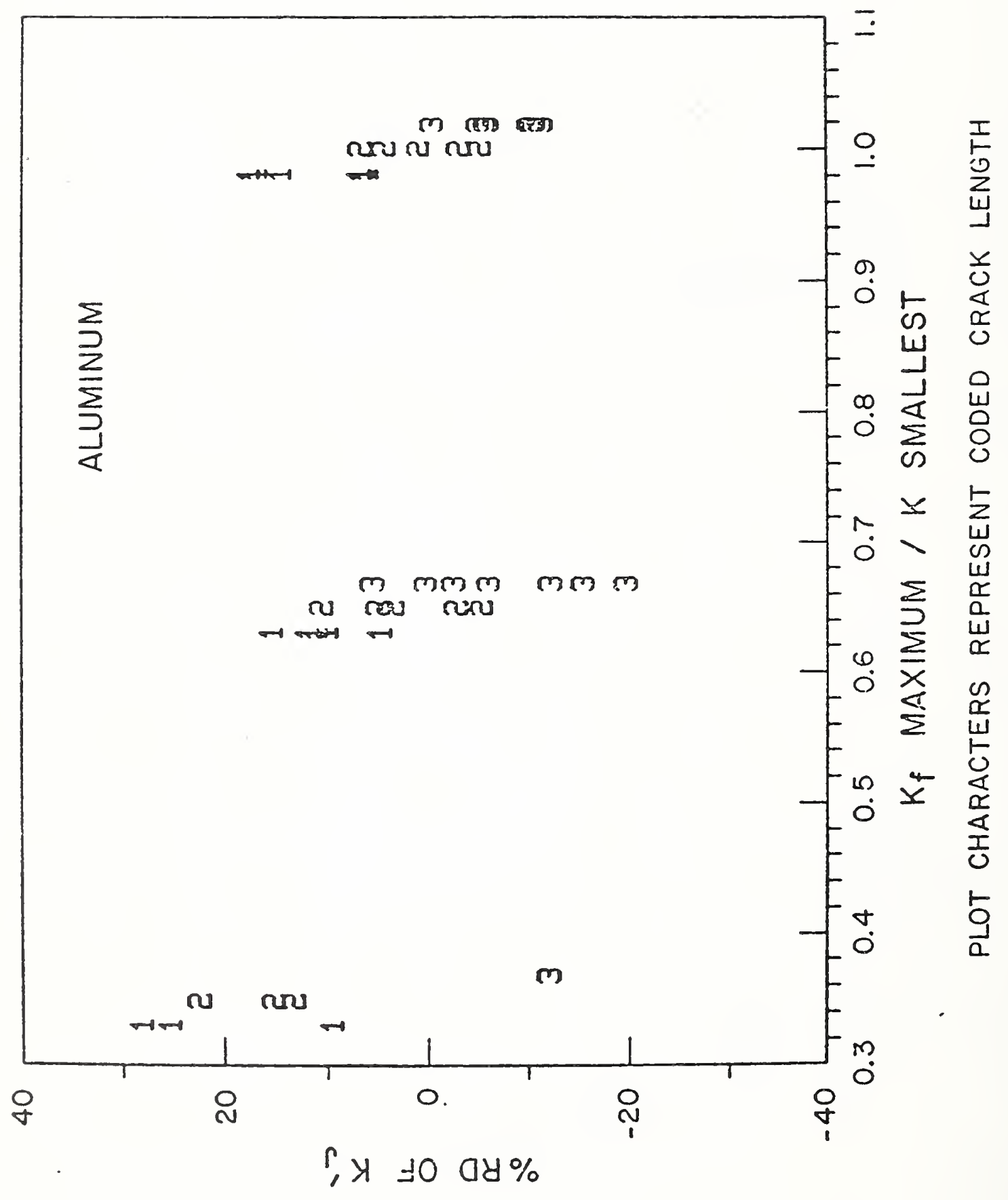




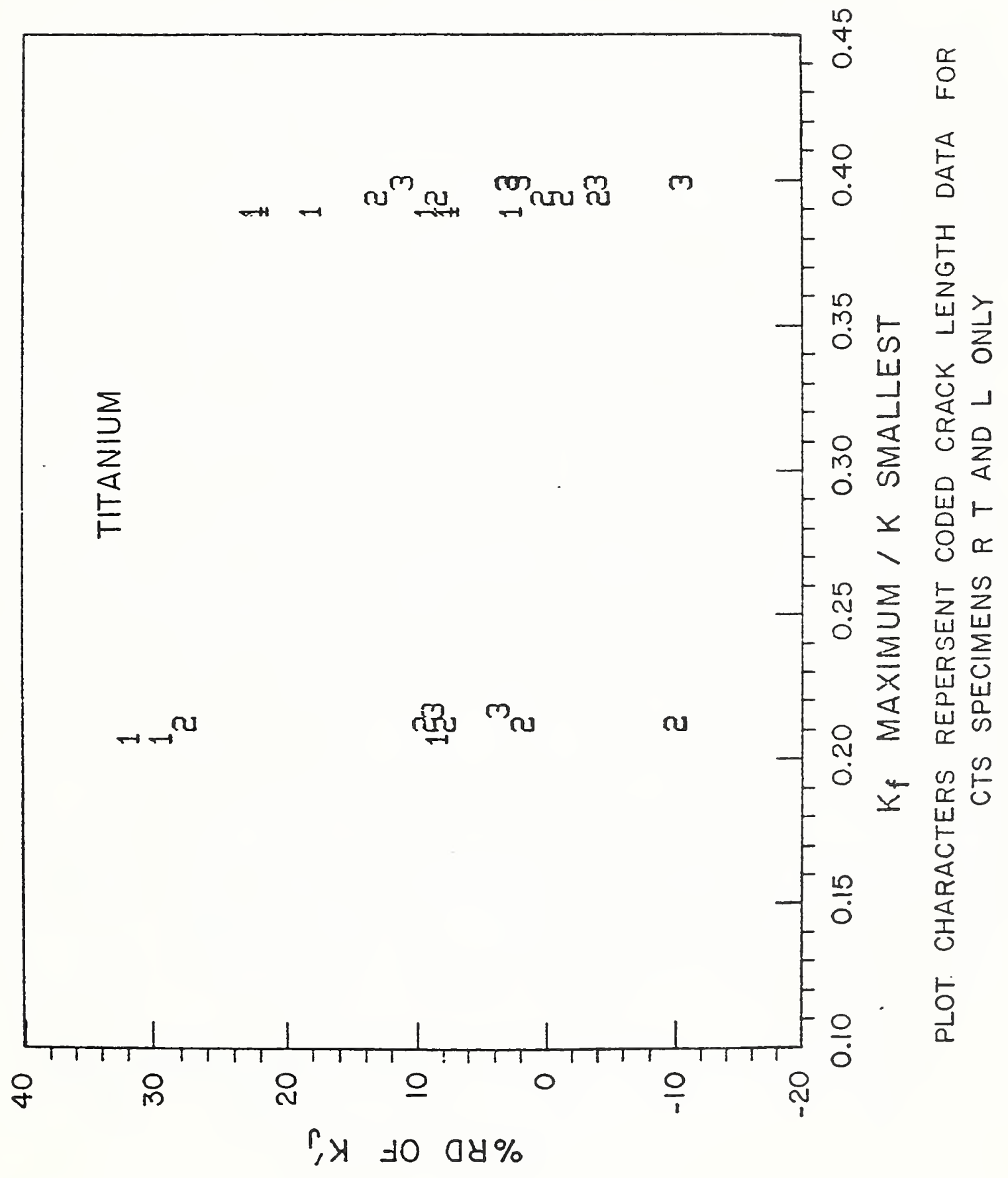




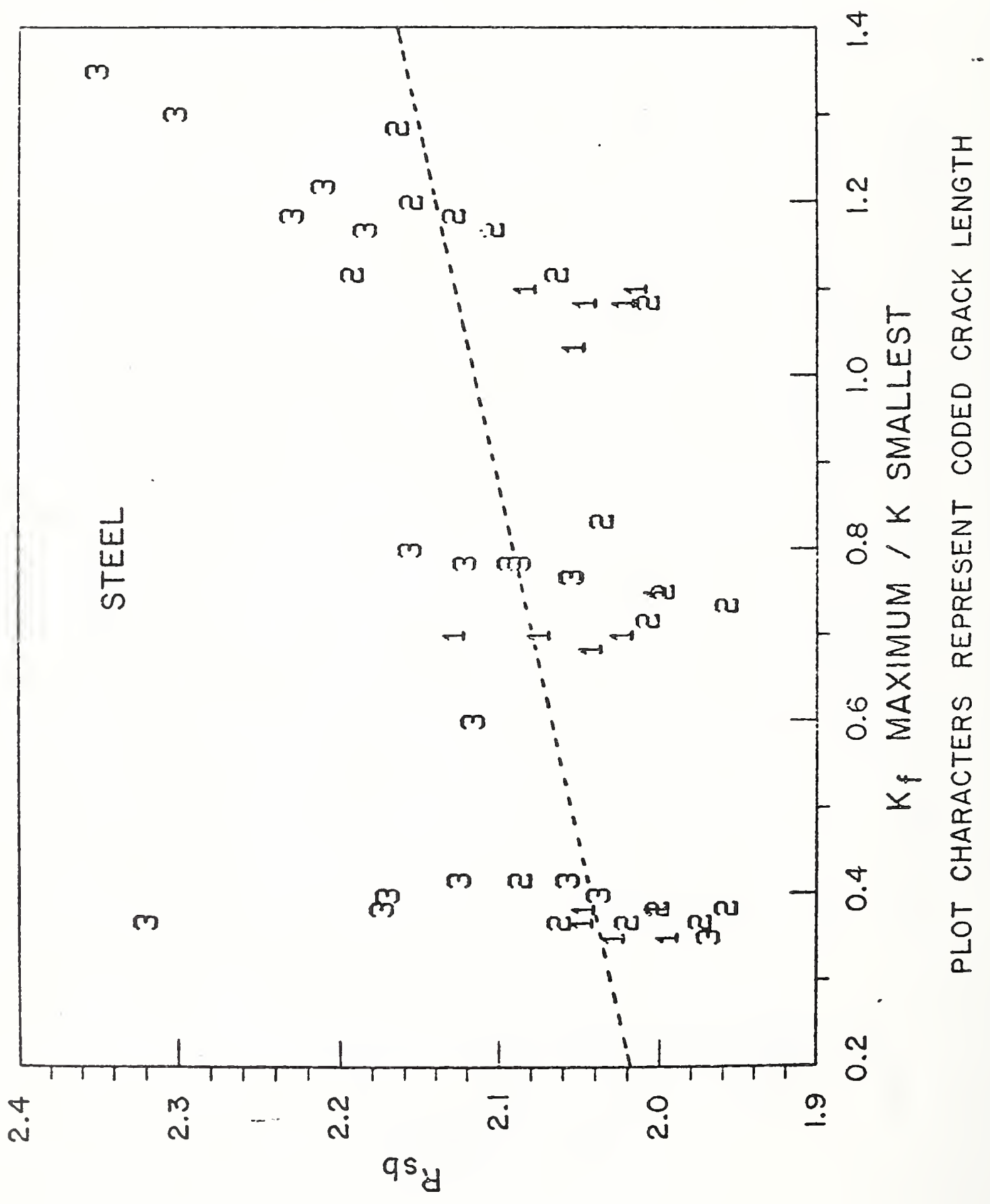




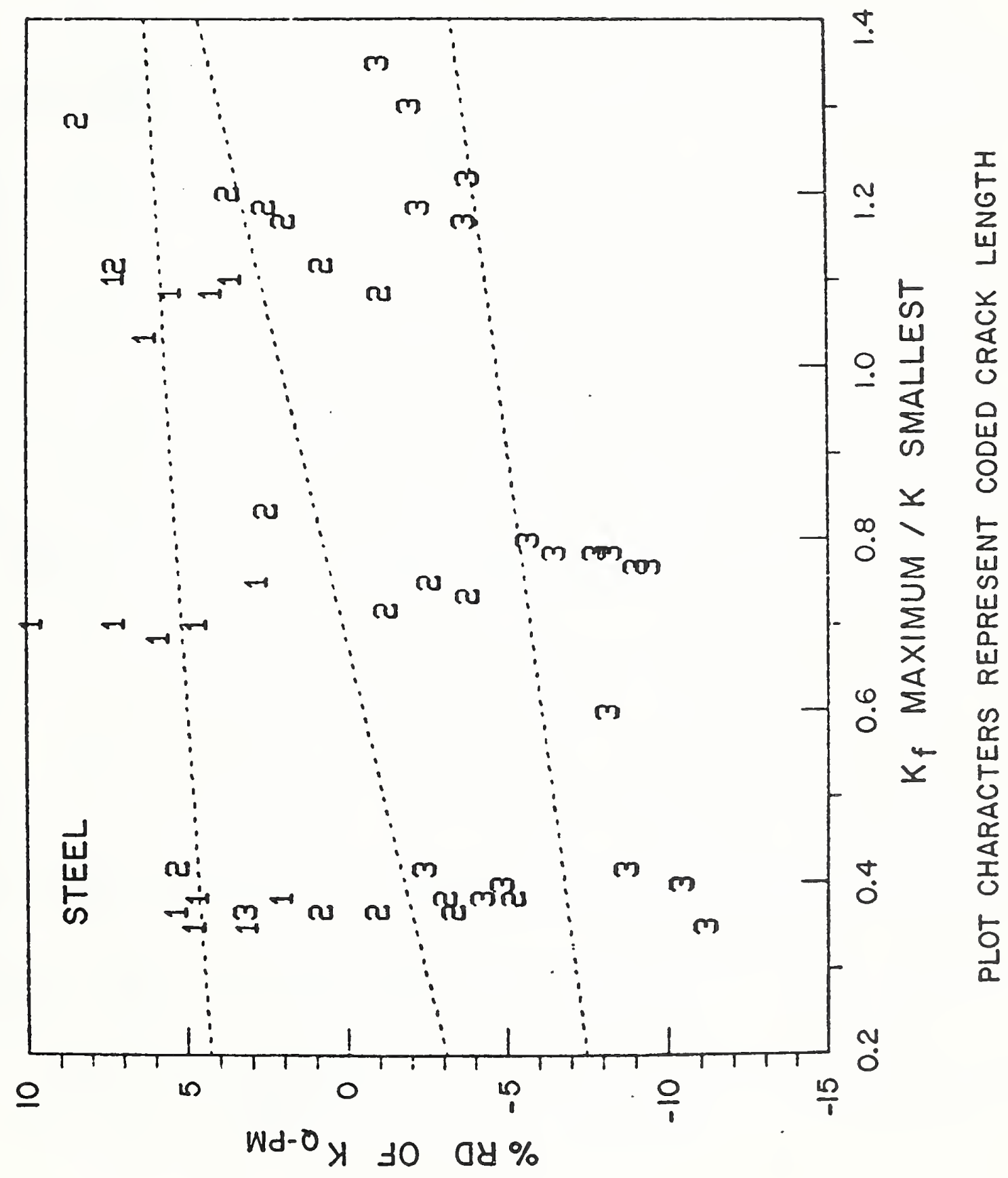




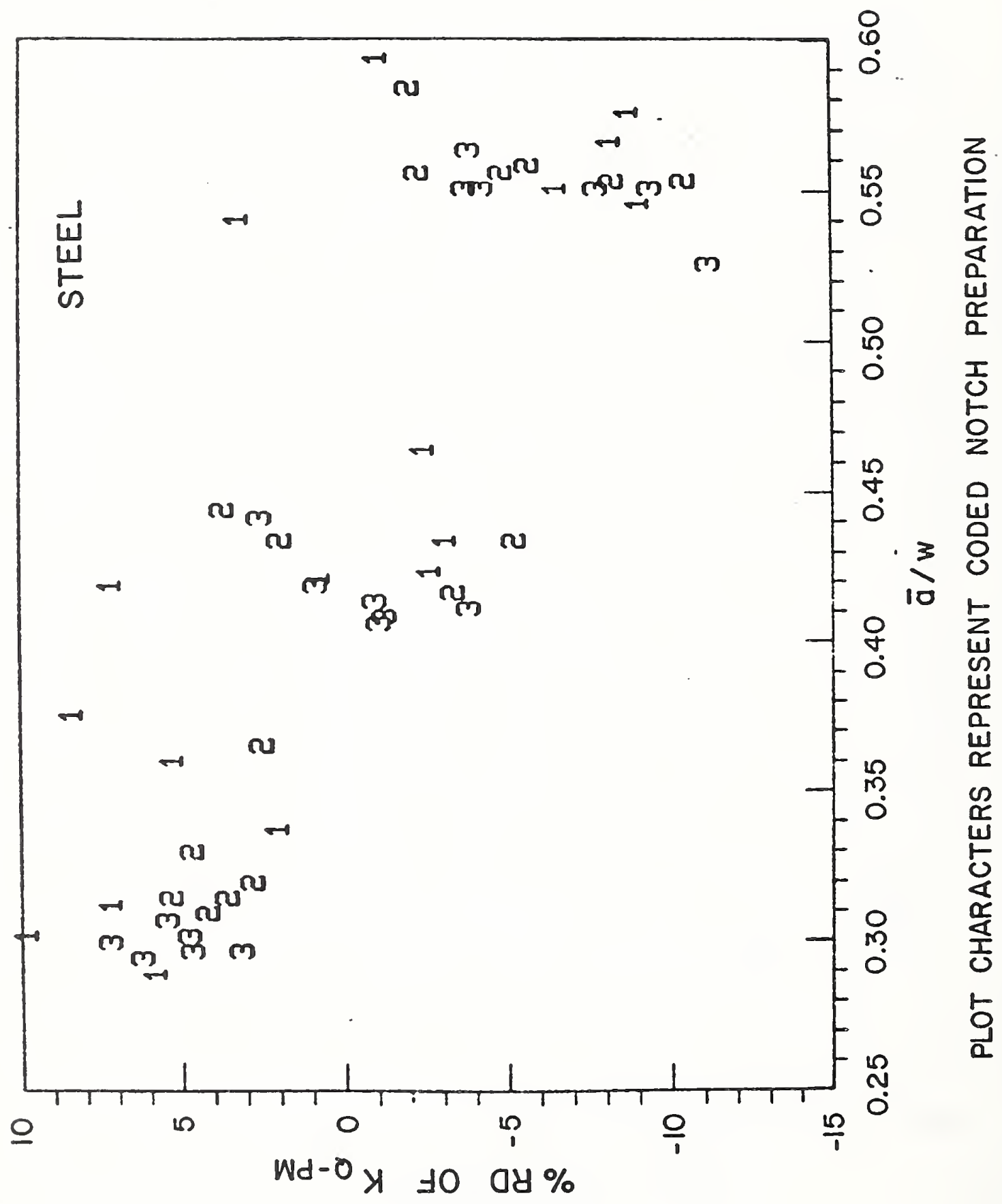




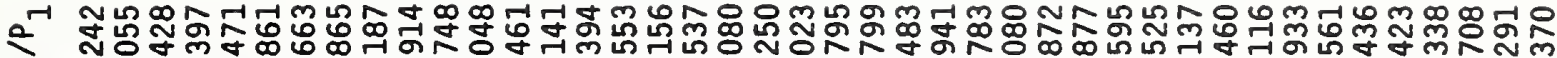
ద

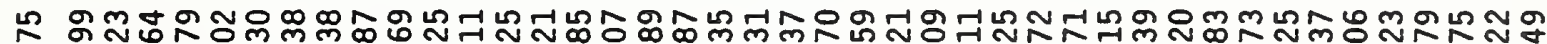
๙

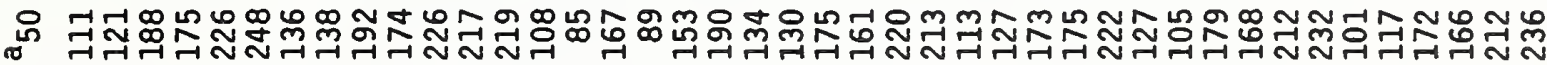

๙ "

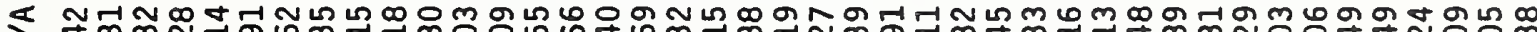

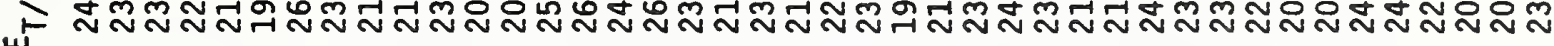

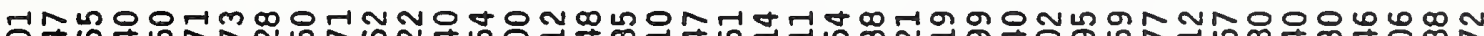

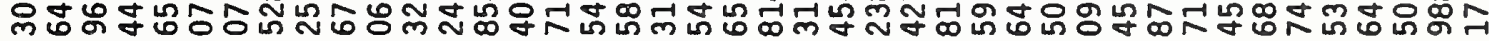

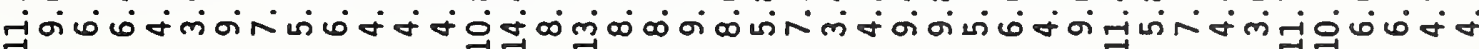

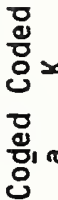
NN $N$ NNmmmmmm

H $\stackrel{2}{z}$

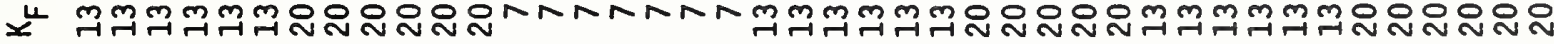

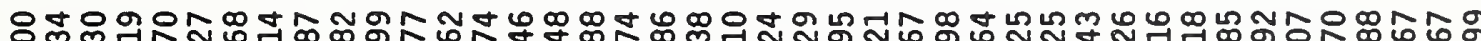

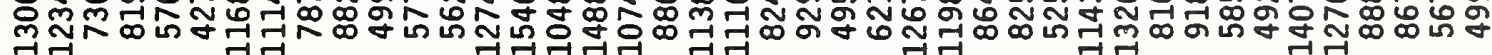

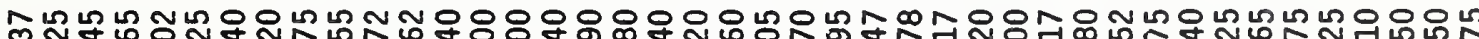

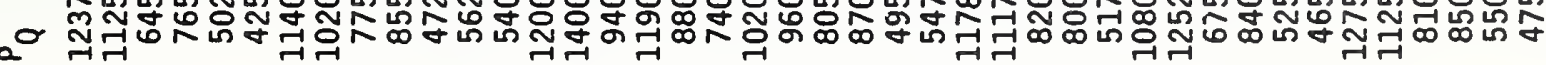

일

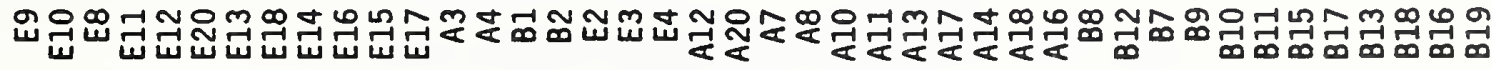




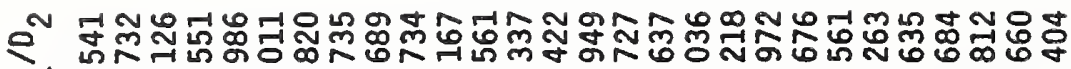
-

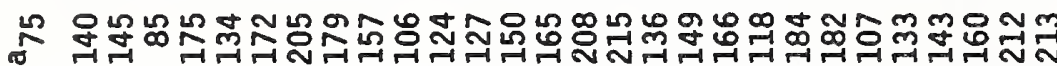

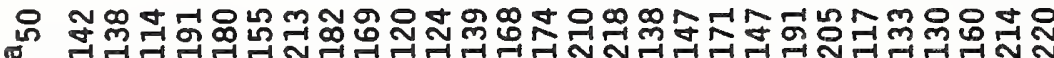

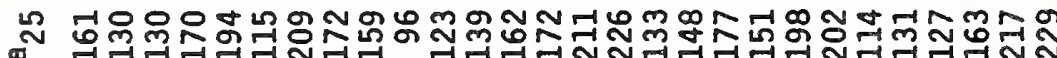

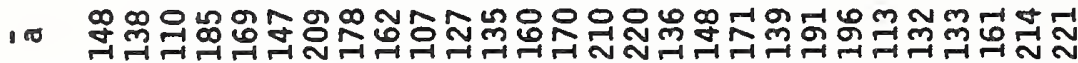

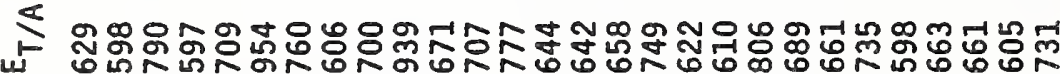

$\Sigma$

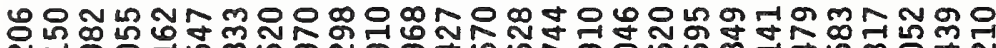
ลี่

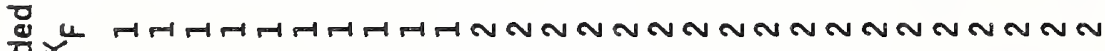
¿

?ृ.

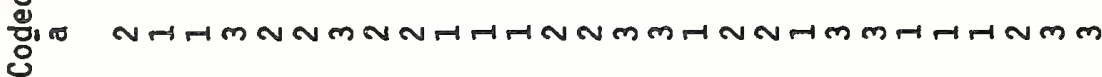

은

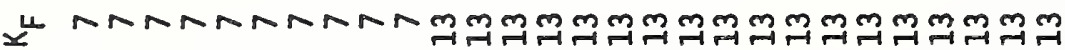

2

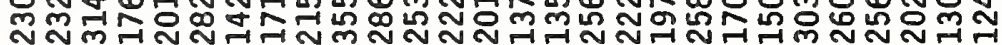

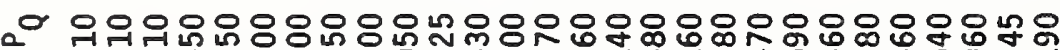
ฟิ

造

พmษ

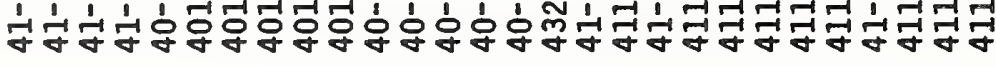




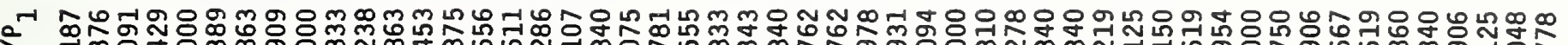

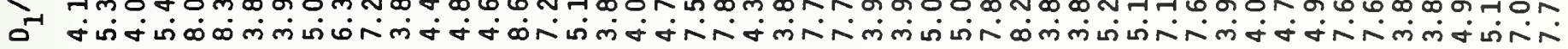

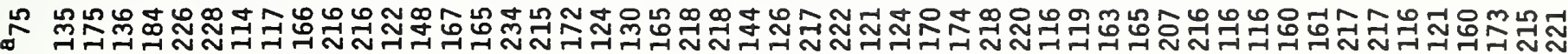

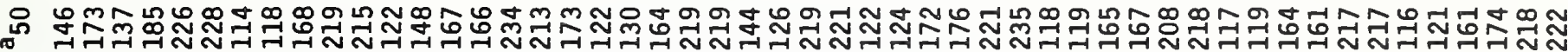

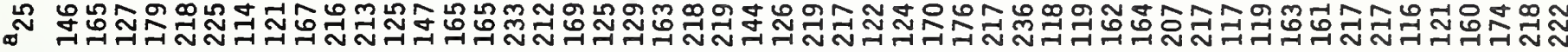

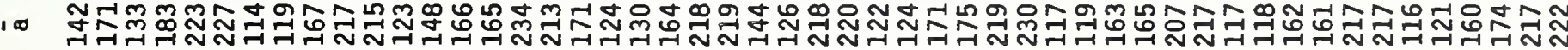

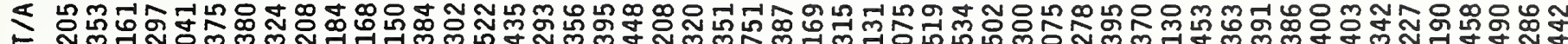
w స్త్య

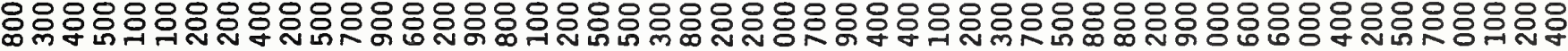

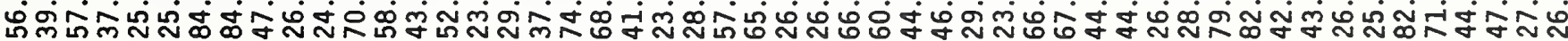

?

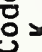

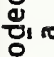

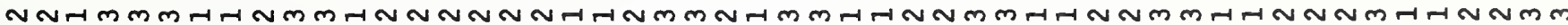

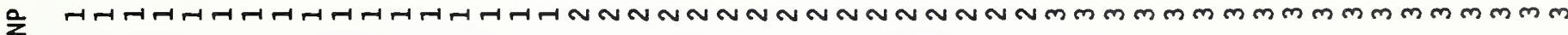

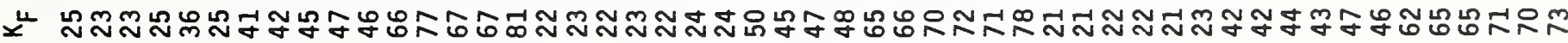

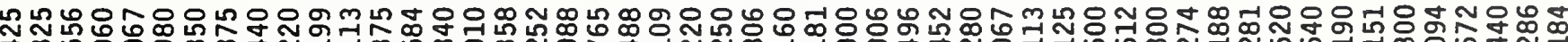

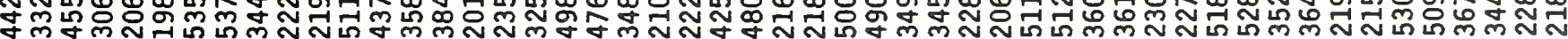

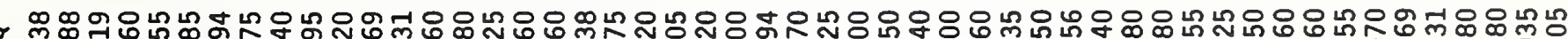

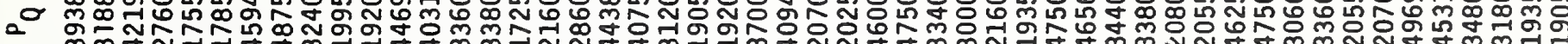

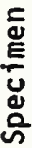

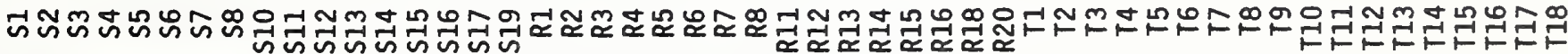


$\propto$

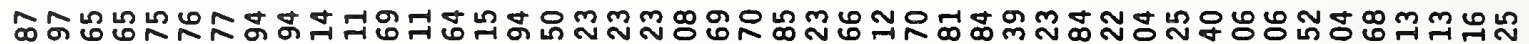

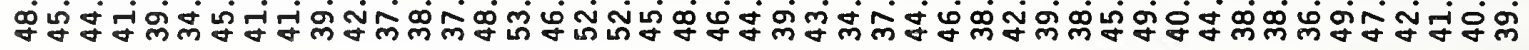

ฉి

de$$
2
$$

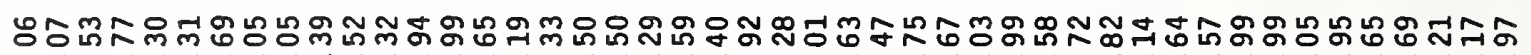
更

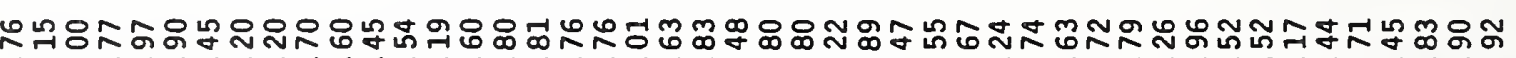

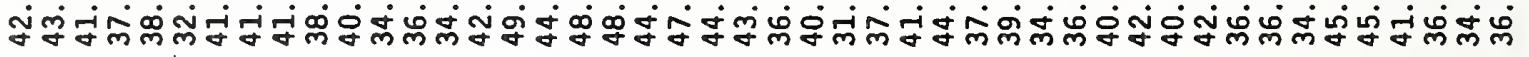

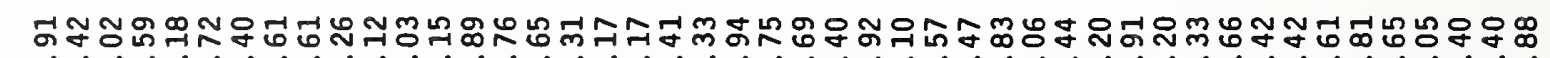

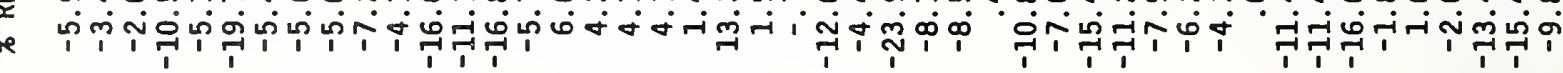

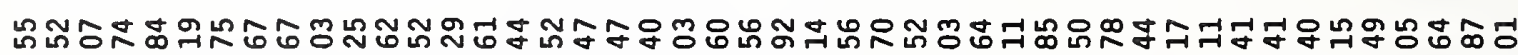

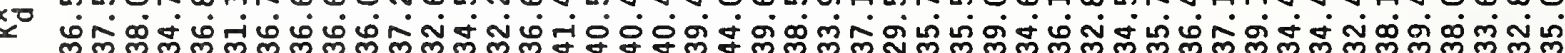

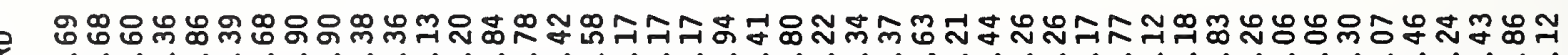

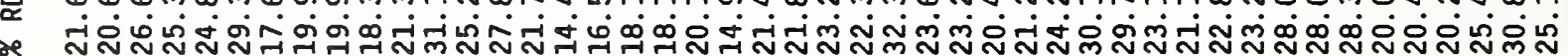

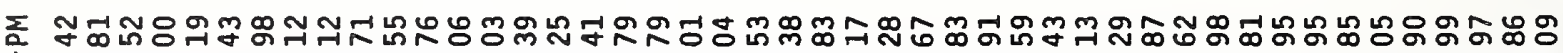

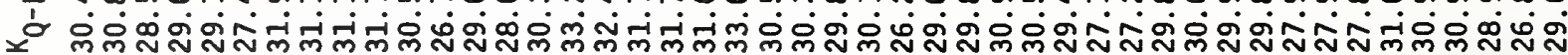

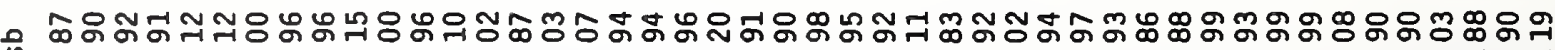

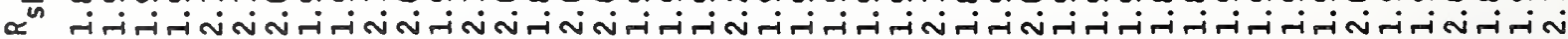

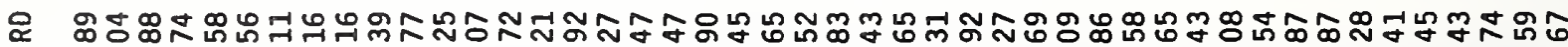

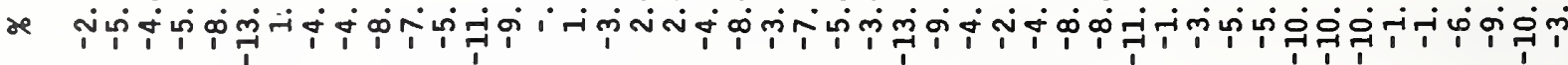

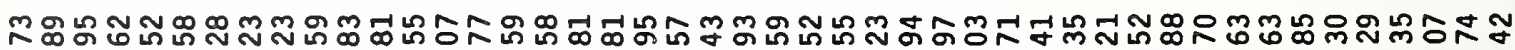

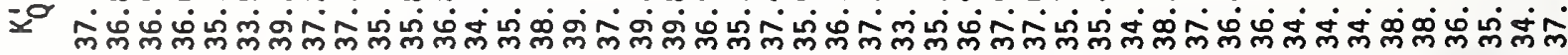

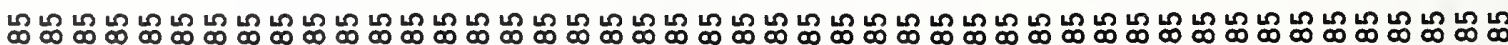

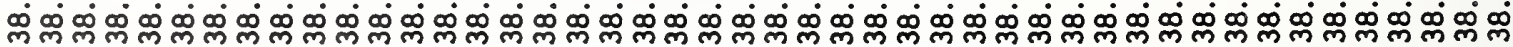

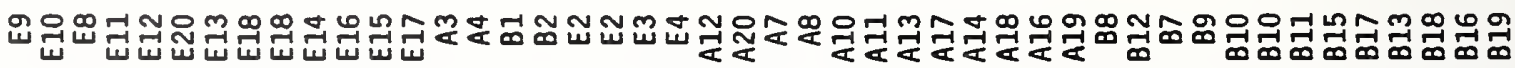




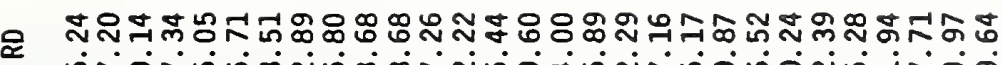

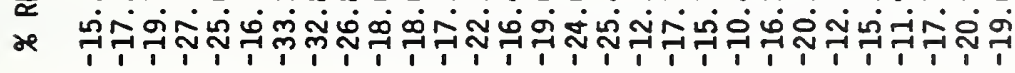

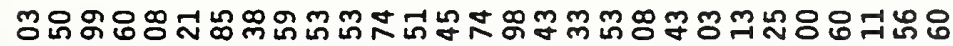

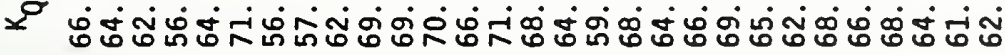

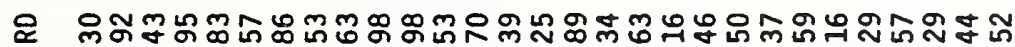

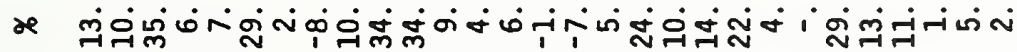

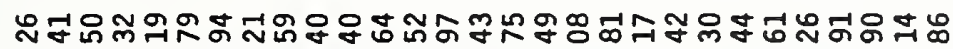

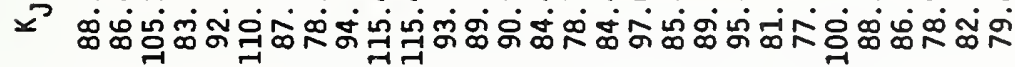

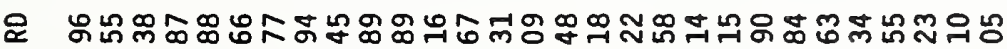

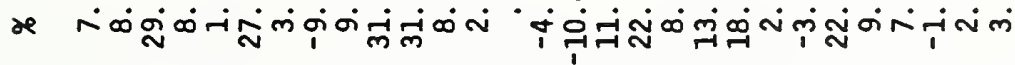

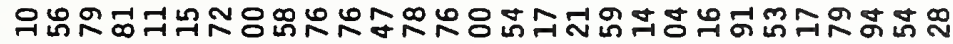

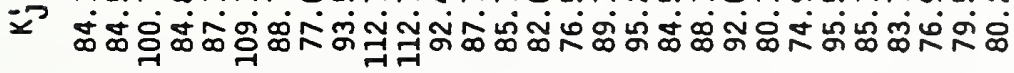

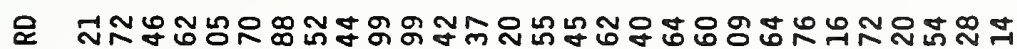

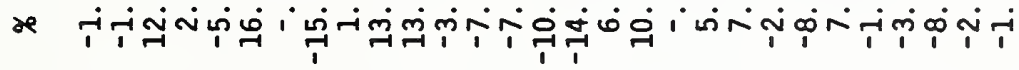

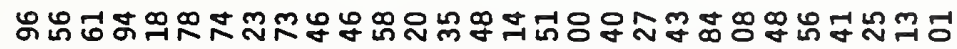
* மீळ

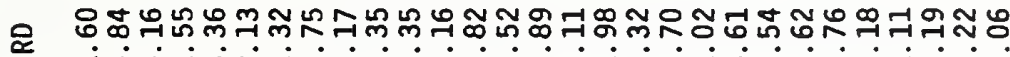
ஓ नं

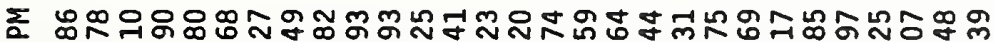
र

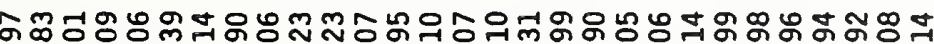

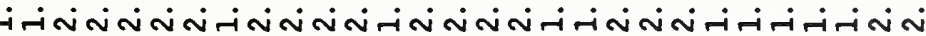

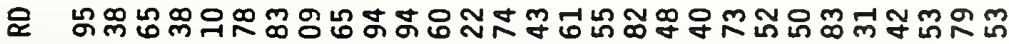

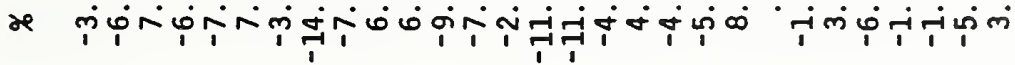

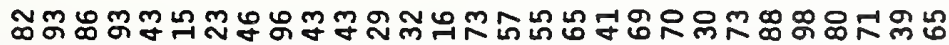

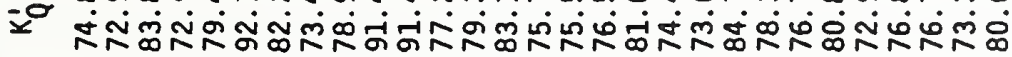

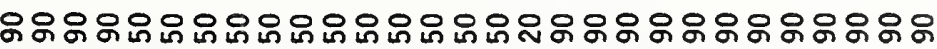

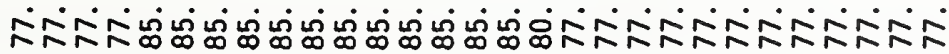

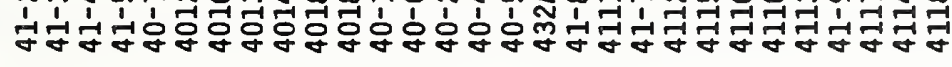




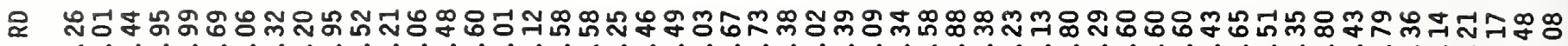

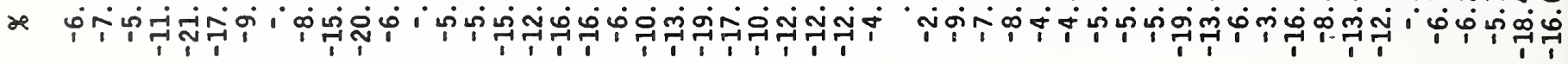

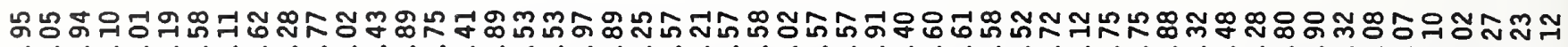
ఒ ت્ન

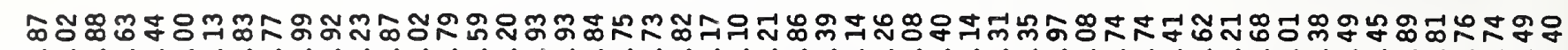

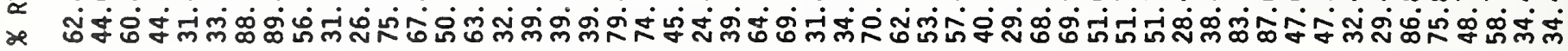

눈

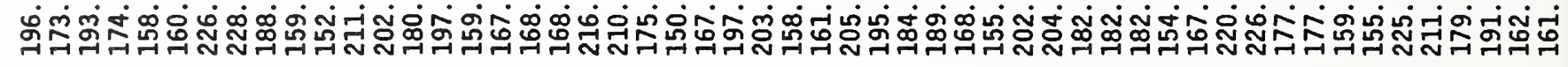

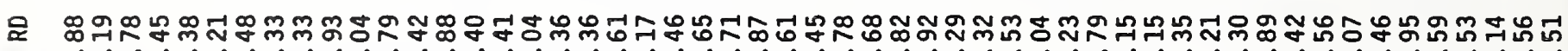

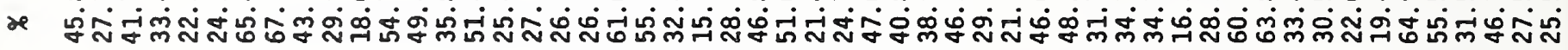

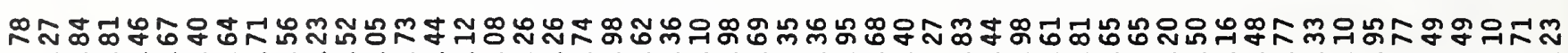

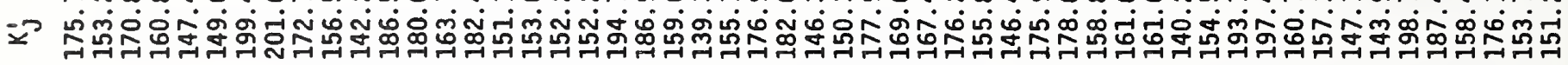

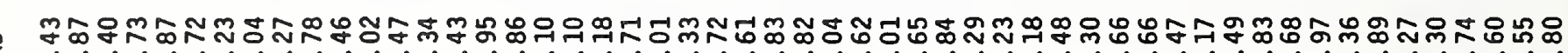

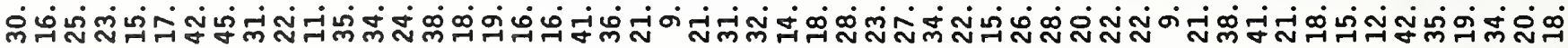

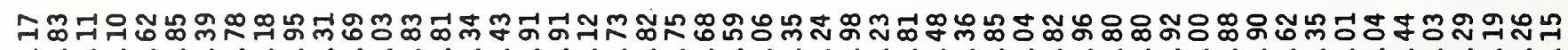
«

ฉ

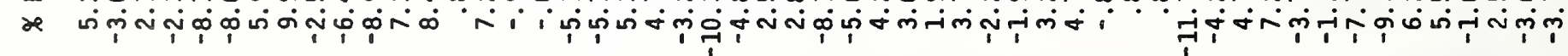

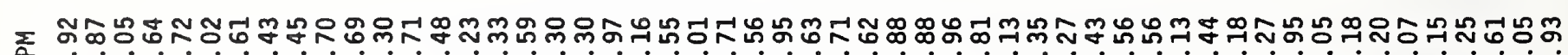

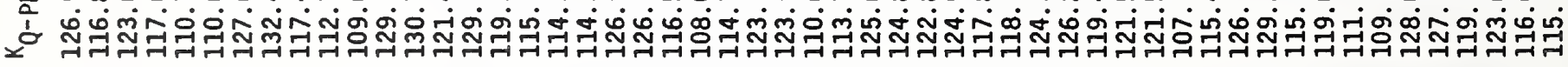

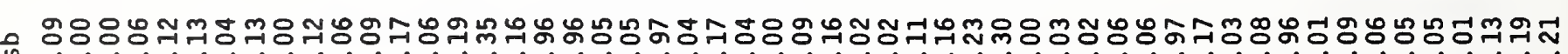

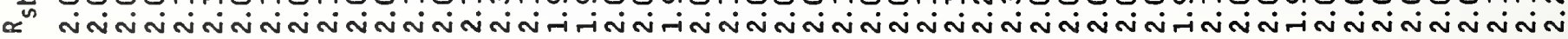

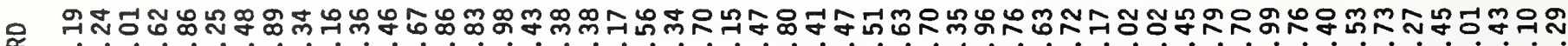

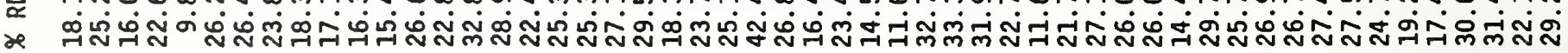

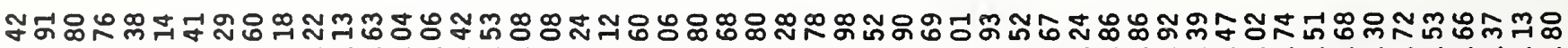

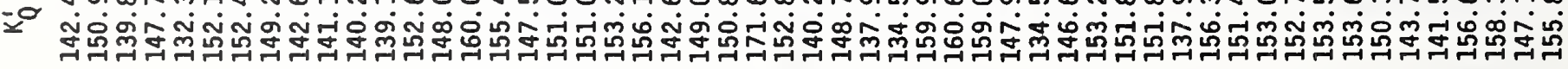

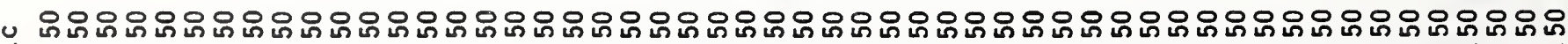

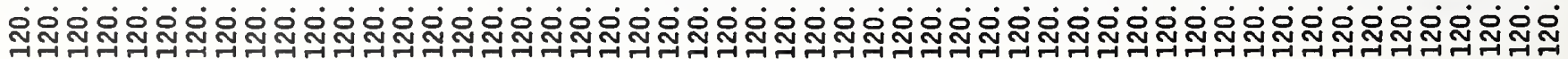




\section{Appendix Table III}

Results of Kruskal-Wallis Test of Significance, Cumulative Probability Values, for Factor Crack-Size, $\bar{a}$.

A]uminum

N $\quad R_{s b}$

$K_{Q}^{\prime}$

$K_{Q-P M}$

$K_{Q}$

$K_{j}^{\prime}$

$K_{J}$

$K_{d}^{*}$

Accuracy

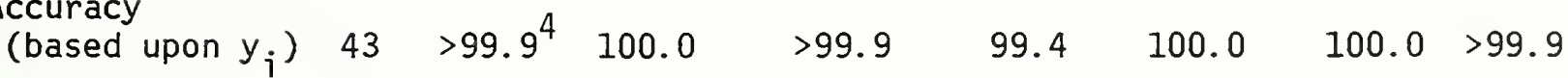

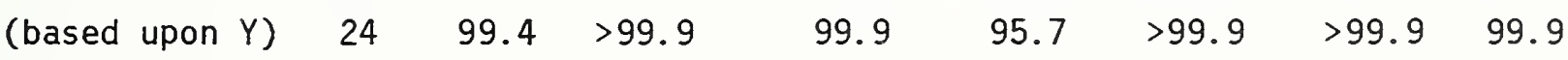

Reproducibility

(based on s)

$\begin{array}{lll}17 & 96.8 & 76.9\end{array}$

69.7

$57.8 \quad 94.6$

$69.0 \quad 96.8$

Titanium (R, T, \& L data)

\section{Accuracy}

$\left(y_{i}\right)$

(Y)

Reproducibility

(s)
28

$\begin{array}{lll}16 & 95.1 & 76.0\end{array}$

$\begin{array}{lll}11 & 37.2 & 2.6\end{array}$
94.9

98.5

96.8

$99.7 \quad 69.4$

94.1

92.7

96.2

97.8

83.8

$8.7 \quad 79.2$

6.9

$34.6 \quad 36.0$

\section{Steel}

Accuracy

$\left(y_{i}\right)$

5199.998.

100.0

100.0

100.0

$100.0 \quad 100.0$

(Y)

$27 \quad 99.6$

$88.7>99.9$

99.9

$>99.9$

$>99.9>99.9$

Reproducibility

(s)

$21 \quad \begin{aligned} & 75.5^{2} \\ & N=20\end{aligned}$

86.9

78.2

42.0

60.3

$8.2 \quad 59.5$

Combined ${ }^{1}$

Accuracy
$\left(y_{i}\right)$

(Y)

Reproducibility

(s)
$122 \quad 100.098$.

$\begin{array}{lll}67 & 99.9 & 94.9\end{array}$
$100.0 \quad 100.0$

100.0

100.0100 .0

100.0

$>99.9$

100.

$100.0 \quad 100.0$

90.0

0.0

94. 6

42.196 .3

$$
N=48
$$

$49 \quad \begin{aligned} & 99.547^{3} 95.4 \\ & N=48\end{aligned}$




\section{Appendix Table IV}

Results of Kruskal-Wallis Test of Significance, Cumulative Probability Values, for the Factor $K_{f}$ maximum.

Aluminum

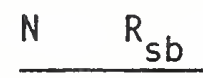

$K_{Q}^{\prime}$

$K_{Q-P M}$

$\mathrm{K}_{\mathrm{Q}}$

$\mathrm{K}_{\mathrm{j}}$

$k_{j} \quad k_{d}^{*}$

Accuracy

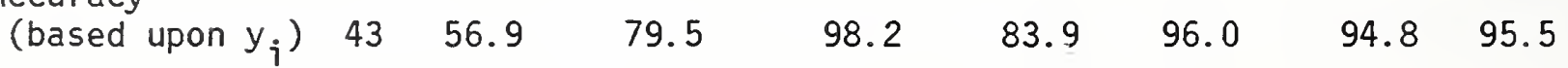

$\begin{array}{lllllllll}\text { (based upon } Y \text { ) } & 24 & 52.8 & 78.0 & 94.7 & 63.7 & 88.3 & 88.2 & 84.9\end{array}$

Reproducibility

(based on s)

$17 \quad 70.7$

38.1

72.4

43.6

60.4

$87.5 \quad 53.7$

Titanium ( $R, T, \& L$ data)

Accuracy

$\left(y_{i}\right)$

$\begin{array}{lll}28 & 49.8 & 22.6\end{array}$

3.8

$96.1 \quad 76.9$

$80.5 \quad 83.6$

(Y)

$\begin{array}{lll}16 & 20.9 & 36.6\end{array}$

44.0

91.9

84.7

$73.4 \quad 89.9$

Reproducibility

(s)

$11 \quad 89.8$

89.8

95.9

$84.7 \quad 95.9$

$98.6 \quad 95.9$

Steel

Accuracy

$\left(y_{i}\right)$

$51 \quad 98.5 \quad 52.0$

95.4

96.8

52.9

$37.6 \quad 68.8$

(Y)

$27 \quad 96.0$

49.5

70.4

69.6

32.0

$13.0 \quad 51.4$

Reproducibility

(s)

$\begin{array}{lll}21 & 25.5^{2} & 43.4\end{array}$

81.2

40.7

85.1

$90.8 \quad 74.5$

Combined $^{1}$

\section{Accuracy}

$\left(y_{i}\right)$

(Y)

Reproducibility

(s)
$122 \quad 99.3$

84.1

98.0

99.9

56.8

66.7

98.1

16.1

$11.9 \quad 31.8$
1.1

$49 \quad 3.5^{3} \quad 31.8$ $M=48$

1

${ }_{2}$ Includes specimens listed above for all three materials.

${ }_{3} N=20$ for $R_{s b}$ only.

${ }^{3} N=48$ for $R_{S b}$ only. 
Appendix Table $V$

Results of Kruskal-Wallis Test of Significance,

Cumulative Probability Values, for the Factor Notch Preparation, NP.

\begin{tabular}{|c|c|c|c|c|c|c|c|c|}
\hline Aluminum & $\mathrm{N}$ & $R_{s b}$ & $K_{0}^{\prime}$ & $K_{Q}-P M$ & $\mathrm{~K}_{0}$ & $k_{j}^{\prime}$ & $k_{J}$ & $K_{d}^{\star}$ \\
\hline $\begin{array}{l}\text { Accuracy } \\
\text { (based upon } y_{j} \text { ) }\end{array}$ & 43 & 68.9 & 36.3 & 68.4 & 0.0 & 41.0 & 50.8 & \\
\hline (based upon $Y$ ) & 24 & 61.2 & 36.7 & 67.8 & 4.6 & 56.9 & 60.0 & 66 \\
\hline $\begin{array}{l}\text { Reproducibility } \\
\text { (based on s) }\end{array}$ & 17 & 51.3 & 86.1 & 67.2 & 83.6 & 8.2 & 56.2 & 18 \\
\hline
\end{tabular}

Titanium (R, T, \& L data)

Accuracy

$\left(y_{j}\right)$

$(Y)$

Reproducibility

(s)
$28 \quad 57.5$

$\begin{array}{lll}16 & 25.0 & 80.1\end{array}$

$11 \quad 40.9$

$47.7 \quad 52.8$

37.8

49.2

28.8

$25.5 \quad 57.5$

16.7

2.5

23.9

$\begin{array}{ll}17.6 & 50.7\end{array}$

Steel

$\begin{array}{lllllllll}\begin{array}{l}\text { Accuracy } \\ \left(y_{j}\right)\end{array} & 51 & 63.5 & 79.8 & 15.3 & 22.6 & 7.7 & 7.6 & 21.7 \\ (Y) & 27 & 35.3 & 72.1 & 13.0 & 23.4 & 8.3 & 0.7 & 26.0\end{array}$

Reproducibility

(s)

$21 \quad \begin{array}{r}77.8^{2} \\ N=20\end{array}$

94.1

6.9

16.0

$38.2 \quad 2.6$ 
Appendix Table VI

Residual-Standard-Deviation from Multiple Linear Regression Analyses for Seven Responses and Three Materials.

\begin{tabular}{|c|c|c|c|c|c|c|c|c|}
\hline \multirow[b]{2}{*}{ Material } & \multirow[b]{2}{*}{ Response $^{1}$} & \multirow[b]{2}{*}{$N$} & \multicolumn{2}{|c|}{$\bar{a}$ (Eq. 14) } & \multicolumn{2}{|c|}{$\bar{a}+k_{f}(E q .16)$} & \multicolumn{2}{|c|}{$\overline{\mathbf{a}}+K f+N P$ (Eq. I7) } \\
\hline & & & res. S.D. & . v & res. S.D. & $v$ & res. S.D. & $v$ \\
\hline 4 & $R_{\text {sb }}$ & 43 & 0.077 & 41 & 0.076 & 40 & 0.073 & 39 \\
\hline 5 & $R_{s b}$ & 28 & 0.118 & 26 & 0.119 & 25 & 0.105 & 24 \\
\hline 6 & $R_{s b}$ & 51 & 0.072 & 49 & $0.060^{\star \star}$ & 48 & 0.059 & 47 \\
\hline 4 & $K_{Q}^{\prime}$ & 43 & 2.39 & 41 & 2.41 & 40 & 2.44 & 39 \\
\hline 5 & $\mathrm{~K}_{\mathrm{Q}}^{\prime}$ & 28 & 5.94 & 26 & 6.06 & 25 & 6.03 & 24 \\
\hline 6 & $k_{\dot{q}}^{\prime}$ & 51 & 6.56 & 49 & 6.49 & 48 & 6.46 & 47 \\
\hline 6 & $\mathrm{~K}_{\mathrm{Q}}^{\prime 2}$ & 36 & 6.14 & 34 & $5.65^{\star}$ & 33 & 5.42 & 32 \\
\hline 4 & $K_{Q-P M}$ & 43 & 3.03 & 41 & 3.02 & 40 & 2.97 & 39 \\
\hline 5 & $K_{Q-P M}$ & 28 & 4.70 & 26 & 4.77 & 25 & 3.18 & 24 \\
\hline 6 & $K_{Q-P M}$ & 51 & 3.07 & 49 & $2.52^{\star \star}$ & 48 & 2.38 & 47 \\
\hline 4 & $k_{Q}$ & 43 & 3.95 & 41 & 3.83 & 40 & 3.87 & 39 \\
\hline 5 & $\mathrm{~K}_{\mathrm{Q}}$ & 28 & 4.95 & 26 & $3.70 \star *$ & 25 & 3.67 & 24 \\
\hline 6 & $K_{Q}$ & 51 & 4.09 & 49 & $3.72^{\star \star}$ & 48 & 3.76 & 47 \\
\hline 4 & $K_{j}^{\prime}$ & 43 & 6.23 & 41 & $5.94^{\star}$ & 40 & 6.00 & 39 \\
\hline 5 & $K_{j}^{\prime}$ & 28 & 8.67 & 26 & 8.64 & 25 & 8.64 & 24 \\
\hline 6 & $\mathrm{~K}_{\mathrm{j}}^{\prime}$ & 51 & 7.08 & 49 & $6.72^{\star}$ & 48 & 6.62 & 47 \\
\hline 4 & $k_{J}$ & 43 & 5.28 & 41 & $4.92^{\star \star}$ & 40 & 4.98 & 39 \\
\hline 5 & $k_{j}$ & 28 & 8.15 & 26 & 8.14 & 25 & 8.13 & 24 \\
\hline 6 & $k_{J}$ & 51 & 6.91 & 49 & $6.65^{\star}$ & 48 & 6.65 & 47 \\
\hline 4 & $K_{d}^{*}$ & 43 & 5.82 & 41 & 5.64 & 40 & 5.70 & 39 \\
\hline 5 & $K_{d}^{*}$ & 28 & 7.60 & 26 & 7.57 & 25 & 7.49 & 24 \\
\hline 6 & $K_{d}^{*}$ & 51 & 6.10 & 49 & $5.77^{\star}$ & 48 & 5.65 & 47 \\
\hline
\end{tabular}

1

For the $R_{s b}$ responses, for which reference values of the response are not available, the residual standard deviation is computed from the response $R_{s b}$. For each of the $K$ responses the computation is made using the \% RD of $K$ and the magnitude of the residual S.D. will reflect this.

2 Includes results for only specimens with $\bar{a}>140$ mils.

* Significant at the 10 percent level

**Significant at the 5 percent level 


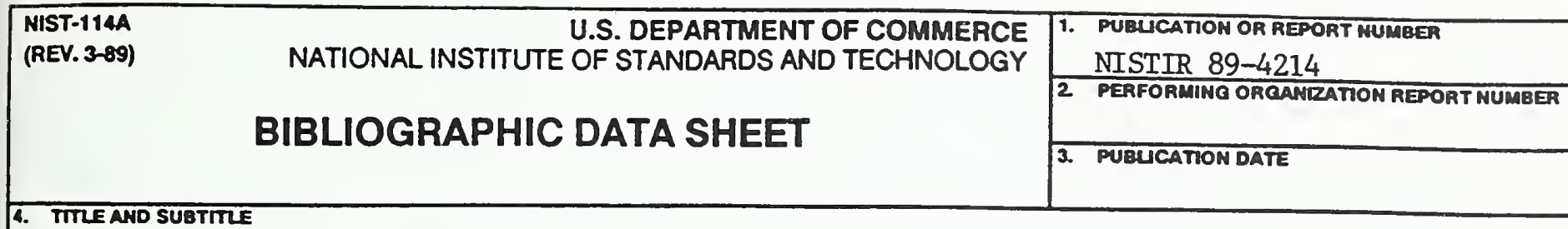

Factors Significant to Precracking of Fracture Specimens

5. AUTHOR(S)

Charles G. Interrante and James J. Filliben

6. PERFORMING ORGAMIZATION (IF JOINT OR OTHER THAN MIST, SEE INSTRUCTIONS) U.S. DEPARTMENT OF COMMERCE MATIONAL INSTITUTE OF STANDARDS AND TECHNOLOGY GATHERSBURG, MD 20899

7. CONTRACT/ORANT NUMBER

8. TVPE OF REPORT AND PERIOD COVERED

9. SPONSORINO ORQAMIZATION NAME AND COMPLETE ADDRESS (STREET, CTY, STATE, ZIP)

10. SUPPLEMENTARY NOTES

DOCUMENT DESCRIBES A COMPUTER PROGRAM; SF-185, FIPS SOFTWARE SUMMARY, IS ATTACHED.

11. ABSTRACT (A 200-WORD OR LESS FACTUAL SUMMARY OF MOST SIQMIFICANT IMFORMATION. IF DOCUMENT INCLUDES A SIOMIFCANT BIBUOGRAPHY OR UTERATURE SURVEY, MENTION IT HERE.)

The significance of four variables in the technique used to precrack Charpy specimens of metallic materials is determined by analyses of seven responses computed from results of slow-bend Charpy V-notch tests. The variables include crack size, stress-intensity factor at the start of precracking $\left(\mathrm{K}_{\mathrm{f}} \mathrm{max}\right)$, notch preparation prior to precracking, and material. Values for the crack-size factor range from $\mathrm{a} / \mathrm{W}=0.25$ to 0.6 . Three levels of $\mathrm{K}_{f} \max$ were used and they range from 0.2 to 1.2 times the value recommended in ASTM Method E399. The notch preparation factor included three levels of root radius: (1) a standard $0.25 \mathrm{~mm}$ root-radius V-notch modified by sharpening the root with a razor blade; (2) a machined, nonstandard V-notch of $0.125 \mathrm{~mm}$ root radius; and (3) a standard V-notch modified by sharpening to about $0.05 \mathrm{~mm}$ by electric discharge machining. The materials included an alumimm alloy, a maraging steel, and a titanium alloy. Three analytical methods are used to determine the significance of each of the test variables. These analyses are conducted for each of seven response parameters (each represent alternative methods for evaluations of fracture toughness) that were evaluated for each test. The results indicate that: (1) All seven computed responses are linearly related to crack length and the sensitivity to crack length is a function of both response parameter and material. (2) Precracking at either very high or very low levels of stress-intensity factor, $K_{f}$, are to be avoided. (3) The method of notch preparation prior to precracking does not signficantly affect the test response.

12- KEY WORDS (6 TO 12 ENTRIES; ALPHABETICAL ORDER; CAPITALIEE ONLY PROPER MAMES; AND SEPARATE KEY WORDS OY SEMICOLONS) Aluminum; Charpy; crack size; fatigue precracking; fracture toughness; Kf maximum; KruskalWallis test; linear regression; notch preparation; precracking; statistical tests; steel; stress-intensity factor; titanium; slow-bend testing.

13. AVALABIUTY

UNLATRED

FOR OFFICIAL DISTRIBUTION. DO NOT RELEASE TO NATIOHAL TECHNICAL INFORMATION SERVICE (NTIS).

ORDER FROM SUPERINTENDENT OF DOCUMENTS, U.S. OOVERNMENT PAINTHO OFFCE, WASHIMOTON, DC 20402

ORDER FROM MATIONAL TECHMICAL INFORMATION SERVICE (MTIS), SPRIMOFIED, VA 22161.

14. NUMBER OF PRINTED PAGES

88

15. PRICE 


